CHRISTIANNE MATIAS BUSSO

\title{
APLICAÇÃO DO INDICADOR OVERALL EQUIPMENT EFFECTIVENESS (OEE) E SUAS DERIVAÇÕES COMO INDICADORES DE DESEMPENHO GLOBAL DA UTILIZAÇÃO DA CAPACIDADE DE PRODUÇÃO
}

Dissertação apresentada à Escola Politécnica da Universidade de São Paulo para obtenção do Título de Mestre em Engenharia Área de Concentração: Engenharia de Produção Orientador: Prof. Dr. Dario Ikuo Miyake

São Paulo 
CHRISTIANNE MATIAS BUSSO

\section{APLICAÇÃO DO INDICADOR OVERALL EQUIPMENT EFFECTIVENESS (OEE) E SUAS DERIVAÇÕES COMO INDICADORES DE DESEMPENHO GLOBAL DA UTILIZAÇÃO DA CAPACIDADE DE PRODUÇÃO}

Dissertação apresentada à Escola Politécnica da Universidade de São Paulo para obtenção do Título de Mestre em Engenharia 
Este exemplar foi revisado e alterado em relação à versão original, sob responsabilidade única do autor e com a anuência de seu orientador.

São Paulo, de novembro de 2012.

Assinatura do autor

Assinatura do orientador

FICHA CATALOGRÁFICA

Busso, Christianne Matias

Aplicação do indlcador de Overall Equipment Effectiveness (OEE) e suas derivações como indicadores de desempenho global da utilização da capacidade de produção / C.M. Busso. ed.rev. -- São Paulo, 2012.

$135 \mathrm{p}$.

Dissertação (Mestrado) - Escola Politécnica da Universidade de São Paulo. Departamento de Engenharia de Produção.

1. Engenharia de produção 2. Produtividade 3. Indicadores de produtividade I. Universidade de São Paulo. Escola Politécnica. Departamento de Engenharia de Produção II. t. 


\section{DEDICATÓRIA}

Aos meus pais Ary e Ana. 


\section{AGRADECIMENTOS}

A Deus, por toda a força, serenidade e paz que me proporciona.

À minha mãe por sempre fazer cara feia quando eu quis desistir e ao meu pai por sempre amenizar a culpa de uma possível desistência. Ambos me fizeram NÃO desistir.

Aos meus irmãos, por me olharem como a irmã do meio e fazer disso um ótimo argumento para mim.

Ao meu orientador, Prof. Dr. Dario Ikuo Miyake, por sua enorme compreensão e paciência e suas diversas correções.

Aos meus amigos Andréia Luz e Flavio Spina, por 6 anos compreendendo a desculpa de muitos fins de semana e feriados: "...preciso focar o mestrado." Entre altos e baixos, vocês estão e sempre estarão em meu coração.

Ao Douglas José Alem Jr, minha referência acadêmica e um marco em minha vida.

Ao Prof. Dr. Paulo Lima, meu primeiro chefe e incentivador desta etapa em minha vida.

Aos meus gestores Gleison Lagares e Claudinei Berti, por facilitarem minhas ausências "estratégicas" no trabalho, confiando no meu comprometimento e responsabilidade.

Aos meus amigos (e não vou listar por nome para não cometer nenhuma injustiça) do TIETÉ, da ETESP, da UFSCAR, da TAKTICA, do ESCALADA, do RA, da BUNGE e da VIDA, por torcerem e incentivarem este propósito.

À minha família, vô, vó, tios, tias, primos, primas, cunhados por serem parte da história que me formou como pessoa.

À Natalia Resende, por ser mais uma prova de que amizade é uma questão de doação e compartilhamento. Obrigada pelo trabalho em conjunto, estarei contigo.

À Lídia Silva, nossa secretária da pós, por me auxiliar em todas as infinitas vezes que precisei.

Aos professores da pós, por me creditarem uma segunda chance.

E por fim, ao Biel e à Bia (que vai chegar) e seus respectivos pais, por me mostrarem que tenho um novo desafio na vida: Ser Madrinha! 
"E aqueles que foram vistos dançando foram julgados insanos por aqueles que não podiam ouvir a música."

(Friedrich Nietzsche) 


\section{RESUMO}

A produtividade e competitividade de empresas intensivas em capital é muito dependente do grau de utilização de sua capacidade industrial. Muitos indicadores têm sido utilizados para medir o desempenho da manufatura, dentre eles o Overall Equipment Effectiveness (OEE). Contudo, somente altos índices de OEE não garantem um desempenho superior em uma fábrica. Alguns autores sugerem que a adoção de indicadores com maior abrangência como o Overall Plant Effectiveness (OPE) é mais adequada à medição e análise do desempenho global da manufatura por contemplar a influência de outras áreas da organização sobre a utilização da capacidade de uma fábrica. Esta pesquisa discute a aplicação do OEE em empresas cuja competitividade depende fortemente da sua habilidade em racionalizar a utilização da capacidade industrial e explora indicadores derivados da sua utilização. Com este propósito é realizada uma revisão bibliográfica da literatura para identificar suas limitações, relacionar os indicadores derivados do OEE e caracterizá-los como ferramentas gerenciais que podem oferecer uma perspectiva mais global à medição do desempenho da utilização da capacidade. Além disto, um estudo de caso é desenvolvido em uma empresa processadora de alimentos para identificar como se pode envolver os diversos agentes responsáveis pelas perdas de capacidade de produção, inclusive aqueles que atual além da área de manufatura, para eliminação ou controle deste problema. O estudo mostra que a aplicação do OPE além do OEE pode tornar a deteç̧ão da causa raiz de problemas mais eficaz, além de induzir a integração da estratégia de produção com outras estratégias funcionais e desta forma promover o aumento do desempenho global da manufatura.

Palavras chaves: OEE. desempenho global da manufatura. OPE. grupo multifuncional. 


\begin{abstract}
Process industries have to strive to attain high resource utilization so as to increase their productivity and competitiveness in the market. Many indicators have been used to measure their manufacturing performance, one of them is the Overall Equipment Effectiveness (OEE). However, high OEE values per se do not ensure superior global performance. Some authors suggest that the consideration of indicators with broader magnitude such as Overall Plant Effectiveness (OPE) is more appropriate to measure and analyze the overall manufacturing performance since it also reflects the impacts of support areas on a plant's capacity utilization. This research reviews the application of OEE in companies that depend heavily on the ability to rationalize the utilization of their production capacity and explores the use of indicators derived from it. With this purpose, a literature review is presented to identify the limitations of OEE, to enumerate indicators derived from OEE and characterize them as management tools that may offer a more global perspective to the measurement of capacity utilization. Moreover, a case study is developed in a food processing company to identify how the diverse agents responsible for the losses in production capacity including those who perform beyond the manufacturing function, can be involved in the effort to eliminate or control this problem. The study shows that the use of OPE besides OEE can make the detection of the root cause of problems more effective and induce the integration of manufacturing strategy with other functional strategies, and thus promote the increase of overall manufacturing performance.
\end{abstract}

Keywords: OEE. Overall Manufacturing Performance. OPE. CrossFunctional Team. 


\section{LISTA DE ILUSTRAÇÕES}

Figura 1 - Hierarquia entre os conceitos de capacidade. Fonte: Javidan (1998)

Figura 2 - Definição dos critérios de desempenho: Eficácia, Eficiência, Produtividade e Rentabilidade. Adaptada de Sink e Tutle (1989).

Figura 3 - Relação de alguns dos critérios de desempenho. Fonte: Tangen (2005b). 19

Figura 4 - Levantamento de Artigos Publicados sobre Overall Equipment Effectiveness (OEE). Levantamento realizado pela autora.

Figura 5 - Relação entre os objetivos e questões desta dissertação. 33

Figura 6 - Variação de produtividade x nível de capacidade utilizada. Fonte: FIESP (2007). 49

Figura 7 - Posições dos grupos de solução de problema na hierarquia da empresa. Adaptada de Shiba et al. (1997). 60

Figura 8 - Estrutura das seis grandes perdas de tempo observadas no indicador de OEE. Adaptada de Braglia et al. (2009) 63

Figura 9 - OEE e indicadores derivados do OEE conforme abrangência do sistema produtivo. 73

Figura 10 - Classificação das perdas de produção para avaliação do desempenho da manufatura. Adaptada de Muchiri e Pintelon (2008). 79

Figura 11 - Matriz das derivações do OEE conforme a classificação dos tipos de perdas e abrangência do sistema produtivo que considera. Fonte: Busso e Miyake (2012). .

Figura 12 - Espaço para acompanhamento das reuniões e tratamento de perdas............................. 91

Figura 13 - Evolução do OEEL e OPEL na L2 durante o primeiro período em 2008. 92

Figura 14 - Análise das perdas que impactam ou não impactam no OEEL - Análise da Fase 1. Fonte: Busso e Miyake (2012). 93

Figura 15 - Evolução das principais paradas que impactam no OEEL durante o primeiro período. Fonte: Busso e Miyake (2012) 94

Figura 16 - Agenda de reuniões e itens de controle para acompanhamento dos resultados obtidos pela vice-presidência, diretoria e gerência.

Figura 17 - Evolução das principais paradas que não afetam o OEEL, mas medidas pelo OPEL. Fonte: Busso e Miyake (2012)

Figura 18 - Evolução do OTE da fábrica e do OEEL das 4 linhas de produção no período de Julho a Dezembro de 2010. Fonte: Busso e Miyake (2012).

Figura 19 - Evolução do OPE da fábrica e do OPEL das 4 linhas de produção no período de Julho a Dezembro de 2010. Fonte: Busso e Miyake (2012). 104

Figura 20 - Indicadores aplicados pela unidade objeto de estudo. Fonte: Busso e Miyake (2012) .. 106 


\section{LISTA DE TABELAS}

Tabela 1 - Avaliação dos resumos dos artigos de maior relevância sobre OEE................................ 27

Tabela 2 - Métodos, requisitos e características principais. Fonte: Corrêa (1992). ............................ 42

Tabela 3 - Definições de capacidade conforme Elmaghraby (1991) ................................................ 50

Tabela 4 - Características dos grupos de solução de problema. Adaptada de Bailey (1997).............. 61

Tabela 5 - OEE $\times$ dimensões e características de um sistema de medição do desempenho global

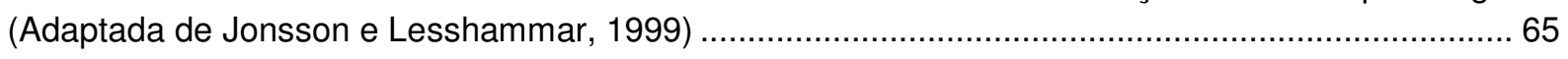

Tabela 6 - Benefícios e limitações do OEE. Fonte: artigos diversos selecionados pelo autor............. 66

Tabela 7 - Critérios para avaliação dos indicadores derivados do OEE, conforme as dimensões e

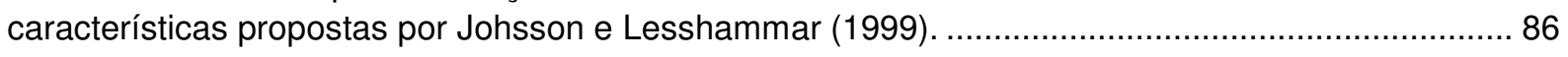

Tabela 8 - Comparação de indicadores vis-à-vis dimensões e características de um sistema de

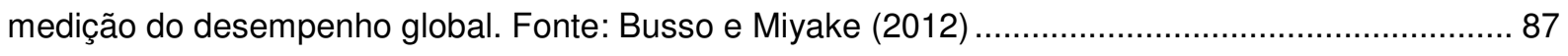

Tabela 9 - Matriz de papéis e responsabilidades - grupo multifuncional ampliado.............................. 96 


\section{LISTA DE SIGLAS}

APG

CQ

FT

JIPM

MTBF

MTTR

$\mathrm{NUCl}$

OAE

OEE

OEEL

OEEML

OFE

OLE

OPE

OPEL

OTE

P\&D

PCP

PEE
Atividades de Pequenos Grupos

Círculos da Qualidade

Força Tarefa

Japan Institute of Plant Maintenance

Mean Time Between Failure

(Tempo Médio Entre Falhas)

Mean Time To Repair

(Tempo Médio para Reparar)

Nível de Utilização da Capacidade Instalada

Overall Asset Effectiveness

(Eficiência Total do Ativo)

Overall Equipment Effectiveness

(Eficiência Total Equipamento)

OEE da Linha

Overall Equipment Effectiveness of a Manufacturing Line (Eficiência Total da Linha de Manufatura)

Overall Factory Effectiveness

(Eficiência Total da Fábrica)

Overall Line Effectiveness

(Eficiência Total da Linha)

Overall Plant Effectiveness

(Eficiência Total da Planta)

Overall Plant Effectiveness - Linha

(Eficiência Total da Linha na Planta)

Overall Throughput Effectiveness

(Eficiência de Saída)

Pesquisa e Desenvolvimento

Planejamento e Controle da Produção

Production Equipment Effectiveness 
(Eficiência Produtiva do Equipamento)

PEE-cont Production Equipment Effectiveness - processos contínuos

(Eficiência Produtiva do Equipamento - processos contínuos)

PEE-disc Production Equipment Effectiveness - processos discretos (Eficiência Produtiva do Equipamento - processos discretos)

TEEP Total Equipment Effectiveness Performance

(Desempenho da Eficiência Total do Equipamento)

TOEE Total Overall Equipment Effectiveness

(Eficiência Total Geral dos Equipamentos)

TPM Total Productive Maintenance

(Manutenção Produtiva Total)

TQM Total Quality Management

(Gerenciamento da Qualidade Total)

WCM World Class Manufacturing

(Manufatura de Classe Mundial) 


\section{LISTA DE EQUAÇÕES}

Equação 1 - Cálculo do NUCl pelo Conselho Nacional das Indústrias (CNI)............50

Equação 2 - Medição da Utilização conforme Slack (2002).....................................54

Equação 3 - Medição da Eficácia conforme Slack (2002)......................................55

Equação 4 - Grau de utilização da capacidade conforme Gold (1973).....................55

Equação 5 - Cálculo da Rentabilidade conforme Gold (1973).................................57

Equação 6 - Cálculo da rentabilidade "expandido" conforme Gold (1973) ................58

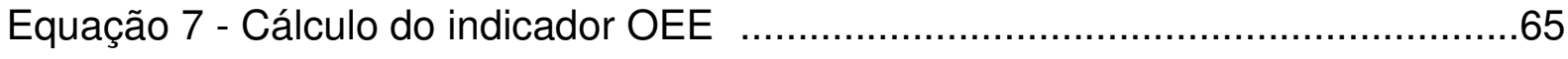

Equação 8 - Cálculo do indicador OEE conforme Kwon e Lee (2004).....................66

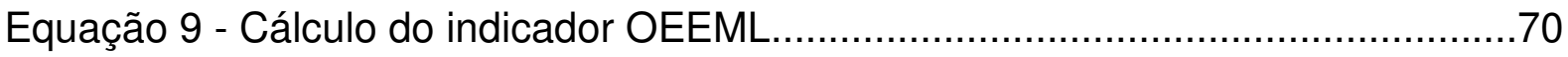

Equação 10 - Cálculo do numerador do OEEML...................................................71

Equação 11 - Cálculo do denominador do OEEML...............................................71

Equação 12 - Cálculo do indicador OLE............................................................

Equação 13 - Cálculo do Fator LA do Indicador OLE ........................................72

Equação 14 - Cálculo do Fator LPQP do Indicador OLE.........................................72

Equação 15 - Cálculo do indicador OFE............................................................

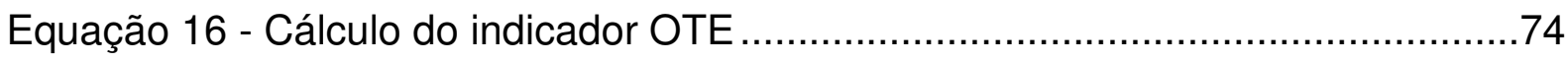

Equação 17 - Cálculo do indicador TEEP..........................................................76

Equação 18 - Cálculo do indicador PEE-disc …………....................................77

Equação 19 - Cálculo do indicador PEE-cont ....................................................77

Equação 20 - Cálculo do indicador do TOEE. …………......................................

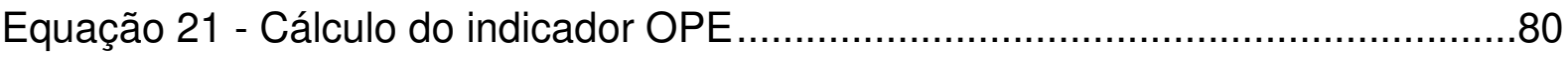

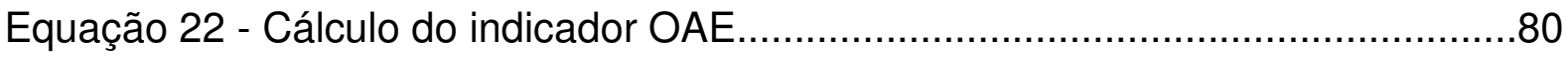

Equação 23 - Cálculo do indicador OTE - Estudo de Caso.....................................104

Equação 24 - Cálculo do indicador OPE - Estudo de Caso ………………….......104 


\section{SUMÁRIO}

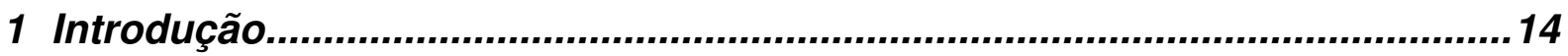

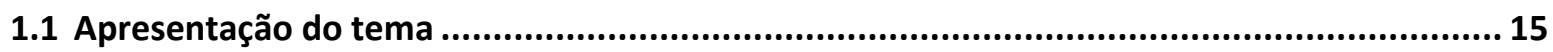

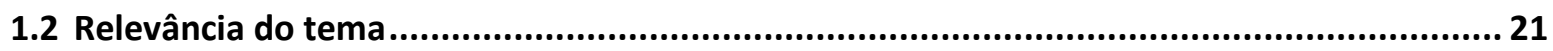

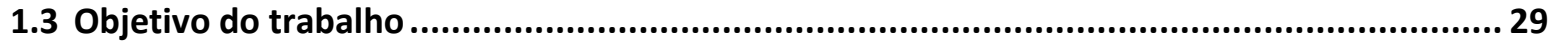

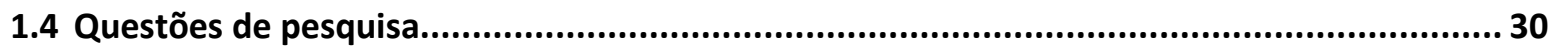

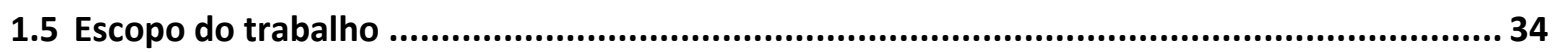

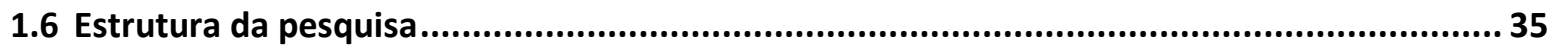

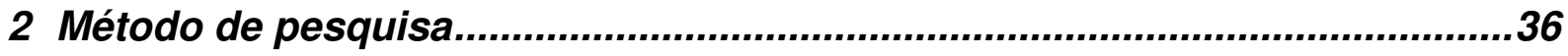

2.1 Método de levantamento e análise da literatura................................................................ 36

2.2 Método de desenvolvimento do estudo de caso ilustrativo .............................................. 41

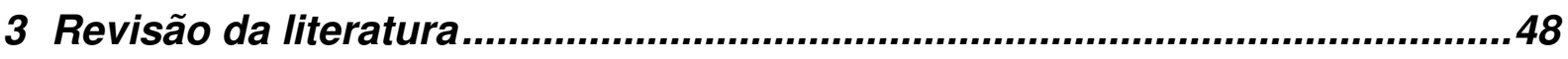

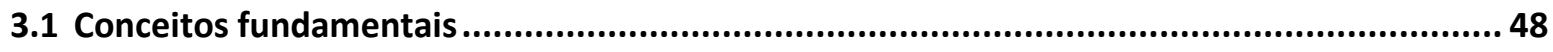

3.1.1 A definição de capacidade e sua medição ........................................................................48

3.1.2 Sistemas de medição de desempenho global ...............................................................54

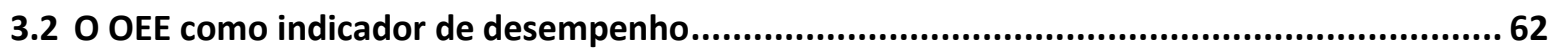

3.3 Limitações do OEE como indicador de desempenho global da manufatura ............................64

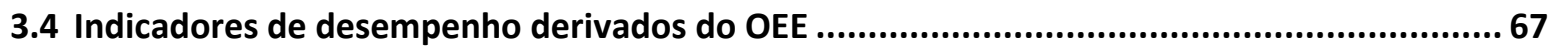

3.4.1 Indicadores que ampliam a abrangência do sistema de operações considerado ..............68

3.4.1.1 Overall Equipment Effectiveness of a Manufacturing Line (OEEML) ....................................68

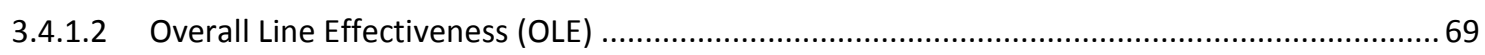

3.4.1.3 Overall Factory Effectiveness (OFE) e Overall Plant Effectiveness (OPE) ............................... 71

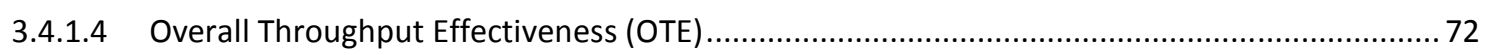

3.4.2 Indicadores que ampliam a classificação de perdas em relação à que o OEE por definição

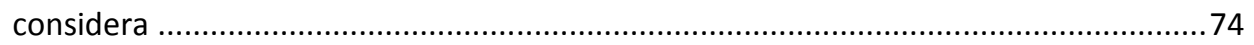

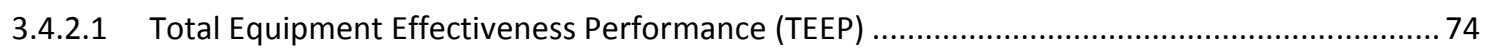

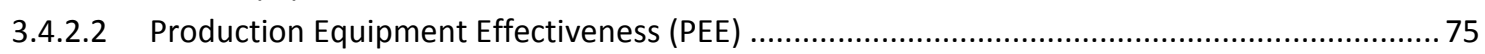

3.4.2.3 Total Overall Equipment Effectiveness (TOEE) ...................................................................... 76

3.4.2.4 Overall Plant Effectiveness (OPE) e Overall Asset Effectiveness (OAE) ................................... 77

3.4.2.5 Síntese das propostas de ampliação da classificação de perdas .............................................78

4 Análise dos indicadores derivados do OEE como instrumentos de medição

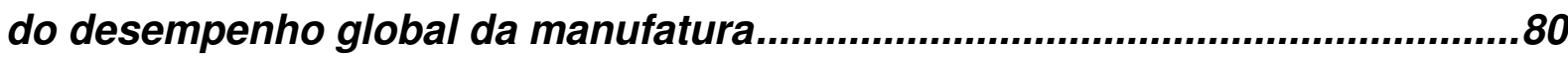

5 Estudo de caso: implementação de indicadores de desempenho global da

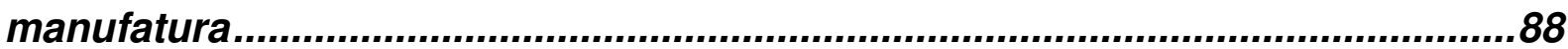

5.1 Descrição do Caso

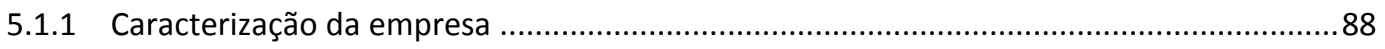

5.1.2 A etapa da introdução do OEE à aplicação do OPEL....................................................... 89 
5.1.3 Organização do grupo multifuncional para solução de problemas ..................................90

5.1.4 Ampliação do grupo multifuncional para solução de problemas ......................................95

5.1.5 A etapa de evolução para a aplicação do OPE e OTE ..................................................101

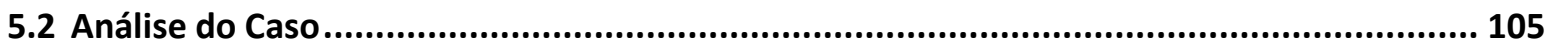

5.2.1 Análise do processo de implementação ...................................................................... 105

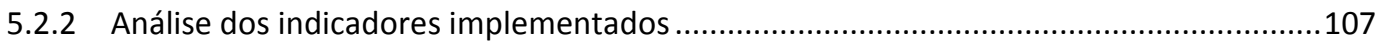

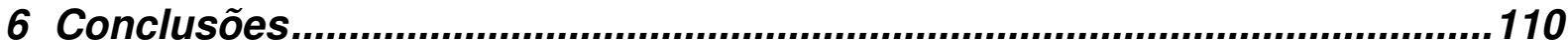

6.1 Conclusões relacionadas com o objetivo do trabalho .................................................. 110

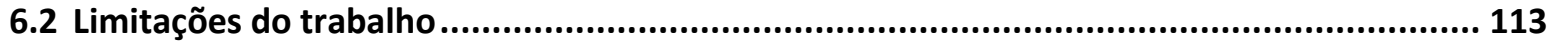

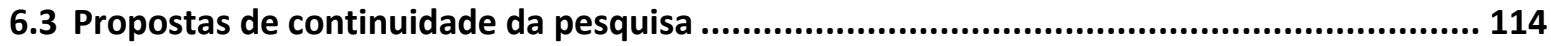

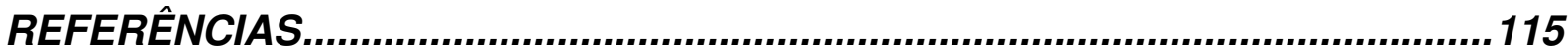

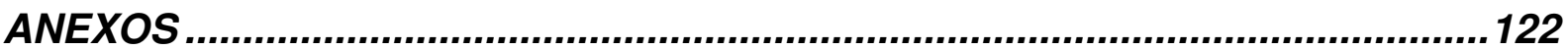

ANEXO 1 - Mapa estratégico do segmento de fabricação de produtos alimentícios .................. 122

ANEXO 1A - Mapa estratégico da divisão de ingredientes e alimentos.................................... 125

ANEXO 1B - Mapa estratégico da divisão de esmagamento de soja. ..................................... 126

ANEXO 2 - Protocolos das etapas 1 e 2 do estudo de caso ....................................................... 127

ANEXO 3 - Participação dos entrevistados nas atividades enumeradas nos protocolos do estudo

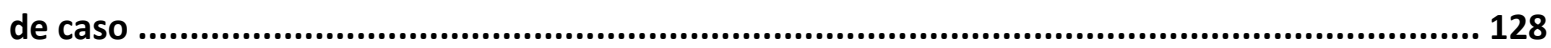

ANEXO 4 -Avaliação dos indicadores derivados do OEE..................................................... 129

ANEXO 4A - Avaliação dos indicadores derivados do OEE conforme critérios definidos na Tabela $7 \quad 129$

ANEXO 4A - Avaliação dos indicadores derivados do OEE conforme critérios definidos na Tabela

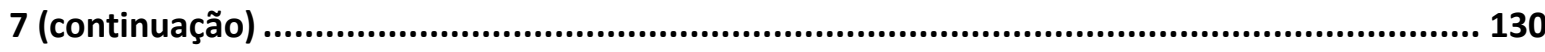

ANEXO 4B - Agrupamento de indicadores afins com base nos critérios definidos na Tabela 7 . 131 ANEXO 4B - Agrupamento de indicadores afins com base nos critérios definidos na Tabela 7

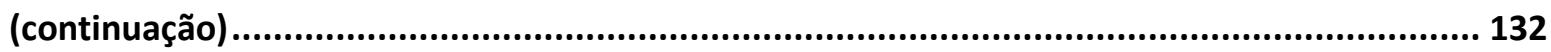

ANEXO 5 - Dados utilizados no cálculo do OEEL e OPEL para a linha analisada (L2) .................. 133 


\section{Introdução}

A intensificação da concorrência tem exigido que as empresas de manufatura lidem cada vez mais com a pressão de mercados mais sofisticados, mudanças nas escolhas dos clientes e competição global (DANGAYACH; DESHMUKH, 2003). O mercado atual tem exigido cada vez mais que as empresas de manufatura disponibilizem seus produtos com qualidade, rapidez, flexibilidade, confiabilidade e menor custo.

Gagnon (1999) afirma que para atender esses objetivos, uma forma de conduzir a gestão estratégica das operações seria basear-se na visão dos recursos de produção. Tais recursos envolvem decisões como desenvolvimento de produtos, tecnologia a ser utilizada, organização da mão de obra, configuração das instalações e capacidade de produção entre outros.

Elmaghraby (1991) afirma que o correto entendimento sobre o que é capacidade de produção, e sua medição precisa e exata são de vital importância para todos os interessados no negócio. A utilização ideal da capacidade de produção para satisfazer a demanda atual e futura pode gerar maiores lucros e clientes satisfeitos (SLACK, 2002). A competência de utilizar de modo mais eficaz a capacidade de produção aumentando a disponibilidade da produção permite maior flexibilidade de volume e assim atender a demanda dos clientes que exigem cada vez mais variedade de produtos. Portanto, quanto maior a capacidade disponível, maior será a possibilidade de produção e então de entregar produtos ao mercado.

Dentro deste cenário, esta pesquisa se propõe a investigar e analisar como o indicador de desempenho da manufatura conhecido por Overall Equipment Effectiveness (OEE) e outras derivações deste indicador podem ser aplicados como indicador de desempenho global da manufatura, que auxilie os gestores nas tomadas de decisão em busca da melhor utilização da capacidade produtiva de seus recursos, com o objetivo de reduzir custo e aumentar a disponibilidade de produto de forma a garantir uma vantagem competitiva. 


\subsection{Apresentação do tema}

A busca pela vantagem competitiva faz as empresas definirem estratégias de sobrevivência. Barney (1991) coloca que uma empresa alcança uma vantagem competitiva quando uma estratégia para criar valor é implementada e esta não é imitada simultaneamente por outra empresa. As empresas podem buscar vantagens competitivas de diferentes maneiras (e.g. liderança em custo, diferenciação, segmentação). Quando buscam vantagem competitiva através de uma estratégia baseada na heterogeneidade e diferenciação dos recursos que sustentam 0 negócio, necessitam entender a relação entre as características e o desempenho de seus recursos internos (BARNEY, 1991).

A literatura sobre o estudo da estratégia baseada na visão de recursos (resource-based view) afirma que uma empresa é entendida como um conjunto de ativos e capacidades e a vantagem competitiva é adquirida por acumulação de ativos estratégicos e capacitação (HAFEEZ et al., 2002). Essas capacidades são bastante discutidas na literatura, pois elas podem ser definidas sob pelo menos três distintas perspectivas.

A primeira delas é capacidade no sentido de competência (competence). Competência é a habilidade de sustentar e coordenar a implantação de ativos de forma a ajudar uma empresa a atingir seus objetivos (SANCHEZ, 2004).

Outra definição de capacidade encontrada na literatura é a de capabilidade (organizational capability), que é definida por Grant (1991 apud Ljungquist, 2008) como a capacidade de um grupo de recursos realizar uma atividade ou tarefa. Javidan (1998) coloca que o conceito de capabilidade está relacionado a uma função especial, por exemplo, existe a capabilidade de marketing, capabilidade de produção, capabilidade de logística e distribuição e capabilidade de recursos humanos.

Stalk et al. (1992 apud Zhang et al. 2003) afirmam que enquanto a competência enfatiza o conhecimento tecnológico e de produção em pontos específicos ao longo da cadeia de valor, a capabilidade de modo geral, emerge de toda a cadeia de valor. Sob este aspecto, a capabilidade seria mais perceptível ${ }^{1}$ para

\footnotetext{
${ }^{1}$ Traduzido do termo visible capability utilizado por Zhang et al. (2003)
} 
o cliente enquanto as competências internas que suportam estas capabilidades raramente são.

O termo capabilidade é muitas vezes usado de forma intercambiável com o termo capacidade quando relacionada ao sentido de ser um dom inerente possuído por indivíduos ou organizações para alcançar o seu potencial pleno (JURIE, 2000).

No âmbito da manufatura, o conceito de capacidade pode ser considerado como o máximo nível de atividade com valor adicionado em um determinado período de tempo que o processo pode realizar sobre condições normais de operação (SLACK, 2002). Essa capacidade, entendida como capacidade de produção, diferentemente das definições de capacidade como competência ou como capabilidade, é mensurada através de dimensões como espaço e tempo, tornando este tipo de capacidade mais perceptível.

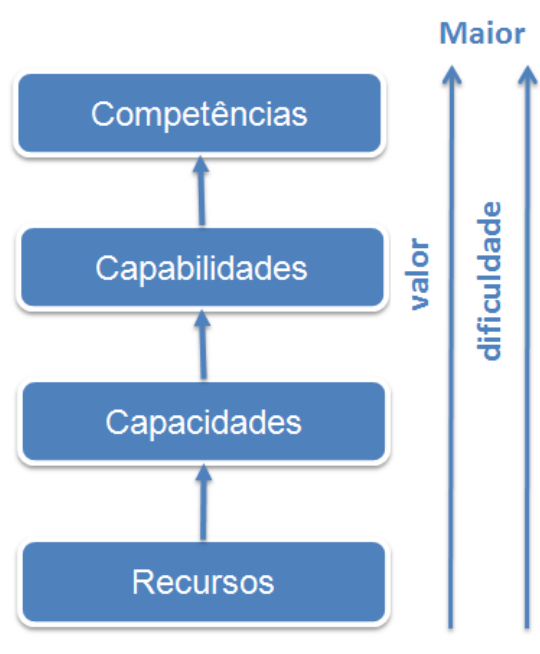

Figura 1 - Hierarquia entre os conceitos de capacidade. Fonte: Javidan (1998)

Esses três conceitos de capacidade podem ser relacionados hierarquicamente como na Figura 1 conforme sugerido por Javidan (1998). Para este autor, esta hierarquia apresenta três características importantes: primeiro cada nível da hierarquia é baseado no nível abaixo, ou seja, é o resultado da integração dos elementos no(s) nível (is) mais baixo(s). Em segundo lugar, os níveis mais altos da hierarquia determinam maior valor agregado, para a empresa, por exemplo, a capabilidade pode ajudar a gerar valor desenvolvendo os recursos; e as competências podem adicionar valor expandindo os limites da capabilidade. E por 
último, o fato de que os níveis mais altos da hierarquia envolvem um âmbito mais amplo da organização implica que eles são mais difíceis de serem efetivamente alcançados.

Este trabalho não tem a pretensão de pesquisar todos estes três tipos de capacidade. A capacidade que é discutida neste trabalho está relacionada à capacidade produtiva, ou seja, a capacidade perceptível, pois é mensurada em medidas que pode ser analisadas para auxiliar na tomada de decisão em busca de uma melhor utilização da capacidade de manufatura.

É importante ressaltar que o conceito de melhorar a utilização da capacidade está relacionado com o desempenho do sistema de produção em utilizar os recursos no seu potencial máximo.

Tangen (2005a) define desempenho como um termo que abrange tanto aspectos operacionais como econômicos. $O$ termo desempenho considera quase todos os objetivos que estão relacionados à capacidade competitiva ou excelência em fabricação, tais como custo, flexibilidade, velocidade, confiabilidade e qualidade (TANGEN, 2005b).

Tangen (2005b) também afirma que na literatura acadêmica e nos círculos comerciais, os termos desempenho e produtividade são comumente usados e raramente definidos ou adequadamente aplicados, o que permite que muitas vezes eles sejam confundidos e referidos de forma intercambiável, juntamente com termos afins como eficiência, eficácia e rentabilidade. Por isso é importante definir adequadamente a aplicação de cada um destes termos para a aplicação correta na avaliação dos resultados esperados pela manufatura.

Sink e Tutle (1989) sugerem uma proposta de definição dos critérios para medição de desempenho de um sistema. Assim, apresentam uma definição para os termos produtividade, eficácia, eficiência e rentabilidade, conforme o resumo na Figura 2.

- O termo Eficácia é definido como o real cumprimento do que se espera no tempo certo e na qualidade correta, ou seja, o grau de atendimento ao esperado. Assim, no contexto de sistema de produção, diz-se que é a relação entre o que pode ser produzido e o que realmente foi produzido, levando em consideração questões de tempo e qualidade. 
- O termo Eficiência é definido como a relação entre quantidade de recursos planejados e/ou estimados para executar o processo de produção e os recursos realmente consumidos.

- O termo Produtividade é a relação entre o que sai do sistema de manufatura, conforme esperado e o que entra, ou seja, os recursos para a produção.

- O termo Rentabilidade é uma medida da razão entre custos de produção com as receitas obtidas.

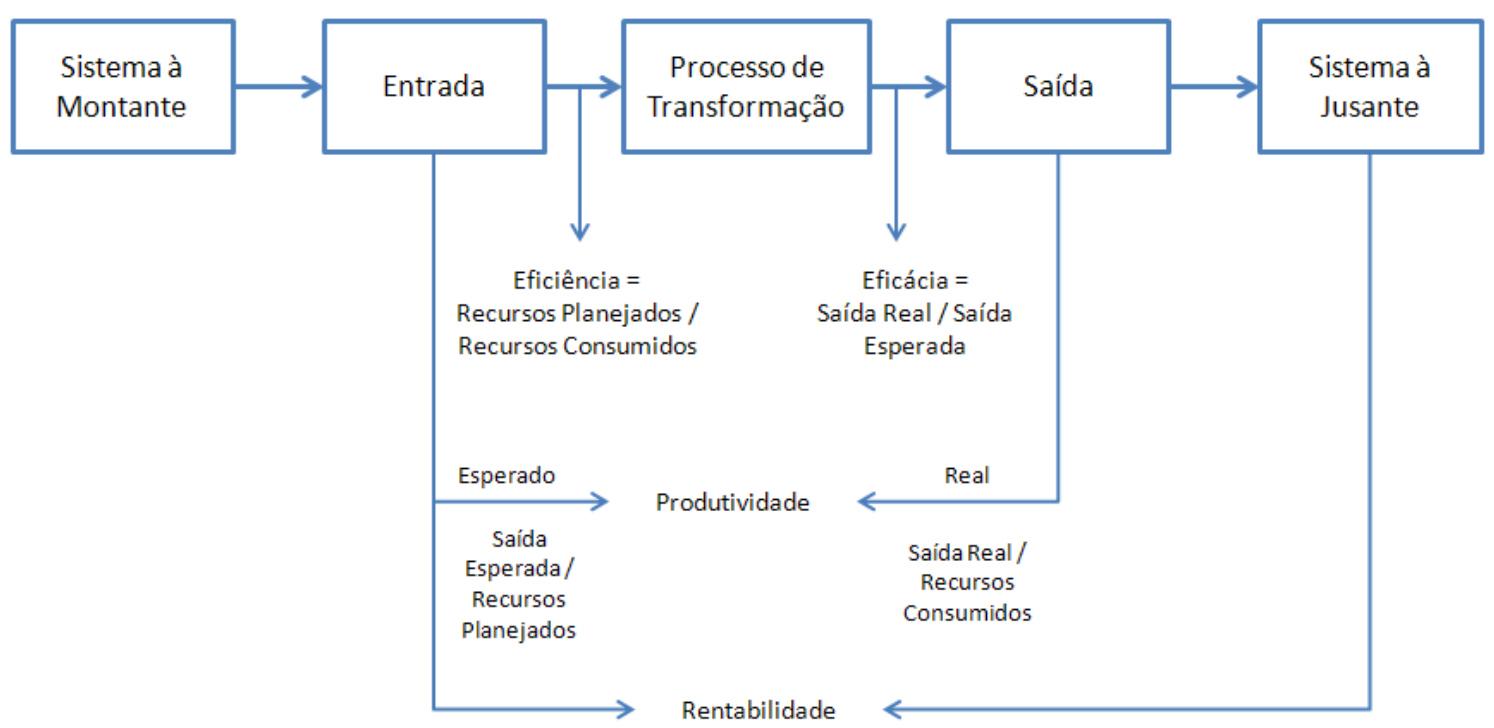

Figura 2 - Definição dos critérios de desempenho: Eficácia, Eficiência, Produtividade e Rentabilidade. Adaptada de Sink e Tutle (1989).

Sumanth (1985) reforça que há muita confusão com o termo produtividade e produção. $O$ autor explica que muitos acreditam que aumentar a produção resulte em um aumento da produtividade, porém isso nem sempre é verdadeiro, pois o termo produtividade consiste na eficiente utilização dos recursos no processo de transformação para se obter ao final bons produtos do processo. Ou seja, é a razão entre a eficácia e a eficiência do sistema de manufatura.

Tangen (2005b) aponta a importância de definir o conceito de desempenho em conjunto com os critérios de eficiência, eficácia, produtividade e rentabilidade e para isso esquematizou a Figura 3. Como é ilustrado por esta figura, a produtividade trata de uma relação entre as saídas e entradas de um processo ou sistema, sendo que as saídas estão relacionadas a eficácia e as entradas com à eficiência. Já a 
rentabilidade engloba a produtividade, a receita atendida com as saídas e os custos das entradas consumidas. Finalmente, o desempenho é o conjunto de todos estes critérios para o sucesso da organização.

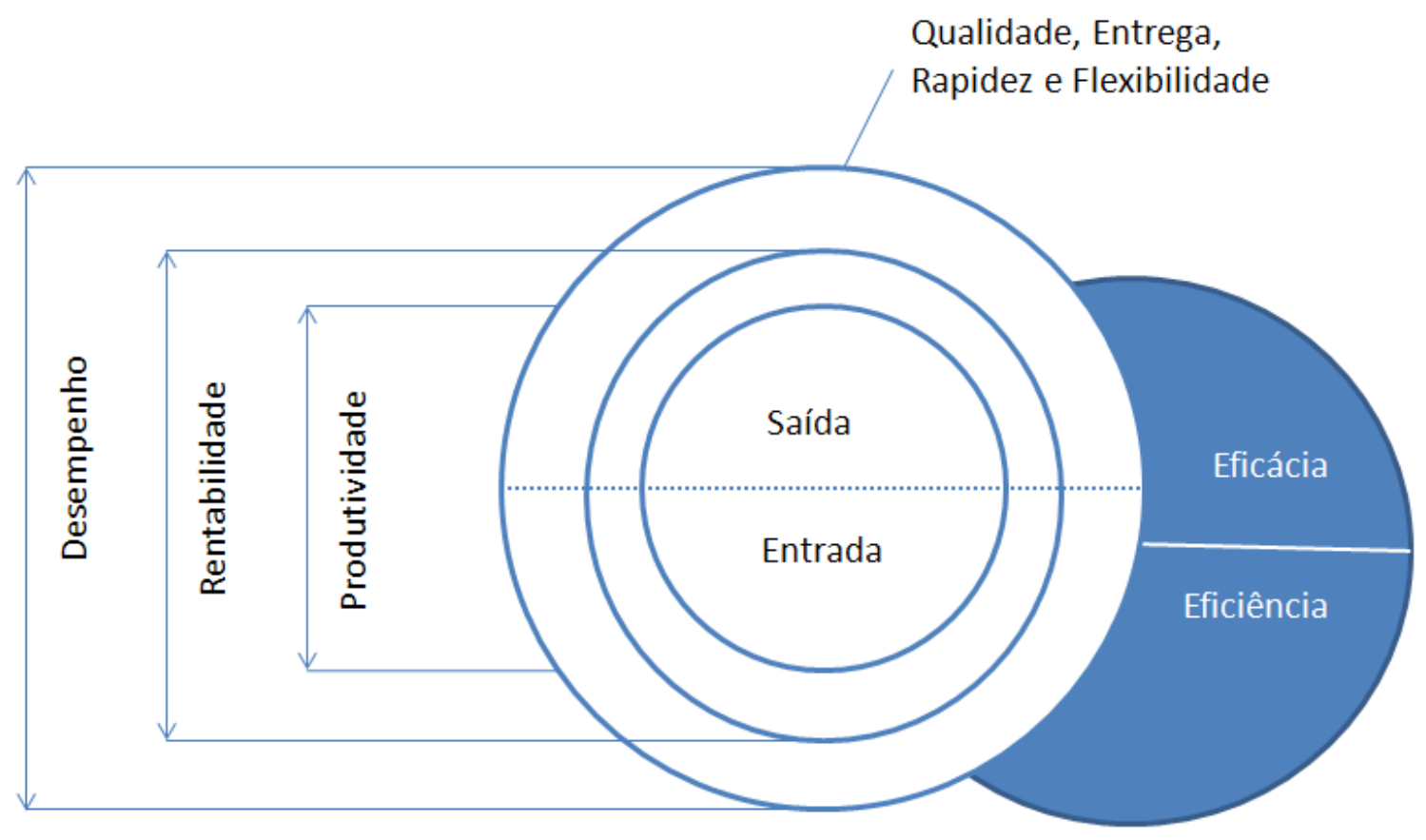

Figura 3 - Relação de alguns dos critérios de desempenho. Fonte: Tangen (2005b).

Neste sentido, esta pesquisa tem como objetivo medir o desempenho do sistema de produção por meio da utilização dos seus recursos em seu potencial máximo, ou seja, avaliar a utilização da capacidade pela medição da eficácia do sistema de produção. Elmaghraby (1991) afirma que a capacidade é algo fácil de definir, porém muito difícil de ser mensurado.

Para a medição da capacidade e avaliação de sua utilização, diversas abordagens têm sido propostas por pesquisadores bem como por especialistas e gestores de empresas de manufatura que tratam da questão do planejamento da capacidade de sistemas produtivos e do gerenciamento de sua utilização.

Uma delas é a que considera que a capacidade de produção pode ser mensurada através da medição da disponibilidade do recurso. O advento da filosofia de Manutenção Produtiva Total (TPM) sob os auspícios da Japan Institute of Plant Maintenance (JIPM) trouxe a noção de que é necessário desenvolver uma visão mais holística do sistema de manufatura e que para isso é fundamental estabelecer 
uma forma mais abrangente de medir a utilização da capacidade produtiva e seu desempenho. O Overall Equipment Effectiveness (OEE) que mede a disponibilidade global na utilização dos equipamentos foi então proposto como um indicador de desempenho da manufatura que cumpre esta função de controle gerencial (LJUNGBERG, 1998; NAKAJIMA, 1989).

O indicador de OEE se apresenta como um indicador global por considerar uma visão bastante abrangente das perdas que comprometem o desempenho do equipamento que se pretende avaliar. Já Muscat (sd) coloca que um indicador global tem como característica considerar o sistema de produção como um todo. Assim um indicador pode ser considerado global ou parcial dependendo da maior ou menor abrangência do sistema que é objeto de análise para o qual se pretende estabelecer uma medição de desempenho.

Martins (1999) coloca que um dos princípios Tayloristas para gestão do desempenho da manufatura era considerar que o custo global é, em grande parte, resultante de um fator dominante na estrutura de recursos consumidos durante 0 processo de produção. Contudo, o autor ressalta que as mudanças que ocorrem nos ambientes internos e externos das empresas de manufatura fazem com que este tipo de premissa perca sua coerência, pois não é possível determinar um fator dominante na estrutura de recursos da produção que o represente de forma global.

A idéia fundamental, após o Taylorismo, passou a ser então de buscar a visão do sistema como um todo e não mais de um recurso específico. Martins (1999) reforça que esta visão sistêmica coloca que qualquer problema está inserido dentro de um sistema mais amplo (síntese) que é composto de subsistemas (análise) que interagem entre si.

Neste sentido, o termo global será aplicado, nesta pesquisa, para se referir à abrangência de sistemas de produção mais amplos que sejam compostos de subsistemas, tais como: equipamentos, linhas de produção e áreas de apoio que interagem com a área produtiva.

Dentre os diversos indicadores concebidos para subsidiar a gestão da capacidade de sistemas de produção, o OEE merece destaque pela grande difusão que alcançou no âmbito internacional no decorrer das últimas décadas. Enquanto um indicador, o OEE é percebido como um instrumento capaz de fornecer 
informações valiosas para planejadores e gestores responsáveis por buscar uma adequada utilização da capacidade do sistema de produção.

Contudo, para medir o desempenho global da manufatura e verificar a utilização da capacidade, estudos sobre a conceituação do OEE enquanto indicador de desempenho global da manufatura tem revelado diversas limitações e fragilidades inerentes ao mesmo. Autores como Ljungberg (1998), Braglia et al. (2009) e Bamber (2003) concordam que o OEE é um ótimo indicador para medir a eficácia de uma única máquina, mas que não seria suficiente para direcionar a melhoria global do processo produtivo quando este envolve diversos equipamentos inter-relacionados.

\subsection{Relevância do tema}

Fleisher et al. (2006) reforçam que a competitividade das companhias de manufatura depende da disponibilidade e produtividade de seus recursos de produção. A necessidade de priorizar a racionalização do uso de um recurso ou outro depende do tipo de processo e produto que a empresa oferece ao mercado: empresas mais intensivas em mão de obra precisam investir mais na capacitação e motivação dos recursos humanos; empresas de produção em massa precisam buscar elevada eficácia na utilização de equipamentos e recursos humanos bem como no consumo de insumos materiais; já as empresas de processo contínuo precisam assegurar fluxo altamente previsível por meio de tecnologias intensivas em capital (SLACK, 2002), nas quais devem ser investidos esforços voltados à disponibilidade e confiabilidade de equipamentos.

Nos casos da manufatura de produção em massa e em processo contínuo, é fundamental assegurar elevada disponibilidade dos equipamentos para ter o produto disponível no tempo certo para o cliente. Assim, quando as causas das perdas na utilização da capacidade de produção podem ser identificadas, é possível empreender esforços para eliminá-las ou reduzi-las.

Segundo Ljungberg (1998), houve uma gradual evolução na forma de avaliação das perdas que impactam na disponibilidade dos equipamentos. $\mathrm{Na}$ década de 1970, a ênfase incidia na avaliação das perdas de produção dos ativos fixos, que eram divididas em falhas mecânicas, elétricas, eletrônicas e hidráulicas. 
Já na década de 1980, procurou-se avaliar os obstáculos para produção classificando-os como causas técnicas e causas organizacionais. Na década de 1990, acentuou-se a preocupação em medir as perdas por paradas, classificando-as como planejadas e não planejadas.

Staudt et al. (2001) colocam a importância de se conhecer a Capacidade Real Necessária (CRN) em relação a Capacidade Atual para se atender a demanda. Essa capacidade deve considerar um incremento em relação à demanda devido às perdas de eficiências dos recursos de produção.

Ghalayini e Noble (1996) colocam que a literatura sobre sistemas de medição de desempenho apresentam duas fases. Na primeira fase, que estes autores delimitam entre o final de 1880 e a década de 1980, os sistemas de medição tradicional enfatizavam os indicadores financeiros para medição do lucro, do retorno sobre investimentos e de produtividade.

Essas formas de avaliação da produtividade são criticadas por Ghalayini et al. (1997) que colocam que as medições de desempenho da manufatura tradicionais não são aplicáveis às novas abordagens de gestão que dão aos operadores de chão de fábrica mais responsabilidade e autonomia nas áreas de produção, qualidade, manutenção preventiva e programação.

A segunda fase, com início no final da década de 1980, veio acompanhada de grandes mudanças de mercado, que fizeram empresas já estabelecidas perder muito market-share e assim, houve um grande movimento para focar não somente o desafio de obter baixo custo, mas também melhor qualidade, flexibilidade e atendimento. Assim, com o auxilio de programas para melhoria do processo de manufatura, foi necessário desenvolver novos sistemas de medição de desempenho com as seguintes características:

- Indicadores com foco na estratégia de manufatura.

- Indicadores não financeiros que possam fornecer a gestores, supervisores e operadores da manufatura informações para tomadas de decisão diárias.

- Indicadores simples que os operadores de fábrica possam entender e utilizar facilmente. 
- Indicadores que possam promover a melhoria dos processos e seu monitoramento.

- Indicadores que possam ser mudados conforme a dinâmica do mercado.

Por este motivo, este trabalho irá priorizar a consideração de indicadores não financeiros de fácil entendimento e gerenciamento para os responsáveis pela tomada de decisões que impactem diretamente na melhor utilização da capacidade produtiva.

Andersson et al. (1989) afirmam que as decisões para melhorar a utilização da capacidade têm impacto nas estratégias atuais e futuras, pois se leva muito tempo para uma empresa mudar a sua capacidade de produção: essa mudança pode requerer um novo prédio, uma ampliação e então levar vários anos. Ou ainda, pode ser necessária a adição de novos equipamentos o que, na maioria das indústrias, é comum levar até dois anos.

Mas como avaliar o desempenho da produção para gerenciar os esforços de busca de maior produtividade no âmbito das empresas e de suas fábricas? Johsson e Lesshammar (1999) sugerem que é necessário estabelecer um sistema integrado de avaliação do desempenho global da manufatura para promover um bom desempenho da empresa pela competente utilização de seus recursos de produção

Neste contexto, o OEE se apresenta como um indicador que reúne atributos importantes para a construção de novos sistemas de avaliação do desempenho em empresas para as quais a efetiva utilização da capacidade constitui um fator crítico de sucesso. Assim, este indicador tem sido amplamente adotado e utilizado em diversas empresas de manufatura no diagnóstico da utilização da capacidade de seu sistema produtivo e direcionamento das ações de melhoria contínua, notadamente nas organizações que utilizam modelos gerenciais como Total Quality Management (TQM), World Class Manufacturing (WCM) e Produção Enxuta, além do próprio TPM (BOHORIS, 1995; TSAROUHAS, 2007; WEE; WU, 2009; GIBBONS; BURGESS, 2010). Sua aplicação tem sido difundida em diversos setores industriais, dentre os quais se destacam o automobilístico, o de semicondutores e as indústrias de processo.

Este indicador promove uma visão ampliada da vida útil dos equipamentos e distingue os principais fatores que caracterizam as condições de uso dos 
equipamentos em termos de disponibilidade, desempenho e qualidade de conformidade. Existem padrões e guias referenciais para sua medição e análise que podem servir como base para permitir a comparação dos resultados de diferentes plantas num dado setor industrial (RON; ROODA, 2005).

Jeong e Phillips (2001) salientam que a abordagem de medição do OEE é muito importante em indústrias intensivas em capital já que este indicador não avalia somente a utilização, e demanda a identificação e análise das perdas escondidas. Ao preconizar a medição destas perdas que podem ocorrer mesmo na utilização dos equipamentos - por falta de qualidade do produto final e variação do tempo de ciclo do processo - o OEE promove a análise dos problemas e o tratamento da causa raiz de modo a tornar mais efetiva as ações de melhoria do processo e aumentar a utilização da capacidade dos equipamentos. Ljungberg (1998) afirma que, em muitas empresas, antes de qualquer intervenção de melhoria, é comum que o valor de OEE seja baixo. Numa pesquisa de campo realizada por estes autores, constatou-se um valor médio de cerca de $55 \%$.

Raposo (2011) destaca a importância da medição e utilização do indicador de OEE e propõe onze etapas para a aplicação do OEE na busca de uma melhor utilização da capacidade produtiva em uma indústria de bebidas no pólo industrial de Manaus, as quais são enumeradas a seguir:

- $1^{\text {a }}$ etapa: Incorporação do indicador OEE por todos os setores a empresa, desde a alta administração até o chão-de-fábrica, por meio de treinamentos.

- $2^{a}$ etapa: Definição, pelo gestor de produção, de uma equipe dentro do setor de produção para ser responsável pela medição e acompanhamento dos resultados do OEE.

- $3^{a}$ etapa: Realização de cronoanálise em cada linha de produção.

- 4a etapa: Determinação do equipamento identificado como o gargalo de cada linha de produção, ou seja, o equipamento com maior tempo de ciclo.

- 5a etapa: Identificação das perdas no processo, também chamadas de paradas de linha, e a codificação destas perdas. O auxílio dos operadores da produção é muito útil nesta etapa, pois estão mais familiarizados com o processo. 
- 6a etapa: Elaboração de documento padronizado utilizado na coleta de informações para o cálculo do indicador OEE e a utilização de um programa para armazenamento, cálculo e controle dos dados.

- $7^{a}$ etapa: Treinamento dos colaboradores envolvidos no processo sobre os conceitos e cálculos para o resultado do indicador OEE.

- 8a etapa: Elaboração de controles visuais com dados sobre a evolução do indicador OEE e as causas dos seus resultados. Assim, todos na empresa podem visualizar a realidade em que o sistema se encontra.

- 9a etapa: Realização de Atividades de Pequenos Grupos (APGs), reuniões com os operadores, supervisores e representante de cada área envolvida, diariamente para discussão dos resultados de OEE do dia anterior.

- $10^{\mathrm{a}}$ etapa: Abertura de um documento padronizado contendo informações sobre os problemas identificados e entrega, conforme o problema, ao representante da área responsável para a tomada de ações corretivas/ preventivas.

- 11aㅡ etapa: Validação das ações realizadas, por meio de novas medições de OEE.

Mathur et al. (2011) afirmam que muito se tem discutido na literatura acadêmica, sobre o desenvolvimento e a utilização do OEE na identificação de diferentes perdas e eliminação destas perdas com o propósito de promover um ambiente de melhoria do desempenho global.

Na realização de uma pesquisa, no portal de Periódicos da Capes $^{2}$ através do mecanismo de busca avançada, utilizando o termo "Overall Equipment Effectiveness" nos campos Assunto ou Título, um total de 210 artigos foram levantados, dentro das bases de periódicos catalogados para a área de Engenharias. A Figura 4 mostra uma distribuição dos artigos que tratam sobre o tema do OEE do período de 1989 (ano da introdução da conceituação do OEE por Nakajima) até o mês de setembro de 2011, quando este levantamento foi realizado.

\footnotetext{
${ }^{2}$ http://www.periodicos.capes.gov.br
} 


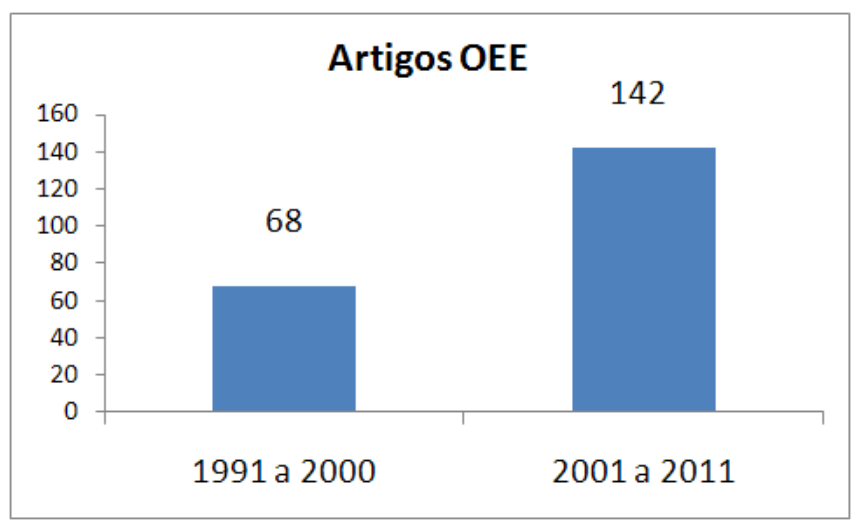

Figura 4 - Levantamento de Artigos Publicados sobre Overall Equipment Effectiveness (OEE). Levantamento realizado pela autora.

Como mostra a Figura 4 é possível observar que houve um aumento pelo interesse no assunto na segunda década após o lançamento do conceito de OEE.

É possível encontrar na literatura artigos que tratam da aplicação do OEE de forma a elucidar como elucidar como aplicá-lo de forma a auxiliar a medição do desempenho da manufatura para a tomada de decisão.

Outra análise realizada no portal de Periódicos da Capes, porém considerando somente os resumos de artigos que foram classificados como tendo relevância de 3 a 5, ou seja, relação mais forte com o termo "Overall Equipment Effectiveness" da busca realizada, revelou uma grande predominância de pesquisas para a aplicação de sua conceituação, visando a melhoria do resultado medido por meio deste indicador. Parcela significativa destes artigos aborda a adoção do OEE no contexto da promoção de um programa de TPM durante a primeira década (1991 a 2000), após a época de sua introdução. Isso revela um grande interesse por parte de pesquisadores e gestores de empresas para se obter um bom entendimento do OEE e desenvolver iniciativas necessárias para implementá-lo e, por meio dele, direcionar os esforços de melhoria dos processos. A Tabela 1 mostra essa análise. 
Tabela 1 - Avaliação dos resumos dos artigos de maior relevância sobre OEE.

\begin{tabular}{|l|c|c|}
\hline \multicolumn{1}{|c|}{ Avaliação do Resumo } & 1991 a 2000 & 2001 a 2011 \\
\hline $\begin{array}{l}\text { Apresenta casos de aplicação do OEE, não cita outros indicadores. Não } \\
\text { apresenta foco em melhoria, mas de entendimento do indicador. }\end{array}$ & 8 & 6 \\
\hline Cita aplicação do OEE vinculada a um Programa de TPM ou Manutenção & 6 & 1 \\
\hline Cita trabalho com foco em melhoria de desempenho medida pelo OEE. & 10 & 9 \\
\hline Explica os maus usos do OEE como indicador de desempenho. & 0 & 1 \\
\hline Apresenta claramente alternativas de indicadores derivados do OEE. & 1 & 7 \\
\hline
\end{tabular}

Não obstante, o OEE tenha se tornado um indicador de vasta utilização pela simplicidade e clareza de sua conceituação, este indicador revela limitações como a falta de clareza na definição e medição de elementos como tempo de ciclo do processo e pequenas paradas (RON; ROODA, 2005; GOUVEA DA COSTA; PINHEIRO DE LIMA, 2002). Da análise da Tabela 1, observa-se que na década de 2001 a 2011 a motivação que passou a predominar entre os artigos que se referem ao OEE foi a busca de novos indicadores derivados do mesmo revelando o aumento da percepção de que é preciso aprimorar ou complementar a medição do desempenho da manufatura com indicadores que sejam mais adequados às reais características e necessidades dos sistemas de produção.

Muthiah e Huang (2007) corroboram o entendimento de que a conceituação do OEE não atende ao propósito central de um sistema integrado de medição da manufatura que é o de medir a eficácia de toda a fábrica. Diante da necessidade de aprimorar a medição do desempenho global da manufatura, Schmenner e Vollmann apud Jonsson e Lesshammar (1999) afirmam que as empresas precisam buscar indicadores que melhor reflitam os resultados de toda a manufatura indo além daqueles contemplados pelo OEE.

Uma questão gerencial relevante levantada por Ljungberg (1998) diz respeito às responsabilidades sobre as perdas. As perdas consideradas pelo OEE são as comumente associadas às áreas de Produção ou de Manutenção. Para Jeong e Phillips (2001), a definição original de OEE não é adequada para indústrias intensivas em capital, que buscam a maior utilização possível dos equipamentos, pois este indicador não considera perdas devido às paradas para manutenção 
preventiva e a não utilização da capacidade em períodos não programáveis como feriados e turnos inativos. Assim, por considerar poucos tipos de perdas, o OEE pode causar distorções, como a possibilidade de atribuir à Produção perdas que não são de fato de sua responsabilidade. Perdas decorrentes de problemas de embalagens do fornecedor ou por reinicialização de processo, após uma queda brusca de energia, são exemplos de falhas que frequentemente têm como causa raiz, problemas externos a uma fábrica.

Jeong e Phillips (2001) destacam que, desta forma, as empresas têm procurado utilizar derivações do OEE que incorporam a medição de perdas por razões não consideradas na definição original de OEE como, por exemplo, tempos não programados, paradas planejadas de manutenção, e realização de testes de produto, bem como decisões resultantes da gestão do negócio. Isso também decorre da necessidade de caracterizar o objeto da medição como uma máquina, um conjunto de máquinas, uma linha, uma planta ou um negócio.

A Tabela 1 revela que essas limitações têm motivado a busca por alternativas de indicadores derivados do OEE para a medição do desempenho da manufatura, o que representa uma significativa mudança da perspectiva com que gestores e pesquisadores têm considerado a aplicabilidade deste indicador no passado recente.

Além da busca por indicadores derivados do OEE, pode-se observar que na literatura sobre indicadores de desempenho em geral é muito comum encontrar artigos que discutem a sua forma e importância de medição. Esta característica também é perceptível na literatura sobre OEE. O que se percebe é que ainda existem vários pontos relacionados com a sua aplicação que não são apresentados, como por exemplo, a indicação do que seria um resultado ideal de OEE para o tipo de manufatura estudada.

Ainda que a literatura sobre indicadores sugira a utilização do critério SMART (Specific - Measurable - Attainable - Realistic - Time Sensitive), que define que uma meta deve ser detalhada para ser específica, deve ser mensurável qualitativa ou quantitativamente, deve ser atingível, porém desafiadora, deve ser uma meta realista e orientada para o resultado e, por último, deve ser atingível dentro de um tempo estabelecido e útil para tomada de decisão (SHAHIN; 
MAHBOD, 2007), este critério não é relacionado na literatura sobre OEE como uma ferramenta para definição de metas para o mesmo.

Uma das contribuições desta pesquisa está relacionada ao desenvolvimento de um estudo bibliográfico que proporcione uma visão consolidada dos diversos aspectos que comprometem a adoção do OEE como um instrumento de medição e avaliação do desempenho global do sistema de produção, identificar indicadores mais abrangentes derivados do OEE e verificar a aplicação destes indicadores no processo de tomada de decisões gerenciais e nos esforços de melhoria da organização.

A motivação principal da pesquisa é de desenvolver um estudo que contribua aos esforços de desenvolvimento de sistemas de medição e avaliação do desempenho global da manufatura que sejam mais adequados à realidade das empresas de manufatura que dele dependem para gerenciar a disponibilidade de seus equipamentos e, assim, alcançar uma utilização mais efetiva da sua capacidade produtiva.

\subsection{Objetivo do trabalho}

Há um crescente volume de publicações que têm revelado a existência de sérias limitações na conceituação original do OEE e feito restrições quanto à sua adoção como um indicador de desempenho global do sistema de produção. Contudo, em geral, tais estudos têm focado e criticado pontos fracos específicos do OEE, sendo que diversos pontos de vista podem ser considerados.

Diante do exposto, esta pesquisa tem como objetivo:

Verificar a existência de indicadores derivados do OEE que possibilitem as empresas aprimorar a medição do desempenho sistêmico e identificar suas principais características. 
Isso envolve revisar a literatura e levantar as derivações que têm sido propostas na forma de aplicação do OEE como ferramenta de gestão por empresas que buscam melhores resultados para a sua manufatura com base numa visão mais sistêmica da empresa.

Sempre que uma organização considera a implantação de um novo indicador de desempenho, deve ter o cuidado de não cometer o erro de confundir a implantação do mesmo como um objetivo em si. É fundamental gerenciar e conduzir esta iniciativa, entendendo claramente a natureza e utilidade das informações que o novo indicador pode gerar e ser capaz que utilizá-las efetivamente no direcionamento e acompanhamento dos esforços de melhoria contínua.

Assim sendo, o objetivo do trabalho contempla também a caracterização dos indicadores derivados do OEE que possibilitem uma melhor medição do desempenho global na utilização da capacidade produtiva que forem identificados na revisão da literatura.

O desenvolvimento deste estudo bibliográfico deve proporcionar uma visão consolidada dos diversos aspectos que comprometem a adoção do OEE como um instrumento de medição/avaliação do desempenho global do sistema de produção, bem como sua aplicação no processo de tomada de decisões gerenciais e nos esforços de melhoria da organização. Já com a caracterização dos indicadores alternativos que forem identificados, pretende-se distinguir as especificidades de cada um e elucidar como podem contribuir para ampliar a abrangência do sistema de medição da utilização de capacidade produtiva.

\subsection{Questões de pesquisa}

Para atender ao objetivo proposto, foram formuladas duas questões de pesquisa para guiar o desenvolvimento deste trabalho.

Identificadas as limitações do OEE é necessário verificar na literatura a existência de indicadores que complementam as lacunas encontradas no OEE e que se adéquam à realidade de empresas que necessitam buscar uma medição global 
da eficácia do sistema de produção. Assim, uma primeira questão (Q1) a ser pesquisada é:

\section{Q1. Quais são os indicadores derivados do OEE para possibilitar uma medição mais abrangente do desempenho da manufatura?}

Uma vez identificados os indicadores de desempenho que podem complementar ou até mesmo substituir o OEE é necessário entender o que estes indicadores oferecem e se são suficientes para as necessidades de identificação e análise de problemas de utilização da capacidade produtiva em uma empresa industrial. Para que as informações geradas por um determinado indicador possam ser efetivamente consideradas na tomada de decisões e direcionar ações de melhoria pertinentes, é necessário entender o quanto estes indicadores atendem os requisitos de uma adequada medição de desempenho global da manufatura. Isso motiva o estabelecimento de uma segunda questão de pesquisa (Q2), conforme segue:

Q2. Como se caracterizam os indicadores derivados do OEE enquanto possíveis instrumentos para balizar o sistema de medição do desempenho global da manufatura?

Com base na pesquisa destas duas primeiras questões, pretende-se elaborar um quadro referencial para o enquadramento conceitual de indicadores para avaliação da utilização da capacidade de produção, que proporcione uma visão comparativa das alternativas de indicadores derivados do OEE para medição da utilização da capacidade de produção e de suas principais características.

Os indicadores quando estabelecidos e adequadamente mensurados devem ser aplicados para promover efetivamente melhorias na utilização da capacidade. $O$ entendimento dos motivos de perdas de produção e o direcionamento da responsabilidade de eliminar e/ou controlar as causas identificadas aos agentes responsáveis são importantes para que os problemas de baixo desempenho na utilização da capacidade de produção sejam eliminados. 
Algumas destas causas, quando analisadas de forma global, deixam clara a necessidade de tomadas de decisões em níveis mais altos da organização, pois estão relacionadas com questões tratadas em níveis mais táticos ou estratégicos. Identificar estas questões só é possível quando o indicador permite uma visão global da organização que abranja as áreas relacionadas. Além disto, para o eficaz tratamento destas causas é necessário o envolvimento dos agentes que tenham a autoridade para efetivar ações direcionadas à solução do problema.

Considerando os artigos que tratam de assuntos relacionados ao OEE examinados para elaboração da Tabela 1, constata-se que há uma carência de estudos que tratam das intervenções que são necessárias numa organização para implementar sistemas de medição mais integrados para gestão do desempenho da manufatura, enfrentando as dificuldades de natureza prática.

Com o propósito contribuir para aumentar o entendimento de como esses indicadores, derivados do OEE, podem ser efetivamente implementados numa organização e auxiliar os gestores nas tomadas de decisões gerenciais em busca de uma melhor utilização da capacidade produtiva de seus recursos, um Estudo de Caso ilustrativo será desenvolvido.

A Figura 5 relaciona os propósitos desta dissertação com o objetivo e as questões de pesquisa que direcionaram o seu desenvolvimento... 


\section{Premissa}

Conforme diversos autores colocam, O OEE é um indicador limitado para aplicações sob circunstâncias e propósitos bem distintos daqueles considerados na sua conceituação inicial.

\section{Propósitos da dissertação}

Contribuir no esforço de identificação de indicadores mais abrangentes derivados do Overall Equipment Effectiveness (OEE) e na análise teórico-conceitual dos mesmos enquanto instrumentos que podem ser aplicados na medição do desempenho global da manufatura.
Contribuir para aumentaro entendimento de como indicadores, derivados do OEE, podem ser efetivamente implementados numa organização e auxiliar os gestores nas tomadas de decisão em busca da melhor utilização da capacidade produtiva de seus recursos, com o objetivo de reduzir custo e aumentar a disponibilidade de produto de forma a garantir uma vantagem competitiva.

\section{Objetivo da pesquisa}

Verificar a existência de indicadores derivados do OEE que possibilitem as empresas aprimorar a medição do desempenho sistêmico e identificar suas principais características.

\section{Questões de pesquisa}

Q1. Quais são os indicadores derivados do OEE para possibilitar uma medição mais abrangente do desempenho da manufatura?
Q2. Como se caracterizam os indicadores derivados do OEE enquanto possíveis instrumentos para balizar o sistema de medição do desempenho global da manufatura?

\section{Estudo de caso ilustrativo}

Estudo de Caso para ilustrar a implementação de indicadores globais de utilização da capacidade produtiva em um nivel mais alto de uma organização, procurando incorporar a participação de agentes responsáveis por perdas de produção, que atuam além da fábrica

Elaborar um quadro referencial para

o enquadramento conceitual dos

indicadores para avaliação da

utilização da capacidade de produção

\section{Resultados da dissertação}

Contribuição aos esforços de desenvolvimento de sistemas de medição e avaliação do desempenho global da manufatura que sejam mais adequados à realidade das empresas de manufatura que dele dependem para gerenciar a disponibilidade de seus equipamentose, assim, alcançar uma utilização mais efetiva da sua capacidade produtiva.

Figura 5 - Relação entre os objetivos e questões desta dissertação.

Outras questões, de natureza teórico-conceitual relacionadas com o tema desta dissertação que mereciam ser elucidadas como por exemplo, quais os cuidados para selecionar um indicador de desempenho global da manufatura em função das características de seu produto, processo de transformação e mercado e qual a meta ideal a ser atingida não fazem parte do escopo desta pesquisa. 


\subsection{Escopo do trabalho}

Uma vez definidas as questões de pesquisa e esclarecida a relevância teórico-conceitual do assunto para as empresas de manufatura no contexto atual, faz-se necessário definir as fronteiras consideradas para o desenvolvimento do presente estudo.

A primeira delimitação considerada nesta pesquisa está relacionada com a definição do conceito fundamental de capacidade produtiva. Dada a diversidade de conceitos relacionados com a noção de capacidade de uma fábrica ou empresa, foi assumido o conceito de capacidade, medida em unidades de espaço ou tempo, como o máximo nível de atividade com valor adicionado em determinado período de tempo que o processo pode realizar sob condições normais de operação.

Uma segunda delimitação para o escopo desta pesquisa decorre da necessidade de caracterizar o tipo de sistema de produção que será estudado. Optou-se por desenvolver o estudo no contexto de sistemas de produção intensivos em capital que caracterizam, por exemplo, as fábricas das indústrias de processo contínuo. Em tais indústrias, o foco na racionalização do uso dos recursos é um aspecto crítico para a competitividade da empresa.

Por último, é preciso observar que o conceito de indicador pode ser tratado em diferentes níveis. Na literatura, são encontradas desde propostas de indicadores parciais mais específicos destinados à medição de uma parte de um sistema ou de um dado recurso (visão micro), até propostas de indicadores globais que medem o desempenho agregado de uma empresa ou mesmo de um grupo de empresas no nível do negócio ou da corporação (visão macro). Neste caso, há uma ênfase em adotar indicadores que possibilitam uma avaliação sob a perspectiva econômicofinanceira. Esta pesquisa se propõe a tratar da aplicação de indicadores de desempenho globais do sistema de produção de uma determinada fábrica/planta, que auxiliem na tomada de decisão dos gestores responsáveis pela racionalização das operações. Assim sendo, os indicadores que promovem a avaliação de resultados sob uma perspectiva econômico-financeira não serão aqui contemplados. 


\subsection{Estrutura da pesquisa}

Após este capítulo de introdução para apresentação dos objetivos, questões de pesquisa e escopo do trabalho, no capítulo 2, são delineados os aspectos metodológicos considerados na revisão e análise da literatura bem como no desenvolvimento de um estudo de caso que teve como propósito levantar subsídios que pudessem contribuir na discussão de pontos que requeriam uma visão empírica de iniciativas práticas de aprimoramento do sistema de medição e avaliação da utilização da capacidade de produção.

No capítulo 3, com base na literatura revisada, discute-se o conceito de capacidade e medição do desempenho da manufatura, o conceito de OEE na sua concepção original, analisam-se suas limitações de aplicação e são apresentados indicadores derivados do OEE para a avaliação do desempenho global da manufatura.

No capítulo 4, a fim de contribuir no entendimento da forma de aplicação destes indicadores, é elaborada uma proposta de enquadramento geral dos mesmos que fornece uma visão comparativa de sua abordagem de medição mostrando como o escopo por eles considerado varia do mais específico ao mais abrangente.

No capítulo 5, é apresentado e analisado um estudo de caso ilustrativo. 0 desenvolvimento deste estudo de caso contribui para elucidar como o uso gerencial do OEE e de indicadores derivados do mesmo pode ser implementado e aprimorado na busca de melhores resultados não apenas para a planta, mas para o negócio.

Por fim, no capítulo 6 , são apresentadas as conclusões relacionadas às questões Q1 e Q2 e as conclusões geradas da análise do estudo de caso. Também são delineadas algumas recomendações para a continuidade de pesquisas sobre 0 tema focado. 


\section{Método de pesquisa}

As questões de pesquisa estabelecidas para o desenvolvimento deste trabalho suscitaram a adoção do método de pesquisa bibliográfica para a realização de uma investigação inicial de natureza teórico-conceitual para desenvolver uma visão abrangente e atual sobre as limitações do OEE e alternativas de indicadores derivados deste. Para se obter dados empíricos sobre uma experiência real de implementação de um sistema de avaliação do desempenho global do sistema de produção com base em indicadores derivados do OEE, recorreu-se à aplicação do método de estudo de caso. A forma como estes métodos de pesquisa foram aplicados é apresentada nas seções seguintes.

\subsection{Método de levantamento e análise da literatura}

A pesquisa de novos indicadores que têm sido propostos na literatura face às limitações do OEE (Questão 1) e verificação de suas características (Questão 2) foram baseadas na realização de uma pesquisa bibliográfica de artigos técnicocientíficos publicados sobre este assunto desde 1989 (ano da introdução da conceituação do OEE por Nakajima) até o ano de 2011.

Neste levantamento as palavras chaves utilizadas foram: Overall Equipment Effectiveness, OEE e Performance Measurement e alguns termos em português como Eficácia Global do Equipamento, EGE, e Sistema de Medição de

Desempenho. A procura foi realizada dentro da base de periódicos que abrange a área de Engenharia do portal Periódicos Capes e foram selecionados os artigos com maior número de citações e/ou relevância conforme classificação indicada por este portal.

Para a apresentação dos indicadores derivados do OEE identificados na pesquisa bibliográfica, procurou-se seguir uma estrutura de descrição comum, contemplando as seguintes informações básicas:

- Quem é o autor que propõe o indicador derivado? 
- Em que $a n o^{3}$ o indicador considerado foi proposto ou introduzido na literatura?

- O que o indicador derivado do OEE considerado mede?

- Como é medido o indicador derivado do OEE considerado?

Mais especificamente, o tratamento da Questão 2 requereu a adoção de uma estrutura conceitual adequada na qual a caracterização dos diversos indicadores derivados do OEE, que foram identificados no tratamento da Questão 1, pudesse ser apoiada.

Diversos quadros conceituais para orientar a caracterização de um sistema de medição do desempenho global da manufatura são encontrados na literatura. Conforme, Martins (1999) as principais características esperadas de um sistema de medição, citadas por diversos autores, se resumem em:

- ser congruente com a estratégia competitiva.

- ter medidas financeiras e não-financeiras.

- direcionar e suportar a melhoria contínua.

- identificar tendências e progressos.

- facilitar o entendimento das relações de causa-e-efeito.

- ser facilmente inteligível para os funcionários.

- abranger todo o processo, desde o fornecedor até o cliente.

- disponibilizar informações em tempo real para toda a organização.

- ser dinâmico.

- influenciar a atitude dos funcionários.

- avaliar o grupo e não o indivíduo.

Martins (1999) apresenta pelo menos 7 (sete) modelos de sistema de medição do desempenho global encontrados na literatura. Dentre estes, um que

\footnotetext{
${ }^{3}$ Ou a data mais próxima da época de sua introdução, caso uma informação mais exata não fosse identificada
} 
merece ser destacado por ser bastante conhecido é o SMART (Strategic Measurement, Analysis, and Reporting Technique), que tem o objetivo de mudar a orientação do sistema de medição de desempenho do foco em custos para o direcionamento à melhoria contínua (MCNAIR et al., 1990 apud Martins, 1999). A mudança é feita através da visão corporativa, traduzida em objetivos financeiros e de mercado e desdobradas até os departamentos e centros de trabalhos. As medidas de desempenho neste modelo são divididas em dois grupos:

1. aquelas que medem a eficiência interna das atividades e dos departamentos expressos para a alta administração, em termos financeiros, e para a gerência de operações, em termos físicos (por exemplo, tempo de ciclo e perdas);

2. e, aquelas que medem a efetividade externa em termos de mercado.

Contudo, este modelo não deixa claro nada referente a como um funcionário de um nível hierárquico tem acesso as informações de outro nível, permitindo assim uma análise e investigação dos trade-offs entre as medidas de diferentes níveis/áreas (MARTINS, 1999).

Outro modelo, bastante difundido na literatura bem como no contexto empresarial é o Balanced Score Card (BSC) (MARTINS, 1999). Apresentado por Kaplan e Norton (1992), este modelo complementa as medidas financeiras com outras três perspectivas que direcionam para o desempenho futuro: a perspectiva do cliente, a perspectiva do processo interno do negócio e a perspectiva de aprendizagem e crescimento. Além destas perspectivas, o modelo propõe o estabelecimento de 4 processos de gestão para assegurar que o sistema de medição de desempenho reflita o resultado esperado, quais sejam:

1. traduzindo a visão: está relacionado a esclarecer a visão e revisar a estratégia anualmente.

2. comunicando e ligando: relacionado ao desdobramento para a gerência e definição de metas individuais.

3. planejando o negócio: que é a relação entre o plano de negócio e o plano financeiro (orçamento). 
4. feedback e aprendizado: que é a etapa de gestão de revisão de todos esses processos.

Martins (1999) coloca que uma crítica a este modelo de sistema de medição de desempenho é que tende a ser um modelo muito aplicado à alta administração e à média gerência, e assim acaba não enfatizando o foco que a produção e outras áreas mais operacionais necessitam para atuar diretamente nos indicadores avaliados por este sistema.

Uma terceira proposta que revela o cuidado de evitar tal deficiência e viés foi apresentada por Johsson e Lesshammar (1999), segundo os quais, um sistema integrado de avaliação do desempenho global da manufatura deve contemplar o que deve ser medido sob quatro dimensões, quais sejam:

i. a perspectiva estratégica,

ii. a da orientação ao fluxo,

iii. a da eficiência interna, e

iv. a da eficácia externa.

Adicionalmente, estes autores apontam duas características sobre o modo pelo qual o desempenho global da manufatura deve ser medido. Estas características dizem respeito:

v. ao potencial de sua utilização no direcionamento de melhorias, e

vi. à simplicidade/facilidade de acesso/atualização.

Estes autores ilustram a utilização destas dimensões e critérios para analisar - OEE como indicador de desempenho global da manufatura. Esta estrutura, contudo, também pode acomodar a análise de outros indicadores que consideram uma visão global da manufatura, por avaliar desde a sua visão estratégica até a consideração da necessidade de integração entre áreas internas e externas. Por este motivo, optou-se por utilizar esta estrutura analítica, pois assim seria possível ter uma base de comparação com os indicadores derivados do OEE, utilizando critérios bem fundamentados e articulados identificados na literatura. 
Assumindo a premissa de que, provavelmente, não existe um sistema de medição que seja uma panacéia que satisfaz plenamente todas estas dimensões e características, estes autores apontam a necessidade de cada organização desenvolver sua própria solução de forma dinâmica e interativa.

Estas quatro dimensões e as duas características do modelo de estrutura analítica de Johnson e Lesshammar (1999) são definidas como seguem:

a) Estratégia: traduz as estratégias corporativas e de negócio para todos os níveis da organização.

b) Orientação do Fluxo: integra atividades, processos e funções ao longo da cadeia de produção.

c) Eficiência Interna: quando possível, pode ser aplicado no controle de produção e na comparação entre as funções.

d) Eficácia Externa: interage com os clientes externos para medir o seu nível de satisfação.

e) Direcionador de Melhoria: o sistema não deve somente informar, mas apoiar a interação na organização para garantir a melhoria contínua.

f) Simples e Dinâmico: permite acesso rápido e mudanças fáceis quando necessário.

Com o objetivo de caracterizar os indicadores verificando seu potencial para ser um indicador de desempenho global da manufatura, estes critérios foram aplicados tanto para verificar os atributos do OEE como indicador de desempenho global, quanto para verificar se os indicadores derivados do OEE encontrados na literatura se adequavam aos mesmos critérios.

No Capítulo 3 onde é apresentada de forma consolidada a revisão da literatura pesquisada, inicialmente, a seção 3.1 é dedicada ao estabelecimento de conceitos fundamentais ao desenvolvimento do presente estudo. A discussão da literatura levantada e pesquisada visando especificamente à elucidação das Questões de pesquisa Q1 e Q2 é apresentada na seção 3.2 em diante. 


\subsection{Método de desenvolvimento do estudo de caso ilustrativo}

Uma vez analisada e organizada a relação de indicadores derivados do OEE identificados na literatura, o estudo teve prosseguimento com uma pesquisa para aumentar o entendimento do seu potencial de efetiva aplicação como ferramenta de avaliação e melhoria do desempenho global da manufatura, através do desenvolvimento de um estudo de caso ilustrativo.

Embora a ampla disseminação do OEE remonte à década de 1980, as iniciativas para estender sua aplicação enxergando a manufatura inserida no contexto mais amplo do negócio constitui uma tendência mais recente. Assim, esta pesquisa caracteriza-se pela investigação de um fenômeno contemporâneo, em seu contexto real, com o propósito de buscar um entendimento amplo da natureza e complexidade dos esforços requeridos para tornar a aplicação da conceituação do OEE efetiva na gestão do desempenho global da manufatura em uma organização

Isso motiva, o entendimento de como indicadores globais de utilização da capacidade podem ser implementados num nível mais alto de uma organização, procurando incorporar a participação de agentes responsáveis por perdas de produção, que atuam além da fábrica.

A realização de um estudo com tal propósito remete a um questionamento do tipo "como". Estas circunstâncias são pertinentes com as que, segundo Meredith (1998), justificam a adoção do método do Estudo de Caso.

Segundo Yin (2005) há, no mínimo, cinco aplicações diferentes para o estudo de caso:

a) Explicar os supostos vínculos causais em intervenções da vida real que são complexos demais para as estratégias de pesquisa experimentais;

b) Descrever uma intervenção no contexto da vida real em que ela ocorre;

c) Ilustrar certos tópicos dentro de uma avaliação de um modo descritivo;

d) Explorar aquelas situações nas quais a intervenção que está sendo avaliada não apresenta um conjunto simples e claro de resultados;

e) O estudo de um estudo de avaliação. 
Corrêa (1992) apresenta uma visão geral das características dos diferentes métodos de pesquisa em relação aos requisitos da pesquisa a ser realizada. A Tabela 2 apresenta esta comparação indicando que adequação dos métodos varia em função do tipo de questão a investigar.

O método do Estudo de Caso como mostra a Tabela 2 pode ser aplicado em pesquisas nas quais o objetivo é responder a questões de pesquisa do tipo "como", assim como os métodos do Experimento e da Pesquisa-Ação. Contudo, o Estudo de Caso não necessita de acompanhamento do pesquisador de forma ativa e também é o mais adequado quando se deseja entendimento profundo do processo de decisão.

Tabela 2 - Métodos, requisitos e características principais. Fonte: Corrêa (1992).

\begin{tabular}{|l|c|c|c|c|}
\hline \multicolumn{1}{|c|}{ Requisitos / Características } & Experimento & Survey & Estudo de Caso & Pesquisa-ação \\
\hline Presença do Pesquisador na Coleta de Dados & Possível & $\begin{array}{c}\text { Não Usual } \\
\text { Difícil }\end{array}$ & Usual & Usual \\
\hline Tamanho pequeno da amostra & Possível & Não Usual & Usual & Usual \\
\hline Variáveis difícies de quantificar & Possível & Possível & Possível & Possível \\
\hline Mensuraç̃̃es perceptivas & Possível & Possível & Possível & Possível \\
\hline Os constructos não são predefinidos & Não Usual & Difícil & Adequado & Possível \\
\hline A casualidade é central na análise & Adequado & Possível & Adequado & Possível \\
\hline $\begin{array}{l}\text { Necessita construir teoria - responder } \\
\text { questões do tipo "como" }\end{array}$ & Possível & Difícil & Adequado & Possível \\
\hline $\begin{array}{l}\text { Necessita de entendimento profundo do } \\
\text { processo de decisão }\end{array}$ & Difícil & Difícil & Adequado & Possível \\
\hline Participação não-ativa do pesquisador & Possível & Possível & Possível & Impossível \\
\hline Falta de controle sobre as variáveis & Difícil & Possível & Possível & Possível \\
\hline
\end{tabular}

O número de casos para realização de um Estudo de Caso pode variar. É importante avaliar que um Estudo de Caso único pode garantir profundidade de entendimento. Os Estudos de Caso único são normalmente longitudinais, e relativos ao período presente ou são realizados durante meses ou anos. Este tipo de Estudo é aplicável principalmente se o objetivo da pesquisa for descrever a mudança ocorrida em um processo de implementação de uma dada prática organizacional, 
cujos resultados não sejam imediatos, ou seja, carecem de tempo e de maturidade para serem avaliados (MIGUEL, 2010).

Voss et al. (2002) colocam que Estudos de Caso único apresentam algumas limitações. Primeiramente, há limites para generalização de modelos, conclusões e teorias. Outra limitação é o risco de julgamento inadequado por ser referente a um caso único. O mesmo risco existe para estudos de múltiplos casos, porém é menor, pois é possível realizar a validação externa com outros casos.

Para que a condução de um estudo de caso seja eficaz, Yin (2005) recomenda alguns cuidados de pesquisa, como descritos a seguir:

a) Validade do constructo: utilizar fontes múltiplas de evidências (tais como: entrevistas, documentos de produção) e preparar um rascunho do relatório que deve ser revisado pelos respondentes. Deve-se estabelecer um encadeamento entre as evidências.

b) Validade interna: desenvolver padrão de convergência e de construção da explanação narrativa; fazer análise de séries temporais.

c) Validade externa: trata-se de saber se as descobertas do estudo são generalizáveis, ainda que o estudo de caso seja único.

d) Confiabilidade: utilizar um protocolo para o estudo de caso; desenvolver um banco de dados para o estudo de caso.

Dado o segundo propósito desta dissertação que é o de buscar um melhor entendimento sobre a forma de condução do processo de definição de indicadores de desempenho global da manufatura visando à sua efetiva aplicação no contexto real de uma empresa para a melhor utilização da capacidade de produção, optou-se por realizar um estudo de caso único e profundo para favorecer a obtenção de um conhecimento detalhado do caso considerado. Contudo, devido à limitação para generalização de resultados, conclusões e teorias, obtidos de um Estudo de Caso único, nesta dissertação, o caso estudado é considerado somente para fins ilustrativos. O método do Estudo de Caso Único longitudinal quando baseado no acompanhamento da trajetória da unidade de análise por um prazo suficientemente longo pode favorecer a observação e análise de diversos aspectos estratégicos, táticos e operacionais que permeiam o processo tomado como objeto de estudo e verificar seus resultados empíricos. 
O caso selecionado refere-se a uma iniciativa empreendida por uma fábrica de processo contínuo que ao se ver compelida a realizar um projeto de melhoria de seu processo de planejamento e controle da produção com o objetivo de aumentar a capacidade de produção e ofertar mais produtos para a equipe de vendas, constatou que teria de rever seu sistema de medição de desempenho que estava baseado na estrutura do OEE. A possibilidade de investigar as limitações deste sistema e a realização das mudanças necessárias para aprimorá-lo motivou sua seleção como unidade de análise e a condução de um estudo com perspectiva longitudinal.

A adequação do caso selecionado aos propósitos desta pesquisa pôde ser verificada pelo conhecimento prévio desenvolvido pela autora sobre o processo para o desdobramento do plano estratégico de manufatura a partir da estratégia corporativa pela alta e média gerência da organização considerada.

Este conhecimento foi desenvolvido pela autora em 2009 quando teve a oportunidade de realizar um estudo de mapeamento deste processo de planejamento e gestão estratégica da manufatura utilizando o método do mapeamento estratégico proposto por Mills et al. (1998). Este trabalho de mapeamento possibilitou elaborar o Mapa Estratégico que descreve como a estratégia de manufatura foi planejada e desdobrada no período de 2000 a 2009 em duas unidades de negócio pertencentes à empresa em que o estudo de caso foi desenvolvido, quais sejam: a divisão de Alimentos e Ingredientes e a divisão de Esmagamento de Soja. Os mapas estratégicos levantados para estas duas divisões são apresentados nos ANEXOS $1 \mathrm{~A}$ e 1B, respectivamente.

Como se pode notar no mapa apresentado no ANEXO 1A, em meados de 2007 a empresa elegeu como objetivo corporativo central a busca do aumento da lucratividade e isso motivou o direcionamento da estratégia de manufatura a ações que possibilitassem melhorar substancialmente o desempenho da fábrica. Isso motivou o planejamento de uma série de ações encadeadas - dentre as quais, preparação de recursos humanos para os esforços de melhoria e ações que visassem ao aumento da disponibilidade do processo - em busca da melhoria do desempenho operacional da fábrica, sendo que para instrumentar tais iniciativas, a liderança decidiu implementar um sistema de medição baseado no OEE. Já na divisão de Esmagamento de Soja, como mostra o ANEXO 1B, no mesmo período pode-se observar que esta demanda não se apresentou crítica. A identificação da 
experiência que a divisão de Alimentos e Ingredientes iria desenvolver na implementação deste sistema baseado no OEE e a concordância da empresa para que autora tivesse acesso à mesma para a realização de um estudo de natureza longitudinal determinaram sua escolha como unidade de análise a ser focada no desenvolvimento do estudo de caso.

Uma vez obtido o acesso a este caso, a pesquisa abrangeu a coleta de dados sobre a condução desta iniciativa no período de 2008 a Fevereiro de 2011 e sua análise. A coleta de dados foi concentrada em duas etapas. Os protocolos de pesquisa utilizados na condução e controle destas etapas são apresentados no ANEXO 2. A primeira etapa foi realizada em Janeiro de 2009 com o propósito de investigar o desenvolvimento inicial da iniciativa no período de Abril a Dezembro de 2008 em que a adequação do sistema de medição e avaliação do desempenho estava sendo questionada. Neste período, os esforços na divisão focada estavam mobilizados para rever este sistema de modo que não ficasse limitado ao controle das perdas medidas pelo OEE e assim ampliar o escopo do processo de melhoria direcionado pelo mesmo.

Embora o objetivo da iniciativa fosse de melhorar o desempenho global da manufatura, neste período, as ações estavam concentradas no aumento da produção de uma linha de produção específica. Foi então realizada uma visita à fábrica considerada com o objetivo de conhecer o sistema de medição do desempenho em desenvolvimento, a dinâmica de análise dos resultados gerados pelo mesmo e a forma como as ações de controle e melhoria vinham sendo desdobradas no âmbito da linha em questão. Como na unidade de análise esta iniciativa envolvia um grupo de gestores da fábrica e das áreas envolvidas, foram entrevistados seus principais componentes, quais sejam; os responsáveis pela Produção, Manutenção, Qualidade e Melhoria Contínua na unidade, e representantes das áreas de Pesquisa e Desenvolvimento (P\&D), Marketing, Comercial e Programação e Controle da Produção (PCP), além do coordenador de Melhoria Contínua Corporativo.

Conforme recomenda Miguel (2010), o desenvolvimento desta etapa de coleta de dados foi guiado por um protocolo. Para direcionar o esforço de coleta de dados, o protocolo de pesquisa foi estruturado com base nos seguintes tópicos: 
- Contexto a se ter em mente: para que o levantamento e análise de dados e as entrevistas fossem conduzidas com o conhecimento do contexto em que o caso considerado estava inserido na empresa e assim assegurar o correto relacionamento da realização da visita e entrevistas com o propósito que motivou o Estudo de Caso.

- Objetivo da visita: alinhado com o contexto a se ter em mente e claramente direcionado aos resultados pretendidos com a realização visita e entrevistas.

- Atividades detalhadas para a condução da pesquisa antes, durante e após a visita: mais especificamente, nas atividades a serem realizadas durante a visita foram enumerados os itens que deveriam ser questionados, para assegurar a coleta de dados importantes para a descrição e análise do caso. Esses itens estão detalhados na atividade 5, do ANEXO 2.

A segunda etapa de coleta de dados foi realizada em Fevereiro de 2011 e teve como propósito investigar a ampliação do sistema de medição do desempenho global para o âmbito da fábrica como um todo. Para isso, foi realizada uma segunda visita à fábrica para entrevistas e observações. Esta etapa também foi conduzida com base em um protocolo estruturado de forma semelhante ao protocolo utilizado na primeira etapa. A prescrição das atividades de coleta de dados nesta segunda etapa foi revista tendo em vista que o contexto a se ter em mente e os objetivos eram outros Os itens chave que distinguem qualitativamente a realidade observada nesta etapa daquela capturada na etapa anterior estão relacionadas no item 18 , do ANEXO 2.

A coleta de dados em duas etapas possibilitou obter uma visão da evolução do sistema de medição do desempenho global em desenvolvimento. Na visita realizada em ambas as etapas, a entrevista do grupo de pessoas envolvidas no sistema de medição investigado foi realizada por meio de uma reunião com duração de aproximadamente duas horas, seguindo o roteiro semi-estruturado apresentado no item "Procedimento de coleta de dados no local" dos protocolos de pesquisa.

A participação dos entrevistados abordados nas 25 atividades enumeradas nos protocolos do ANEXO 2 é apresentada no ANEXO 3. O fato de a autora fazer 
parte do quadro de colaboradores desta empresa e atuar na área de melhoria de processos facilitou acesso a muitos dados primários.

As entrevistas proporcionaram a coleta de dados de natureza tanto qualitativa como quantitativa que possibilitaram estabelecer relações entre os fatos levantados e os resultados constatados e assim construir uma detalhada descrição do caso. Adicionalmente, em cada visita, após a reunião, o coordenador de melhoria contínua corporativo forneceu uma explicação mais detalhada do método de medição dos indicadores de desempenho que foram adotados.

Em estudos de caso é importante que a coleta de dados seja realizada de diversas maneiras pela combinação de diferentes procedimentos e múltiplas fontes para que a triangulação reforce a análise e o julgamento do pesquisador (SAKAKIBARA et al., 1990). Assim, na coleta de dados durante as reuniões, procurou-se sistematicamente discutir cada questão até que dois ou mais participantes demonstrassem concordar com a resposta. Os dados coletados nestas reuniões foram complementados por meio de observações realizadas nas visitas às instalações, levantamento de dados históricos utilizados na medição do indicador de desempenho global, análise documental de atas de reunião do grupo responsável pela avaliação e controle deste indicador, e atas de reuniões de acompanhamento do projeto de melhoria no qual o caso está inserido. 


\section{Revisão da literatura}

\subsection{Conceitos fundamentais}

\subsubsection{A definição de capacidade e sua medição}

$\mathrm{Na}$ economia, a medição de capacidade é utilizada como índice para determinar a possibilidade de expansão da oferta de produtos industriais, considerando somente as indústrias de transformação (LOPES; MOLLO, 2008).

Entre os diversos indicadores que são utilizados em análises econômicas, vale mencionar o Nível de Utilização da Capacidade Instalada (NUCl) que fornece um resultado global do nível de atividade num setor industrial.

Segundo Feijó (2006 apud Lopes e Mollo, 2008), este índice divulgado pelo Conselho Nacional das Indústrias (CNI), é calculado conforme a Equação 1.

$$
\mathrm{NUCl}=\frac{\text { Produção Corrente (Efetiva) }}{\text { Produção Plena Capacidade (Potencial) }}
$$

A Figura 6 mostra uma comparação entre os dados de $\mathrm{NUCl}$ e de variação da produtividade em diferentes setores. 
$\mathrm{NUCl}$ e Produtividade por setor industrial

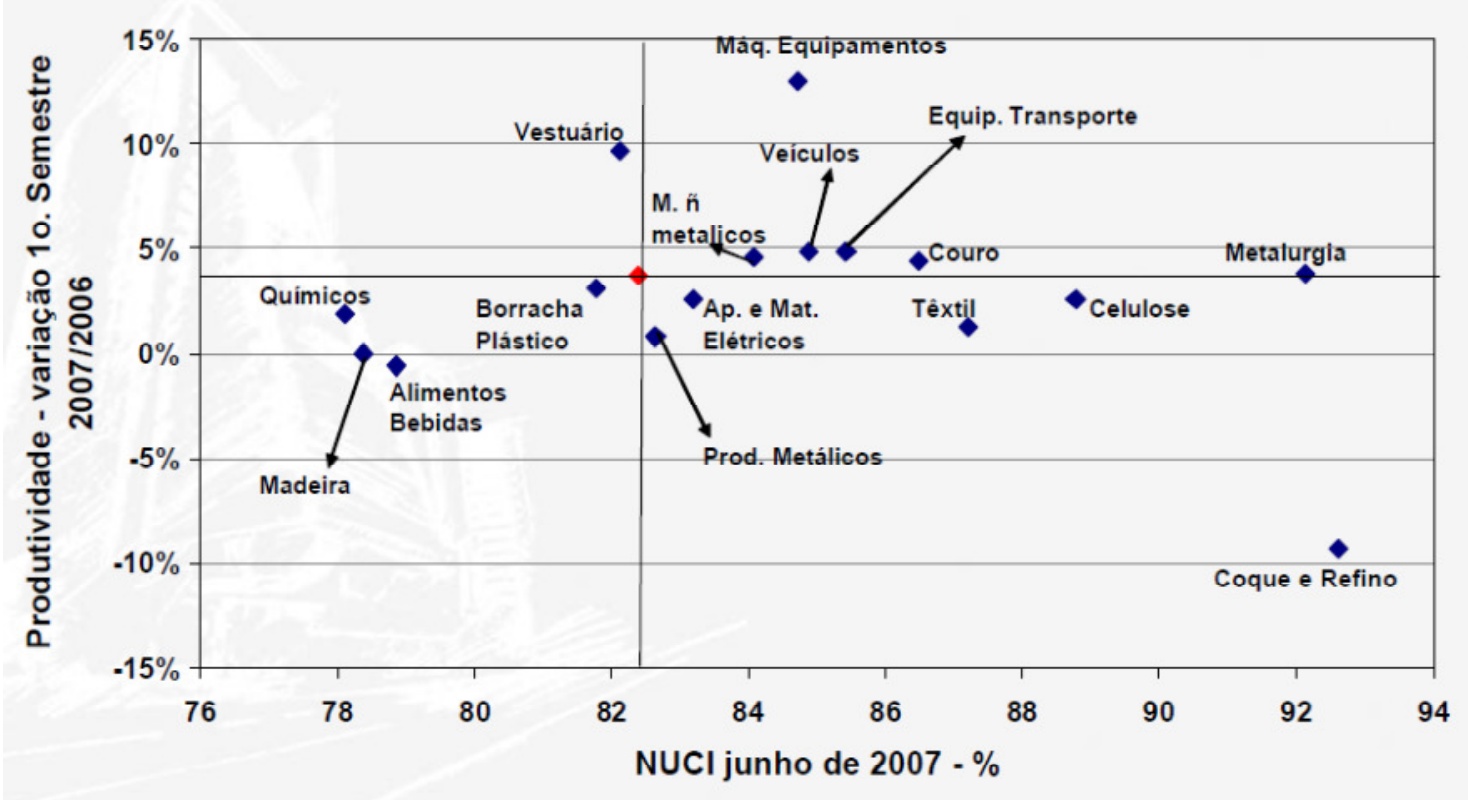

Figura 6 - Variação de produtividade x nível de capacidade utilizada. Fonte: FIESP (2007).

Observa-se que em setores onde o valor do $\mathrm{NUCl}$ é alto, há um maior estímulo para realizar investimentos em busca de aumento na produtividade (FIESP, 2007). Isso sugere que antes de fazer um novo investimento em equipamentos ou ampliações, as empresas tendem a investir em aumento e melhoria da produtividade, ou seja, para buscar uma melhor utilização da capacidade produtiva já instalada.

O Banco Central do Brasil utiliza o $\mathrm{NUCl}$ para definir sua política, ou a trajetória da taxa Selic: um NUCI mais alto pode indicar a ampliação do hiato de produto, qual seja a incapacidade da indústria de suportar, com elevações de oferta, um projetado aumento de demanda.

Como apresentado anteriormente, a capacidade de produção pode ser definida como o máximo nível de atividade com valor adicionado em um determinado período de tempo que o processo pode realizar sobre condições normais de operação (SLACK, 2002).

Conhecer a capacidade produtiva de um sistema de produção tem um objetivo central: garantir o correto planejamento para atender a demanda de vendas. Elmaghraby (1991) afirma que quase sempre os gestores acreditam que a 
capacidade de produção é algo absolutamente fixo, mas isto não é verdade. $O$ autor apresenta diferentes conceitos de capacidades, pois a definição de capacidade pode variar por diversos motivos. A Tabela 3 apresenta as principais definições de capacidade por ele apresentadas.

Tabela 3 - Definições de capacidade conforme Elmaghraby (1991).

\begin{tabular}{|c|l|}
\hline Capacidade & \multicolumn{1}{|c|}{ Definição } \\
\hline Nominal & $\begin{array}{l}\text { É a capacidade do processo ou da máquina considerando todos os recursos de suporte (matéria-prima, } \\
\text { utilidades, pessoas) quando o processo é dedicado à produção de um único item padrão ou atividade. }\end{array}$ \\
\hline Disponível & $\begin{array}{l}\text { É a capacidade do processo subtraindo-se da capacidade nominal a perda esperada ou inevitável por causa } \\
\text { de: idade do equipamento, manutenções ou revisões exigidas, tempo ótimo de setup definidos pelo mix de } \\
\text { produtos, rejeições padrão, etc., mas assumindo que todos os recursos de suporte estão presentes. }\end{array}$ \\
\hline Planejada & É a parte da capacidade disponivel que se espera utilizar no planejamento de num dado horizonte de tempo. \\
\hline Real & $\begin{array}{l}\text { É a capacidade disponivel realmente utilizada para a realização das unidades de produto realmente } \\
\text { produzidas. }\end{array}$ \\
\hline
\end{tabular}

Segundo Elmaghraby (1991), há muita discussão em considerar dentro da definição de capacidade nominal as perdas de utilização da capacidade do processo/máquinas por manutenções ou revisões exigidas, pois muitas empresas utilizam o conceito de capacidade teórica ou máxima para incluir as paradas provocadas por tais perdas. Contudo, o autor defende que ao permitir tantos desdobramentos é possível que se perca a visão de melhoramento no padrão de uso da capacidade, pois muitas empresas utilizam tempos não programados para realizar essas manutenções e assim, não há impacto na capacidade disponível. Se estas perdas por manutenções e revisões não puderem ser realizadas durante tempos não programados, haverá uma distorção na medição de capacidade, pois o indicador sofrerá impacto das paradas que antes não impactavam na capacidade e então não será possível fazer comparações para realizar melhorias no processo.

São definições importantes os conceitos de tempo ótimo de setup e nível de rejeição padrão. São necessárias estas definições para que não se perca a visão do tempo total gasto com setup entre o processo de diferentes produtos e da quantidade padrão de produtos rejeitados de um processo e assim ter informação 
suficiente para poder avaliar a aderência entre a programação da capacidade (capacidade planejada) e a real utilização (capacidade real).

A diferença entre a capacidade real e a capacidade disponível é a capacidade inativa. Possíveis causas desta capacidade podem ser:

- Redução da demanda por produtos.

- Falta de matéria prima.

- Falta de peças de reposição do equipamento.

- Absenteísmo.

- Falta de energia elétrica.

- Falta de água ou algum outro recurso necessário para o funcionamento da infra-estrutura industrial.

Por fim, o autor coloca que a diferença entre capacidade planejada e capacidade real é que a primeira é baseada na demanda futura, ou seja, não necessariamente ela irá planejar toda capacidade disponível, pois depende do mercado. A capacidade real por sua vez é a capacidade disponível utilizada, ou seja, um retrato de como o que foi planejado foi cumprido. As variações entre os valores de capacidade planejada e capacidade real estão relacionadas com a acurácia da previsão de vendas e da capacidade de produção.

Elmaghraby (1991) relaciona alguns motivos para as variações que ocorrem entre capacidade planejada e a capacidade real:

- O problema do mix de produtos: as empresas enfrentam a dificuldade de considerar que o mix de produtos varia mês a mês e, como a capacidade é contemplada inicialmente com base no valor de produção de um produto padrão, as perdas por variação do mix são desprezadas e isso gera um falso valor de capacidade.

- O problema do setup: por consequência da grande variação de mix de produtos, um elevado número de trocas de produtos é exigido da fábrica. $\mathrm{A}$ dificuldade de se ter um número real para cada uma destas trocas prejudica o dimensionamento do real valor da capacidade. $O$ autor ressalta ainda, que 
o desconhecimento deste valor é devido a não medição dos tempos e que um trabalho de acompanhamento dos tempos de setup para cada tipo de troca reduziria os erros nos cálculos de capacidade.

- O problema da rejeição: é comum as empresas realizarem o planejamento da produção com base num valor médio de perdas por rejeição (não conformidade às especificações de qualidade) o que causa, devido à flutuação do mix de produtos, uma variação da capacidade real, pois nem todos os produtos apresentam o mesmo índice de rejeição do processo.

- Considerações sócio-culturais e econômicas: o autor levanta a preocupação quanto à falsificação de números quando estes estão relacionados às metas de bônus dos funcionários. Os responsáveis nas plantas ou linhas de produção geram os valores corretos e podem divulgálos de forma falsa para se beneficiarem do resultado em seu bônus. Neste caso, é necessária uma atuação da alta liderança para promover uma atmosfera de confiança, compreensão e trabalho para o bem comum.

Slack (2002) observa que a decisão para a utilização da capacidade depende da demanda e para conhecê-la é importante considerar flutuações de demanda mensais, semanais e diárias e sazonalidades. Além disso, para se conhecer a capacidade real de produção é necessário considerar o mix de atividades e produtos bem como a capacidade de projeto e a capacidade efetiva.

Para se avaliar o desempenho de manufatura na utilização de sua capacidade, diferentes indicadores têm sido propostos. Slack (2002), por exemplo, apresenta como indicadores de desempenho da manufatura as duas equações dadas a seguir para medição da utilização (Equação 2) e da eficácia da planta (Equação 3).

Utilização $=\frac{\text { Volume de Produção Real }}{\text { Capacidade de Projeto }}$ 
Eficácia $=\frac{\text { Volume de Produção Real }}{\text { Capacidade Efetiva }}$

Nestas equações, a capacidade de projeto e capacidade efetiva definidas por Slack (2002) são equivalentes à capacidade nominal e à capacidade disponível definidas por Elmaghraby (1991).

Para a medição do desempenho da manufatura de forma global e com perspectiva financeira, Gold (1973) propõe verificar a utilização da capacidade e sua eficácia de forma mais ampla considerando não somente a capacidade, mas também os relacionamentos entre os custos de insumos (entradas) e produtos (saída) e o investimento fixo. Este autor destaca seis componentes da produtividade quais sejam,

i. produtividade do trabalho (homens-hora)

ii. produtividade dos materiais

iii. produtividade do investimento fixo

juntamente com as proporções em que estas produtividades estão relacionadas, conforme segue:

iv. produtividade do trabalho $\mathrm{x}$ produtividade dos materiais

v. produtividade do trabalho $\mathrm{x}$ produtividade do investimento fixo

vi. produtividade do investimento fixo $\mathrm{x}$ produtividade dos materiais.

Mais especificamente, a produtividade do investimento fixo pode ser relacionada à capacidade de um sistema de produção, conforme mostra a Equação 4. Nesta equação, o termo "Saídas/Capacidade" diz respeito ao grau de utilização da capacidade.

$\frac{\text { Saídas }}{\text { Investimento Fixo }}=\frac{\text { Capacidade }}{\text { Investimento Fixo }} \times \frac{\text { Saídas }}{\text { Capacidade }}$ 
Além destas medições, tem-se a proposta do OEE, como apresentado anteriormente, de medir o desempenho de um sistema de produção global, sob uma perspectiva mais operacional e não financeira que será discutida nas próximas seções.

\subsubsection{Sistemas de medição de desempenho global}

Martins (1999) demonstra com base num levantamento de artigos publicados entre 1980 a 1998, como o interesse pela medição de desempenho aumentou significativamente após a década de 1990. Neely et al. (1994) mostram que empresas que competem por qualidade e rapidez dão maior importância à utilização de sistemas de medição de desempenho, do que empresas que competem por preço, ainda que estas últimas tenham a tendência de perceber a entrega no tempo como importante medida de desempenho.

Mathur et al. (2011) afirmam que a medição do desempenho é chave para a melhoria da produtividade e é um pré-requisito para diagnosticar, resolver problemas e melhorar o sistema de manufatura.

Kaydos (1999 apud Mathur et al. 2011) define cinco razões principais para as empresas medirem seu desempenho, quais sejam

1. Controle de melhorias: para ter o retorno do processo, que é essencial para qualquer sistema.

2. Responsabilidades claras e objetivas: porque uma boa medição de desempenho define quem é responsável por cada resultado e permite identificar problemas.

3. Alinhamento estratégico dos objetivos: porque a medição do desempenho tem-se mostrado um bom meio de comunicação da estratégia da companhia para a organização.

4. Entendimento do negócio: pois os dados de medição requerem o entendimento do processo. 
5. Determinação da capacidade do processo: porque entender 0 processo também significa conhecer sua real capacidade.

Chakravarthy (1986 apud Martins 1999) coloca que desde 1980, alguns autores têm chamado a atenção para a inadequação dos sistemas de medição de desempenho tradicionais, por não permitirem diferenciar o desempenho estratégico por meio das medidas tradicionais de produtividade, lucratividade e outras medidas financeiras.

Mathur et al. (2011) afirmam que, a difusão dos programas de melhoria do desempenho da manufatura fez com que as medidas com foco financeiro perdessem representatividade e começassem a surgir medidas individuais com o objetivo de informar resultados sob uma única perspectiva. Contudo, os sistemas de medição modernos são multidimensionais, ou seja, consistem em vários indicadores selecionados que informam sobre as necessidades do negócio.

As medidas multidimensionais de produtividade e medidas de produtividade global foram propostas para compensar as desvantagens das medidas de produtividade parcial. Muscat (sd) coloca que um indicador parcial permite um maior grau de detalhe na análise do sistema de produção do que um indicador global, mas possui menor abrangência do que este, pois não considera o sistema de produção como um todo.

Diversos modelos de medição de desempenho global são apresentados na literatura. Gold (1973) apresenta um estudo que relaciona os aspectos financeiros da empresa com seus aspectos físicos e afirma que a empresa não pode simplesmente definir a redução dos seus custos fixos com base no resultado da diferença entre seu lucro e seu investimento. Nas Equações 5 e 6 apresentadas por este autor, é mostrado um modelo simples que relaciona a rentabilidade, com aspectos físicos do sistema de produção e seu desempenho financeiro.

$\frac{\text { Lucro }}{\text { Investimento Total }}=\frac{\text { Saídas }}{\text { Investimento Total }} \times \frac{\text { Lucro }}{\text { Saídas }}$ 
$\frac{\text { Lucro }}{\text { Investimento Total }}=\left(\frac{\text { Valor do Produto }}{\text { Saídas }}-\frac{\text { Custo Total }}{\text { Saídas }}\right) \times \frac{\text { Saídas }}{\text { Capacidade }} \times \frac{\text { Capacidade }}{\text { Investimento Fixo }} \times \frac{\text { Investimento Fixo }}{\text { Investimento Total }}$

Sumanth (1979) desenvolveu um modelo de produtividade total, que considerou o impacto de todos os fatores de entrada e saída de uma forma mais tangível. Mathur et al. (2011) colocam algumas das outras propostas de medidas multidimensionais de produtividade para avaliação de produtividade global são como a produtividade total dos fatores (TAYLOR; DAVIS, 1977), a produtividade total (SCHROEDER, 1985), a produtividade total da empresa (SLACK et al., 2001) e a produtividade total dos produtos (ANDERSSON, 1996).

Tangen (2002 apud Mathur et al. 2011) sugerem que em um indicador de desempenho global:

- As medidas devem ser derivadas dos objetivos estratégicos para garantir que o comportamento adotado seja consistente com as metas corporativas.

- As medidas devem fornecer feedback relevante e preciso em tempo útil, tanto em uma perspectiva de longo prazo quanto em uma perspectiva de curto prazo.

- A medição deve ser realizada de maneira que seja facilmente compreendida por aqueles cujo desempenho está sendo avaliado.

- A medição deve ser realizada por um número limitado de medidas de desempenho que incluam tanto medidas financeiras como não financeiras.

Slack (2002) coloca que as medidas de desempenho global da manufatura são necessárias para que os gestores possam determinar o nível de desempenho atual e atuar para atingir o melhor resultado no futuro.

Neste trabalho o conceito de indicador de desempenho global da manufatura será aplicado para referir-se a um indicador capaz de medir o impacto da atuação de diversas áreas no resultado esperado. Um indicador parcial da manufatura é definido como um indicador que mede somente o impacto de parte das áreas envolvidas no 
processo sejam estas áreas de apoio, como Qualidade, Manutenção, Planejamento e Controle da Produção (PCP), Pesquisa e Desenvolvimento (P\&D) e Marketing ou áreas de operação como Produção, Vendas e Distribuição.

Para que os gestores possam gerenciar com base em indicadores de desempenho, Liker e Meier (2007) colocam que ao realizar a avaliação do desempenho de uma área, processo ou sistema é necessário estruturar análise para solução de problemas utilizando uma metodologia formal e a abordagem correta, dependendo do tamanho da oportunidade.

Nakajima (1989) propõe que ações de melhoria sejam desdobradas a partir da análise do indicador de OEE por meio de ferramentas de gestão da qualidade como o gráfico de Pareto e o diagrama de causa-e-efeito: o primeiro permite identificar os tipos de perdas que têm maior impacto no resultado do OEE e o segundo ajuda a organizar a investigação do real motivo da ocorrência dos mesmos facilitando sua identificação e eliminação.

Neste esforço de análise e melhoria, Bamber et al. (2003) ressaltam a importância do envolvimento de grupos multifuncionais que detenham uma adequada combinação de conhecimentos e habilidades sobre todo o processo considerado, observando que a adoção do OEE promove o alinhamento de visões na investigação e isso possibilita à gerência delegar-Ihes maior responsabilidade e autoridade para implementar as ações de melhoria.

Guzzo e Dickson (1996) colocam que diferentes tipos de grupos podem ser encontrados nas organizações. Um destes tipos de grupos é o dos grupos de solução de problemas.

$\mathrm{Na}$ literatura, diversas configurações de grupos de solução de problemas são propostas dependendo do âmbito de atuação e do propósito. Quatro dentre os principais tipos propostos são descritos nas seguintes subseções:

\section{a) Círculo da qualidade}


Os círculos da qualidade (CQ) são grupos desenvolvidos para gerar idéias que, se implementadas, podem melhorar a qualidade do produto (bens ou serviços) ou do processo, visando à redução de defeitos, erros e reclamações, entre outros.

Os CQs são compostos por 6 a 12 colaboradores que trabalham diretamente com o produto ou com a atividade tomada como foco, ou que têm conhecimento do problema ou das oportunidades para melhoria da qualidade. Os integrantes de um $\mathrm{CQ}$ lidam com questões relacionadas à sua função dentro da sua área de atuação na organização.

Lawler et al. (1992 apud Guzzo e Dickson, 1996) colocam que os CQs têm resultado de baixo impacto e muitas vezes não duradouro para a organização. Estes grupos contribuem muito para gerar ganhos significativos, mas podem não ser eficazes na sustentação.

É comum os CQs abordarem problemas não somente de qualidade, mas também de produtividade, segurança e ergonomia.

\section{b) Grupo de melhoria contínua}

São grupos de operadores de uma mesma área que são organizados com o objetivo de participar de um projeto sugerido pela gerência ou determinado pelo grupo coletando e analisando dados, pesquisando e desenvolvendo em grupo uma possível solução a ser aprovada pela gerência.

Caso a proposta de solução elaborada seja aprovada, este grupo ou parte dele fica responsável pelas implementações em linha e, ao final, o grupo é desfeito ao atingir seu objetivo declarado.

\section{c) Grupo de trabalho autônomo}

Esses grupos são também conhecidos como grupos auto-gerenciáveis. São grupos de colaboradores que possuem alto desempenho em suas atividades ou nas atividades relacionadas e capazes de assumir a responsabilidade sobre diversos aspectos do seu trabalho, como: planejamento, organização, distribuição de 
atividades entre os colaboradores e tomada de decisão observando o impacto econômico.

Bailey (1997) coloca que esses grupos são organizados para melhorar o desempenho da atividade a qual pertencem. Sua composição é de colaboradores do mesmo turno/período que trabalham na mesma linha, durante a jornada de trabalho, de forma contínua. Os grupos de trabalho autônomo atuam não apenas para melhorar o resultado dos processos, mas também, para conseguir mantê-los.

\section{d) Força tarefa}

Os grupos de força tarefa (FT) são grupos organizados para alcançar um objetivo específico durante um tempo determinado. May e Schwoerer apud Guzzo e Dickson (1996) colocam que estes grupos são formados com o objetivo de resolver um problema crônico e/ou reincidente da companhia.

Os grupos do tipo FT são formados por 7 a 9 pessoas representando diversas funções da organização. Essas funções frequentemente tratam de problemas mais estratégicos e por este motivo os participantes de uma FT devem ter mais autoridade para a tomada de decisão e por este motivo são compostos por membros da gerência e/ou nível tático (SHIBA et al., 1997). Guzzo e Dickson (1996) colocam que assim que seu objetivo é cumprido um grupo de FT é desfeito.

A Figura 7 ilustra como grupos com caráter mais permanente formados no nível operacional como os CQs e grupos de caráter temporário como os grupos de FT se posicionam na organização (composição dos membros e propósito interfuncionais ou internos a uma área funcional) e na hierarquia (nível operacional, média gerência, alta direção). Esta posição hierárquica define o tipo de problema a ser solucionado, e sugere qual nível de autoridade os membros devem possuir para aprovar e implementar as ações necessárias à solução do problema focado. 


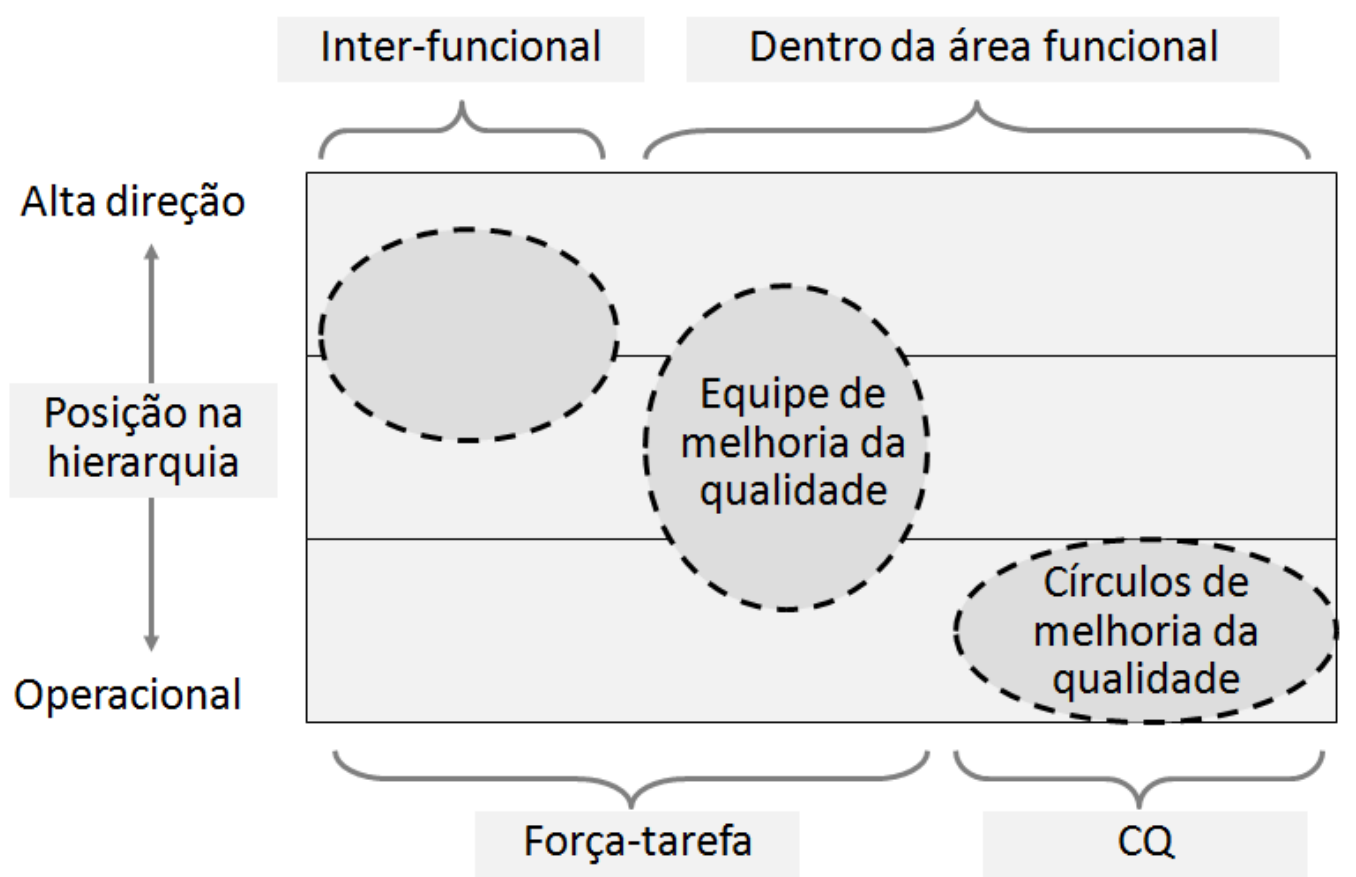

Figura 7 - Posições dos grupos de solução de problema na hierarquia da empresa. Adaptada de Shiba et al. (1997).

A Tabela 4 resume os tipos de grupos de melhoria e as possibilidades de sua aplicação na solução de problemas. 
Tabela 4 - Características dos grupos de solução de problema. Adaptada de Bailey (1997).

\begin{tabular}{|c|c|c|c|c|}
\hline Característica & $\begin{array}{l}\text { Círculo da } \\
\text { Qualidade }\end{array}$ & $\begin{array}{l}\text { Grupo de } \\
\text { Melhoria } \\
\text { Contínua }\end{array}$ & $\begin{array}{l}\text { Grupo de } \\
\text { Trabalho } \\
\text { Autônomo }\end{array}$ & Força Tarefa \\
\hline Tipo & Off-line & Off-line & On-line & Off-line \\
\hline Duração & Permanente & Curto Prazo & Permanente & Curto Prazo \\
\hline Participação & Voluntária & Voluntária & Mandatória & Mandatória \\
\hline Composição & $\begin{array}{c}\text { Funções da } \\
\text { área }\end{array}$ & $\begin{array}{l}\text { Multi-funcional } \\
\text { da área }\end{array}$ & $\begin{array}{c}\text { Funcional da } \\
\text { área /turno }\end{array}$ & $\begin{array}{c}\text { Multi-funcional } \\
\text { entre áreas }\end{array}$ \\
\hline $\begin{array}{l}\text { Cargo dos } \\
\text { membros }\end{array}$ & Operadores & $\begin{array}{c}\text { Na maioria } \\
\text { operadores, } \\
\text { porém podem } \\
\text { participar } \\
\text { técnicos e } \\
\text { engenheiros. }\end{array}$ & $\begin{array}{c}\text { Operadores, } \\
\text { algumas vezes } \\
\text { técnicos. }\end{array}$ & $\begin{array}{l}\text { Colaboradores } \\
\text { nos níveis tático } \\
\text { e estratégico. }\end{array}$ \\
\hline $\begin{array}{l}\text { Escopo do } \\
\text { tipo de } \\
\text { problema }\end{array}$ & $\begin{array}{c}\text { Problema da } \\
\text { área }\end{array}$ & $\begin{array}{c}\text { Problema da } \\
\text { fábrica }\end{array}$ & $\begin{array}{l}\text { Problema da } \\
\text { área ou do } \\
\text { turno }\end{array}$ & $\begin{array}{c}\text { Problema crítico } \\
\text { que afeta a } \\
\text { estratégia da } \\
\text { empresa }\end{array}$ \\
\hline
\end{tabular}

Shiba et al. (1997) afirmam que a maior dificuldade para a efetividade das equipes é o conflito inter-pessoal. Estes autores sugerem que para reduzir este tipo de problema e conseguir os resultados esperados é necessário dar às equipes uma missão clara, exigindo planejamento baseado em fatos comprovados, e fornecer padrões para analisar os fatos e alcançar o consenso.

É importante neste sentido que a alta direção promova o trabalho dos grupos de solução de problema proporcionando tempo para que os membros se dediquem aos encontros, encorajando a equipe para serem auto-suficientes, desencorajando debates divisivos que gerem conflito dentro da equipe, fornecendo ferramentas para análise e solução dos problemas e acompanhando os resultados conquistados pelo 
grupo para reconhecer e redirecionar decisões, quando necessário (SHIBA et al.,1997).

\subsection{O OEE como indicador de desempenho}

A implementação do modelo TPM na gestão de sistemas de manufatura é baseada em três conceitos centrais: maximização da eficácia dos equipamentos, manutenção autônoma realizada por operadores e organização de pequenos grupos de melhoria (LJUNGBERG, 1998). Neste contexto, o OEE tem sido amplamente utilizado como um indicador para medição do desempenho global do(s) equipamento(s) na manufatura que, ao estruturar a análise das perdas de utilização de sua capacidade, ajuda a direcionar os esforços de melhoria contínua dos pequenos grupos (JONSSON; LESHAMMAR, 1999) e a avaliar o progresso na implementação do TPM na organização (JEONG; PHILLIPS, 2001). Como métrica de uso gerencial, o OEE tem sido adotado principalmente por indústrias que precisam assegurar elevada disponibilidade de seus equipamentos.

O cálculo do OEE é realizado pela medição de três classes principais de perdas as quais são desdobradas em seis tipos básicos de perdas, conforme enumeradas a seguir e ilustradas na Figura 8:

A.Perdas de Disponibilidade

A1.Paradas provocadas por falha de equipamento.

A2.Paradas para setup ou ajustes.

B.Perdas de Desempenho

B1.Pequenas paradas ou interrupções devido ao mau funcionamento do equipamento.

B2.Redução da velocidade do equipamento devido a alguma anomalia que o faça operar com tempo de ciclo maior que o tempo padronizado. 
C. Perdas de Qualidade

C1.Produção defeituosa ou retrabalho.

C2.Perdas de startup ou perdas ocasionadas no início da produção devido aos ajustes para estabilização do equipamento.

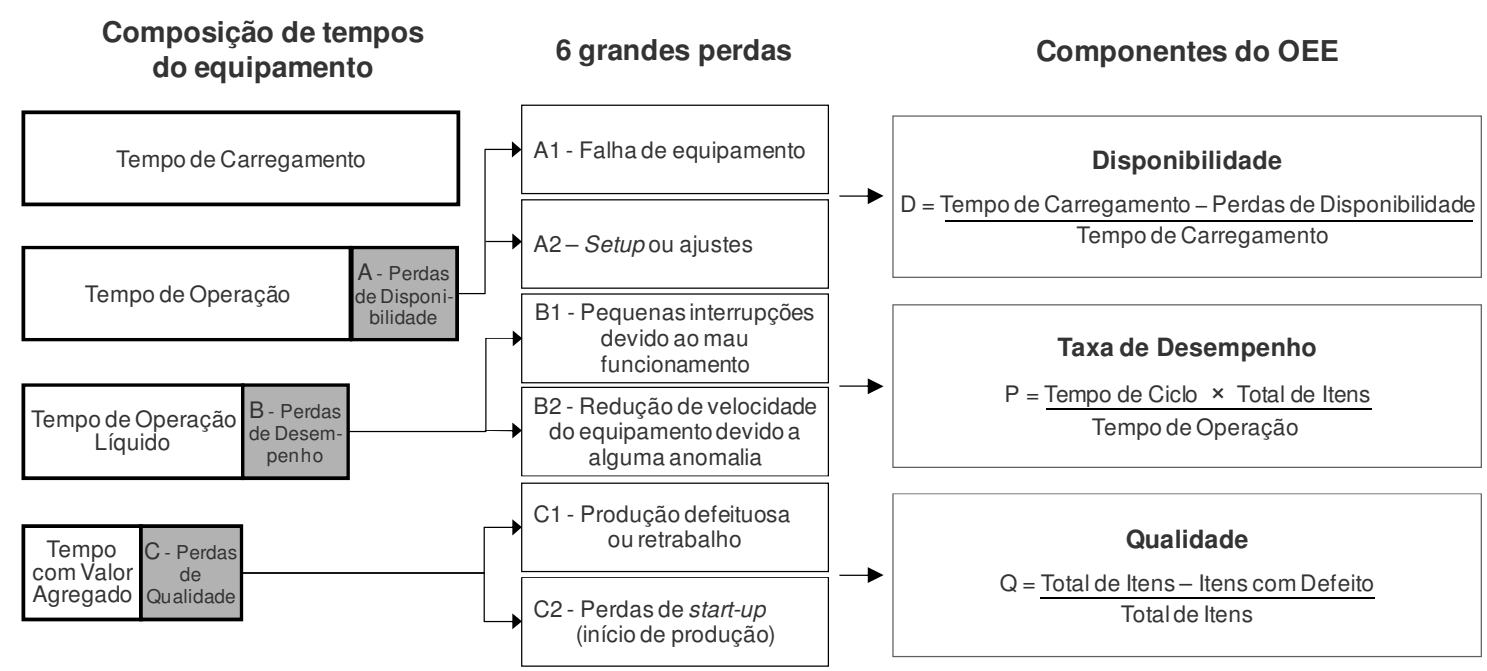

Figura 8 - Estrutura das seis grandes perdas de tempo observadas no indicador de OEE. Adaptada de Braglia et al. (2009)

O OEE pode ser entendido como uma relação entre o tempo em que houve agregação de valor ao produto e o tempo de carregamento do equipamento, ou seja, descontando-se as perdas de disponibilidade (A), perdas de desempenho (B) e perdas de qualidade $(\mathrm{C})$. Para o seu cálculo, é adotada a Equação 7 que considera as definições para Disponibilidade (D), Desempenho (P) e Qualidade (Q) dadas na Figura 8.

$\mathrm{OEE}=\mathrm{D} \times \mathrm{P} \times \mathrm{Q}$

Alternativamente, o OEE pode ser calculado pela razão entre a quantidade de produto bom obtido no tempo com valor agregado ${ }^{4}$, e a quantidade de produto

\footnotetext{
${ }^{4}$ O termo "tempo com valor agregado" para os autores de Produção Enxuta, como Liker (2005) está relacionado à idéia de agregação de valor sob a perspectiva do cliente, que abrange outras perdas além das perdas consideradas no de OEE.
} 
que poderia ter sido obtida durante o tempo de carregamento, conforme a Equação 8 (KWON; LEE, 2004).

OEE $=\frac{\text { Total de Produtos Bons }}{\text { Tempo de Carregamento } \mathrm{x} \text { Capacidade de Produção Teórica por Hora }}$

Vale salientar que a eliminação ou redução dos tipos de perdas identificados por este indicador requer que além da Manutenção e Produção, outras áreas como Qualidade e Engenharia colaborem no desenvolvimento de esforços de melhoria de modo mais sistêmico.

A utilização do OEE tem sido relevante na avaliação do retorno de investimentos realizados no âmbito de programas de melhoria como os baseados no modelo TPM. Para Chand e Shirvani (2000), a efetividade de um sistema de manutenção bem como das práticas de gestão de equipamentos pode ser avaliada medindo-se a eficácia global dos equipamentos por meio do OEE. Segundo Kwon e Lee (2004), é possível contabilizar como o aumento do OEE resultante dos esforços de melhoria contínua para aumentar a disponibilidade de equipamentos reverte-se em redução do custo de manufatura e aumento incremental na margem de lucro.

\subsection{Limitações do OEE como indicador de desempenho global da} manufatura

$\mathrm{Na}$ literatura, são encontrados diversos questionamentos sobre a aplicação do OEE como indicador de desempenho global da manufatura. Jonsson e Lesshammar (1999) advertem que a maioria das empresas utiliza de forma incorreta os indicadores de desempenho ou falham na escolha de tais indicadores. Na Tabela 5 é apresentada uma síntese da análise elaborada por estes autores considerando seus atributos fundamentais enquanto um sistema de medição do desempenho global (ver seção 2.1), segundo a qual o OEE, como indicador, não atende a todas as dimensões e características examinadas. No que diz respeito à perspectiva da orientação ao fluxo, o OEE não considera de forma integrada as atividades, 
processos e funções encontrados ao longo da cadeia de produção. Em relação à eficiência interna, revela uma visão limitada por contemplar somente as paradas causadas por problemas de manutenção e produção. Além disso, vale salientar que uma grande fragilidade do OEE é a sua falta de visão da eficácia externa o que o impede de refletir o que ocorre na cadeia de valor identificando perdas que afetam o fluxo de processo, entre o recebimento do pedido e sua entrega ao cliente. Isso dificulta a percepção de trade-offs entre o objetivo da manufatura e o de outras áreas que interagem com a mesma na busca dos resultados do negócio como um todo.

Tabela 5 - OEE $\times$ dimensões e características de um sistema de medição do desempenho global (Adaptada de Jonsson e Lesshammar, 1999)

\begin{tabular}{|c|c|c|c|}
\hline & & Definicaio & Avaliaça do OEE \\
\hline \multirow{4}{*}{$\begin{array}{l}\frac{8}{8} \\
\frac{d}{8} \\
\frac{8}{2} \\
\frac{1}{0}\end{array}$} & Estratégia & $\begin{array}{l}\text { Traduz as estratégias corporativas e de negdeio para todos os niveis da } \\
\text { organizaçdo }\end{array}$ & 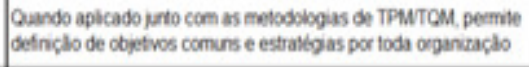 \\
\hline & Orientaçð̃o do Fluxo & $\begin{array}{l}\text { Contempla funçôes, attividades e precesses de forma integrada ao longo } \\
\text { da cadeia de produçáo. }\end{array}$ & Naso consemsida peto CEE \\
\hline & Eficiencia Interna & $\begin{array}{l}\text { Permite medir e comparar a eficiéncia funcional internamento de uma } \\
\text { organizaçalo. }\end{array}$ & $\begin{array}{l}\text { OEE e uma medda simsies, mas abrangerte. Porem nem serrope } \\
\text { permte ser comparado erte dierentes áreas ou funcles. }\end{array}$ \\
\hline & Eficacia Externa & $\begin{array}{l}\text { Contempla mediçbes externas, inclusive o nivel de satisfaçdo dos } \\
\text { clientes. }\end{array}$ & Näo contenclada peso OEE \\
\hline \multirow{2}{*}{ 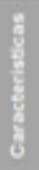 } & $\begin{array}{l}\text { Direcionador de } \\
\text { Melhoria }\end{array}$ & $\begin{array}{l}\text { Serve nlo somente para informar mas também para acionar esforçes de } \\
\text { melhoria continua. }\end{array}$ & $\begin{array}{l}\text { Cferece grande cortribuçalo quando uilzado como indicador de } \\
\text { Sesemperho em processos de methoris corthua. }\end{array}$ \\
\hline & Simples e Dinâmico & $\begin{array}{l}\text { Simples e facil de entender, calcular e usar. Pode evoluir com o tempo } \\
\text { mediante revisdes para se manter atualizado como indicador. }\end{array}$ & 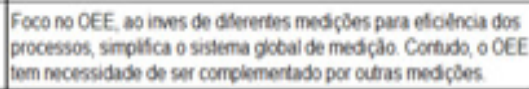 \\
\hline
\end{tabular}

A conceituação básica do OEE fornece uma boa forma de medir a eficácia de uma única máquina (BRAGLIA et al., 2009). Contudo, a simples extensão da sua aplicação convencional à avaliação de um sistema de produção com mais máquinas, não seria suficiente para direcionar sua melhoria global considerando sistemicamente os possíveis impactos num âmbito mais amplo.

Assim como Jonsson e Lesshammar (1998) e Braglia et al. (2009), outros autores têm identificado limitações para se aplicar o OEE em contextos mais amplos, sob condições não previstas e para fins mais complexos que os originalmente admitidos na sua concepção.

A Tabela 6 resume alguns dos principais benefícios que o OEE oferece, mas aponta que existem limitações que dificultam ampliar a utilização do OEE como indicador de desempenho global da manufatura. 
Tabela 6 - Benefícios e limitações do OEE. Fonte: artigos diversos selecionados pelo autor.

\begin{tabular}{|c|c|}
\hline Benefficios & $\begin{array}{l}\text { - Possibilita a análise de problemas de produção ou manutenção e } \\
\text { consequente atuação na causa raiz (JEONG; PHILLIPS, 2001) } \\
\text { - Possibilita a identificação de máquinas que devem ser foco de } \\
\text { atividades de gestão da manutenção (BAMBER et al., 2003) } \\
\text { - Permite comparação interna entre as máquinas de uma mesma } \\
\text { planta (BAMBER et al., 2003) } \\
\text { - Registros de paradas para identificação das perdas permitem a } \\
\text { complementação dos planos de manutenção já existentes (CHAND; } \\
\text { SHIRVANI, 2000) }\end{array}$ \\
\hline Limitações & $\begin{array}{l}\text { - Quando aplicado a um escopo maior que uma única máquina (linha } \\
\text { de produção ou planta), não direciona adequadamente as ações para } \\
\text { melhoria contínua (BRAGLIA et al., 2009) } \\
\text { - Não fornece visão sistêmica das perdas do negócio, pois não } \\
\text { considera interações além do equipamento (JONSSON; } \\
\text { LESSHAMMAR, 1999) } \\
\text { - A utilização somente do OEE pode definir responsabilidades para a } \\
\text { área de produção que não necessariamente são da mesma } \\
\text { (LJUNGBERG, 1998) } \\
\text { - Dificuldade de reconhecer outras perdas com base na taxonomia } \\
\text { das seis grandes perdas do OEE (JEONG; PHILLIPS, 2001) }\end{array}$ \\
\hline
\end{tabular}

Assim, faz-se necessário buscar indicadores que não somente meçam o desempenho de um equipamento ou uma área, mas que também possibilitem avaliar os impactos de sistemas de manufatura maiores em sua cadeia de valor, que possam ser usados em comparações intra- e inter-organizações, que contemplem as necessidades do cliente, e que sejam simples de serem compreendidos, atualizados e utilizados em processos de melhoria contínua. 


\subsection{Indicadores de desempenho derivados do OEE}

O OEE é amplamente aceito como uma medição primária para a fábrica que auxilia a avaliação dos equipamentos e que estabelece uma disciplina para melhoria. Porém, ao se restringir à medição do desempenho de equipamentos específicos e não abranger a interação com recursos relacionados, sua utilização acaba sendo confinada a um contexto local (MUTHIAH; HUANG, 2007).

Diferentes conceituações de indicadores que procuram suprir carências do OEE foram identificadas na literatura. Nas seções seguintes, elas são apresentadas divididas em dois grupos: 1) derivações do indicador OEE que ampliam a abrangência do sistema de operações considerado e 2) indicadores que ampliam a classificação das perdas em relação à que o OEE por definição considera.

Por estas razões, a forma de aplicação do OEE está sujeita a adaptações para se adequar ao contexto e às condições daquilo que deve ser medido. Muchiri e Pintelon (2008) colocam que na literatura são encontradas derivações do termo OEE conforme a natureza de sua aplicação. Quando considerado em relação à eficácia de fábrica, é denominado como Overall Factory Effectiveness (OFE), em relação à eficácia de planta, como Overall Plant Effectiveness (OPE) ou Overall Asset Effectiveness (OAE). Já, quando considera uma ampliação da classificação das perdas além das pertinentes ao processo focado, resulta no Total Overall Equipment Effectiveness (TOEE) e quando considera a utilização da capacidade pela medição das saídas de produto, é denominado Overall Throughput Effectiveness (OTE). Há ainda derivações como o Total Equipment Effectiveness Performance (TEEP) que propõe uma pequena ampliação à classificação das perdas admitidas pelo OEE e o Production Equipment Effectiveness (PEE) que considera que os diferentes tipos de perdas devem ser ponderados de forma diferente na avaliação global. 


\subsubsection{Indicadores que ampliam a abrangência do sistema de operações} considerado

Neste tipo de derivações do OEE, o objeto avaliado vai além de um equipamento isolado, o que implica em contemplar diferentes máquinas/processos e o modo como estes estão relacionados (e.g. se os equipamentos estão em série ou em paralelo).

\subsubsection{Overall Equipment Effectiveness of a Manufacturing Line (OEEML)}

Braglia et al. (2009) apresentam o conceito de Overall Equipment Effectiveness of a Manufacturing Line (OEEML). Trata-se de uma derivação do OEE, que além das perdas de disponibilidade e qualidade, considera as perdas decorrentes de problemas de alimentação de matéria prima na linha, as ineficiências do gargalo e as paradas planejadas de manutenção. O OEEML considera que em uma linha de produção, há estoques entre suas etapas de processo e admite que a produção resultante depende do nível destes estoques. Em uma linha com baixo OEEML, quanto mais à jusante se encontrar a etapa de processo com o menor OEE, maior tende a ser o estoque acumulado antes da mesma. Quando o OEEML é alto, os materiais fluem melhor e o estoque na linha tende a ser baixo. Tais relações e efeitos não podem ser constatados somente pela consideração do OEE. Já em sistemas de manufatura em linha com dois ou mais equipamentos sem estoque intermediário significativo, Braglia et al. (2009) sugerem que a conceituação do OEE pode ser aproveitada, tomando-se como referência as limitações impostas pelas perdas na etapa gargalo do processo.

O cálculo do OEEML é realizado conforme a Equação 9.

$$
\text { OEE ML }=\frac{\text { Saída Real }}{\text { Saída de Referência }}
$$


O numerador e o denominador desta razão são dados respectivamente pelas Equações 10 e 11 conforme segue:

$$
\text { Saída Real }=\text { Olm }=\text { CTIm } \times \text { MVTIm }
$$

Saída de Referência $=$ LLT $\times$ CTbn

nas quais têm-se que:

CTIm = Tempo de ciclo do produto na saída da linha ${ }^{5}$

MVTIm = Tempo de agregação de valor na linha ${ }^{6}$

LLT $=$ Tempo disponível para carregamento $^{7}$

CTbn $=$ Tempo de ciclo ideal do equipamento gargalo ${ }^{8}$

\subsubsection{Overall Line Effectiveness (OLE)}

Nachiappan e Anantharaman (2006) apresentam o indicador Overall Line Effectiveness (OLE) que foi introduzido por Chairman, num documento intitulado “TPM activity pre audit report, internal circulation copy” publicado em 2004.

Nachiappan e Anantharaman (2006) propõem o cálculo do OLE como uma extensão do OEE para o cálculo da eficácia total da linha, considerando além das 6 grandes perdas, as perdas relacionadas às paradas por manutenção planejada.

Chand e Shirvani (2000) propõem estender a aplicação do conceito de OEE para a avaliação de uma célula de produção/linha considerando dados de saída de produtos conformes, tempo médio de ciclo e tempo de carregamento da célula/linha

\footnotetext{
${ }^{5}$ Cycle time of the last machine of the line, em inglês.

${ }^{6}$ Machine valuable time of the last machine, em inglês.

${ }^{7}$ Line loading time, em inglês.

${ }^{8}$ Ideal cycle time of the bottleneck machine, em inglês.
} 
seguindo a lógica da Equação 8. Para facilitar sua distinção, neste trabalho este indicador é denominado de OEEL (OEE de uma célula ou linha).

Nachiappan e Anantharaman (2006) apresentam uma proposta de cálculo para o OLE, conforme Equação 12.

OLE = LA $\times$ LPQP

$\mathrm{Na}$ qual,

$\mathrm{LA}=$ eficiência de linha em termos de disponibilidade calculada conforme a Equação $13 .{ }^{9}$

$$
\mathrm{LA}=\frac{\mathrm{OTn}}{\mathrm{LT}} \times 100
$$

Nesta equação, tem-se que:

OTn = tempo de operação do n-ésimo equipamento (o do processo final) da linha. ${ }^{10}$ $\mathrm{LT}$ = tempo disponível para carregamento ou tempo planejado para a produção operar num dado período. ${ }^{11}$

e,

LPQP = eficiência do desempenho e da qualidade da linha calculada conforme a Equação $14 .^{12}$

$$
L P Q P=\frac{G n \times C Y T}{\mathrm{OT}_{1}} \times 100
$$

na qual,

\footnotetext{
${ }^{9}$ Line avaiability, em inglês.

${ }^{10}$ Operation time of the nth machine, em inglês.

${ }^{11}$ Loading time, em inglês.

${ }^{12}$ Line production quality performance, em inglês.
} 
$\mathrm{Gn}=$ Taxa de produtos bons entregue pelo n-ésimo processo da linha. ${ }^{13}$

CYT = tempo de ciclo no processo que é o gargalo da linha. ${ }^{14}$

$\mathrm{OT}_{1}=$ tempo de operação do primeiro processo da linha. ${ }^{15}$

\subsubsection{Overall Factory Effectiveness (OFE) e Overall Plant Effectiveness (OPE)}

Para levar a idéia da medição pelo OEE ao nível de toda uma fábrica, existe a proposta do Overall Factory Effectiveness (OFE) - ou Plant OPE como chamado por Högfeldt (2005) - de avaliar o desempenho global da mesma admitindo que isso resulte da interação de diferentes máquinas/processos e de decisões/ações tomadas por seus diversos sistemas e subsistemas (OECHSNER et al., 2003).

Segundo Muchiri e Pintelon (2008) ainda não existe uma abordagem comum para a definição de OFE. Uma proposta inicial para isso foi elaborada em 1998 por Scott e Pisa apud Muchiri e Pintelon (2008), na qual sugerem que o OFE seja tratado como uma métrica que resulta de um composto de indicadores (e.g. tempo de ciclo teórico/tempo de ciclo real, índice de entregas no prazo, utilização de capacidade, taxa de retrabalho, rendimento, etc.).

Assim, cada fábrica poderia ponderar estes indicadores com pesos próprios, de acordo com suas metas, e obter um resultado global. Oeschner et al. (2003) colocam que há propostas para se padronizar a definição e cálculo do OFE. Mais especificamente na indústria de semicondutores há uma iniciativa para promover a forma de cálculo apresentada na Equação 15, em que o componente relacionado à produtividade é medido em função da taxa de produção e pelo índice "tempo de ciclo

\footnotetext{
${ }^{13}$ Good items produced in the line $n$, em inglês.

${ }^{14}$ Cycle time, em inglês.

${ }^{15}$ Operation time of the first machine, em inglês.
} 
teórico/tempo de ciclo real" e o componente relacionado ao rendimento é dado pelo produto do rendimento da linha pelo rendimento na etapa teste de qualidade ${ }^{16}$.

OFE = (Eficiência em termos de produtividade) $\times$ (Eficiência em termos de rendimento)

\subsubsection{Overall Throughput Effectiveness (OTE)}

Uma derivação do OFE seria o Overall Throughput Effectiveness (OTE) introduzido por Razzak et al. (2002 apud Oeshsner 2003). O indicador do OTE deve ser derivado da forma de conexão existente entre os equipamentos da unidade a ser avaliada.

Muthiah e Huang (2007) sugerem que os subsistemas que constituem uma fábrica podem assumir quatro tipos básicos de configuração - equipamentos em série, em paralelo, montagem alimentada por múltiplos equipamentos e equipamento que fornece para vários outros - sendo que no cálculo do OTE para cada tipo de subsistema é preciso observar como sua produção total é limitada pela capacidade dos recursos restritivos e por ineficiências encontradas no percurso do fluxo produtivo. Isso vai além da abordagem simplificada de calcular um indicador global para um conjunto de equipamentos como uma média dos resultados individuais de cada equipamento como se a ineficiência de cada um fosse independente das condições de operação dos demais. Muthiah e Huang (2007) e Muthiah et al. (2008) acrescentam que assim como a produção de equipamentos encadeados em série é limitada pelo equipamento-gargalo, para se obter o numerador global do OFE de uma fábrica é necessário identificar o subsistemagargalo e verificar como seu OTE restringe as saídas finais.

O cálculo do OTE é considerado conforme a Equação 16.

OTE $=\frac{\text { Quantidade de produtos bons produzidos pelo sistema no tempo total }}{\text { Quantidade teórica de produtos esperada do sistema no tempo total }}$

\footnotetext{
${ }^{16}$ Na Equação 15, os termos "Eficiência em termos de produtividade" e "Eficiência em termos de rendimento" são as traduções da autora para os termos Productivity efficiency e Yield efficiency adotados por Oeschner et al. (2003).
} 
Para facilitar a extensão do cálculo do OEE ao nível de uma fábrica, vale resgatar a idéia de confrontar o total de produtos bons entregues pela mesma com o total de produtos que teoricamente ela poderia ter produzido (OECHSNER et al., 2003; MUCHIRI; PINTELON, 2008), de modo análogo ao seu cálculo para um determinado equipamento com base na Equação 8.

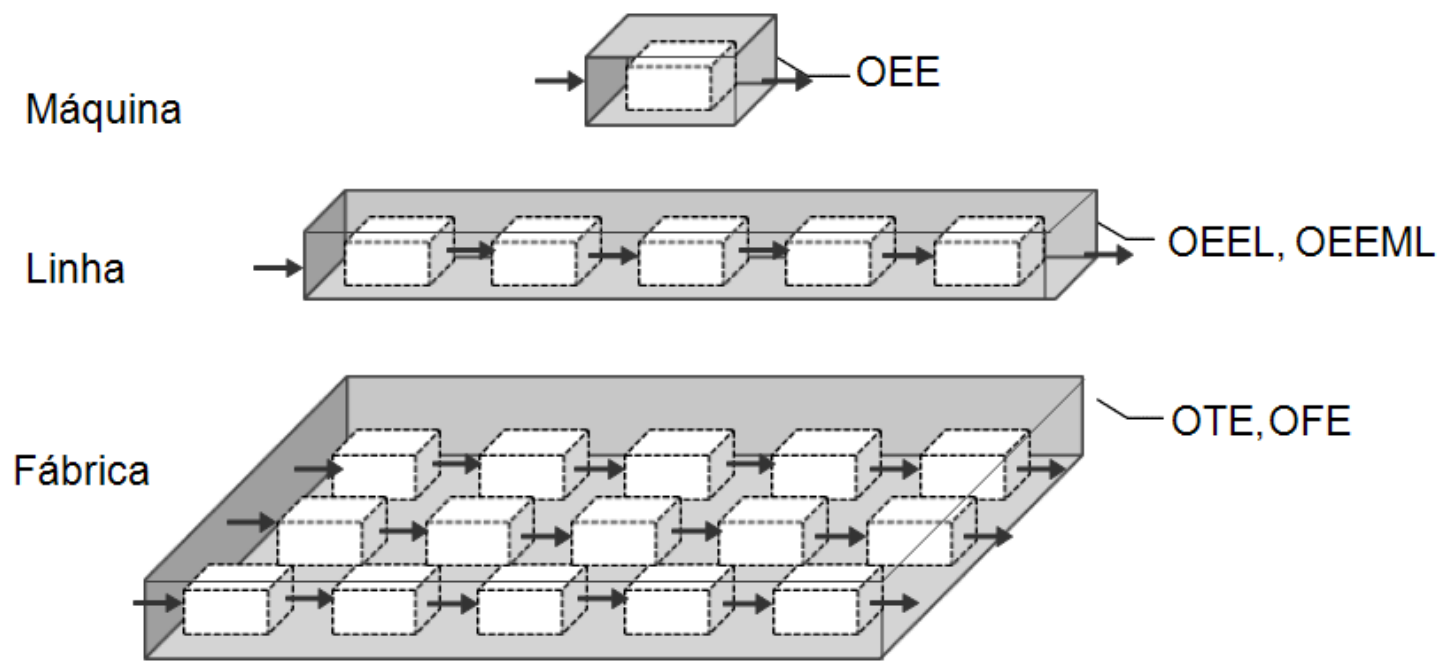

Figura 9 - OEE e indicadores derivados do OEE conforme abrangência do sistema produtivo.

A Figura 9 ilustra algumas possibilidades de ampliação das fronteiras do objeto de avaliação. A abrangência da avaliação pelo OEE pode ser estendida a sistemas de produção em linha dedicados a um produto ou a uma família de produtos similares (flow shop) mediante certas simplificações, mas preservando-se em grande parte sua perspectiva analítica original. Já para sistemas de produção sem padrões de fluxo bem definidos, como fábricas com características de job shop, a extrapolação da conceituação do OEE do nível micro de um equipamento para o nível macro da fábrica envolve uma complexidade muito maior e não será tratada neste trabalho. 


\subsubsection{Indicadores que ampliam a classificação de perdas em relação à que 0 OEE por definição considera}

A derivação de indicadores a partir do OEE pode ser também considerada ampliando a classificação das perdas, ou seja, considerando outros tipos de paradas, além dos considerados na conceituação básica do OEE apresentada na Figura 8. Suzuki (1994) foi um dos primeiros a reconhecer que é preciso contemplar também a influência de fatores externos à fábrica, como suprimentos e vendas, que impedem a plena utilização da capacidade. Alguns dos principais indicadores derivados conforme esta abordagem são apresentados nas seguintes seções.

\subsubsection{Total Equipment Effectiveness Performance (TEEP)}

Ivancic (1998 apud Muchiri e Pintelon 2008) propôs uma derivação do OEE chamada de Total Equipment Effectiveness Performance (TEEP) que considera as paradas planejadas no cálculo do indicador. O TEEP mostra mais claramente como a função Manutenção está impactando na produtividade da Manufatura, pois as paradas planejadas de manutenção são estimadas com base no Tempo Médio entre Falhas (MTBF) e no Tempo Médio de Reparo (MTTR). Dessa forma o TEEP indica como melhores práticas de manutenção que reduzem o MTTR ou que aumentam o MTBF resultam em uma melhor utilização dos equipamentos.

Segundo Muchiri e Pintelon (2008), o cálculo do TEEP, pode ser feito utilizando a Equação 17, na qual o denominador inclui além do total de tempo planejado de produção, o tempo total de manutenções planejadas.

$$
\text { TEEP }=\frac{\text { Tempo de operação com valor }}{\text { Tempo total disponivel }}
$$

A aplicação do TEEP foi concebida para se avaliar a produtividade no nível de um equipamento, mas pode ser estendida à avaliação de um sistema maior como uma planta de processos ou fábrica do tipo flow shop que pode ser tratada como uma entidade de produção única. 


\subsubsection{Production Equipment Effectiveness (PEE)}

Outra derivação do OEE é o Production Equipment Effectiveness (PEE) apresentado por Raouf (1994) que propõe medi-lo de forma diferente conforme o tipo de produção: no caso de produção discreta, considera os mesmos três componentes do OEE (disponibilidade, desempenho e qualidade), mas no caso de processo contínuo inclui componentes adicionais para considerar outros tipos de perdas como falta de demanda. Neste trabalho, estas variações são chamadas respectivamente de PEE-disc e PEE-cont sendo que ambas, diferentemente do OEE, admitem que seus componentes afetam o resultado final com pesos distintos.

Com base na proposta de Raouf (1994) para processos discretos, o cálculo do PEE-disc, se dá pela Equação 18.

PEE-disc $=A^{K 1} \times E^{K 2} \times Q^{K 3}$

na qual,

$$
\begin{aligned}
& A=\text { Disponibilidade } \\
& E=\text { Eficiência } \\
& Q=\text { Índice de qualidade } \\
& K 1, K 2, K 3 \text { são os pesos de cada componente. } \\
& \sum K i=1 \text { e } 0<K i \leq 1 .
\end{aligned}
$$

Com base na proposta de Raouf (1994) para processos contínuos, o cálculo do PEE-cont, se dá pela Equação 19.

$$
\text { PEE-cont }=A_{1}{ }^{K 1} \times A_{2}{ }^{K 2} \times E^{K 3} \times Q R^{K 4} \times P S E^{K 5} \times O U^{K 6}
$$

na qual,

$$
\text { A1 = Disponibilidade }
$$




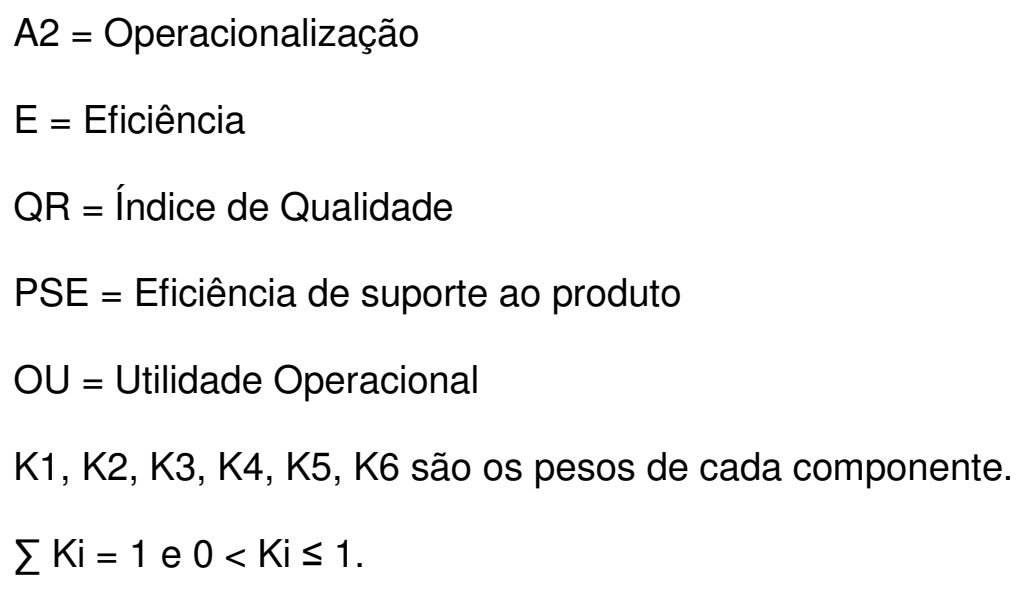

\subsubsection{Total Overall Equipment Effectiveness (TOEE)}

Mais recentemente, Braglia et al. (2009) definiram o Total Overall Equipment Effectiveness (TOEE) como um indicador que considera o efeito das paradas denominadas de perdas independentes do equipamento, tais como perdas por falta de operador, por bloqueio do fluxo de saída, por falta de suprimento, e pela realização do controle de qualidade, que não dependem das condições de funcionamento do equipamento em si. Este tipo de perda passa a ser relevante quando se considera a avaliação da utilização da capacidade de equipamentos interrelacionados que operam em conjunto, por exemplo, numa linha de produção.

Este indicador pode ser obtido através de uma equação simples, na qual para se medir o tempo de produção com valor agregado $\left(\mathrm{MVT}^{17}\right)$, que indica a capacidade efetivamente utilizada, são subtraídos todos os tempos causados por perdas dependentes e independentes do equipamento além dos tempos de paradas por manutenção planejada. A Equação 20 mostra que o TOEE é obtido de uma razão entre MVT e o tempo disponível para carregamento de linha $\left(L L T^{18}\right)$. Sendo que este é obtido subtraindo-se do tempo calendário os tempos de parada preventiva pelos planejadores de produção (para reformas, férias, etc.).

\footnotetext{
${ }^{17}$ Machine available time, em inglês.

${ }^{18}$ Line loading time, em inglês.
} 
TOEE $=\frac{\text { MVT }}{\text { LLT }}$

\subsubsection{Overall Plant Effectiveness (OPE) e Overall Asset Effectiveness (OAE)}

Finalmente, vale destacar o Overall Plant Effectiveness (OPE) e Overall Asset Effectiveness (OAE), apresentadas por Muchiri e Pintelon (2008), que além das perdas consideradas pelo OEE, consideram perdas provocadas por outras causas além da alçada dos gestores responsáveis pela operação do processo produtivo, quais sejam:

- Causas comerciais: falta de demanda ou baixa demanda.

- Problemas logísticos externos: falta de fornecimento, problemas com transporte, queda de energia, etc.

- Regulamentações ambientais: quotas de produção estabelecidas em função de limites para emissão de dióxido de carbono, etc.

- Causas naturais: condições climáticas adversas, desastres como tempestades e furacões.

- Causas relacionadas com a gestão do negócio que afetam a fábrica (estoques, logística interna, segurança, investimentos em novos produtos, etc.).

Uma diferença entre o OPE e o OAE é a forma de cálculo, sendo que o OAE não é calculado com dados em tempo, mas em unidades de produto. Segundo Muchiri e Pintelon (2008), ambos são indicadores ainda pouco discutidos na literatura que carecem de uma definição mais consagrada.

O cálculo para estes indicadores apresentados pelos autores é apresentado nas Equações 21 e 22. 


$$
\begin{aligned}
& \mathrm{OPE}=\frac{\text { Tempo de agregação de valor }}{\text { Tempo total }} \\
& \mathrm{OAE}=\frac{\text { Quantidade real de produtos bons }}{\text { Quantidade de produtos que teoricamente poderia ser produzido }}
\end{aligned}
$$

Pode-se observar que o cálculo do OPE está diretamente relacionado à Equação 7, aplicada para o cálculo do OEE, porém para o OPE se considera uma classificação de perdas maior, e assim seu resultado tende a ser sempre menor que o resultado do OEE. O mesmo acontece para o OAE, que é uma derivação do cálculo do OEE quando este é considerado pela Equação 8.

\subsubsection{Síntese das propostas de ampliação da classificação de perdas}

A Figura 10 ilustra possíveis extensões à classificação de perdas considerada pelo OEE. Nota-se que o escopo ampliado das perdas consideradas por certos indicadores derivados do OEE pode contemplar o efeito de perdas causadas por áreas de suporte, outras áreas da cadeia de valor e mesmo por decisões estratégicas da organização, proporcionando uma visão mais sistêmica do desempenho que a produção pode alcançar.

Esta visão é muito mais ampla que a considerada na avaliação de um dado equipamento, com base no indicador do OEE que dentre os diversos tipos de perdas apresentados por esta figura, considera somente os codificados como g2, g3, g4, g5 e g6.

Tais perdas podem ser diretamente atribuídas ao(s) equipamentos(s) cujo desempenho operacional se queira avaliar, e são de natureza interna à fábrica em que está(ão) instalado(s). Os indicadores derivados do OEE como TEEP, OEEML e o OLE ampliam de forma incremental os tipos de perdas que considera. Já os indicadores PEE-cont, OAE, OPE e TOEE consideram o impacto de um leque muito mais amplo de tipos de perdas que comprometem o desempenho da manufatura, inclusive incluindo perdas cujas causas são externas à fábrica. 


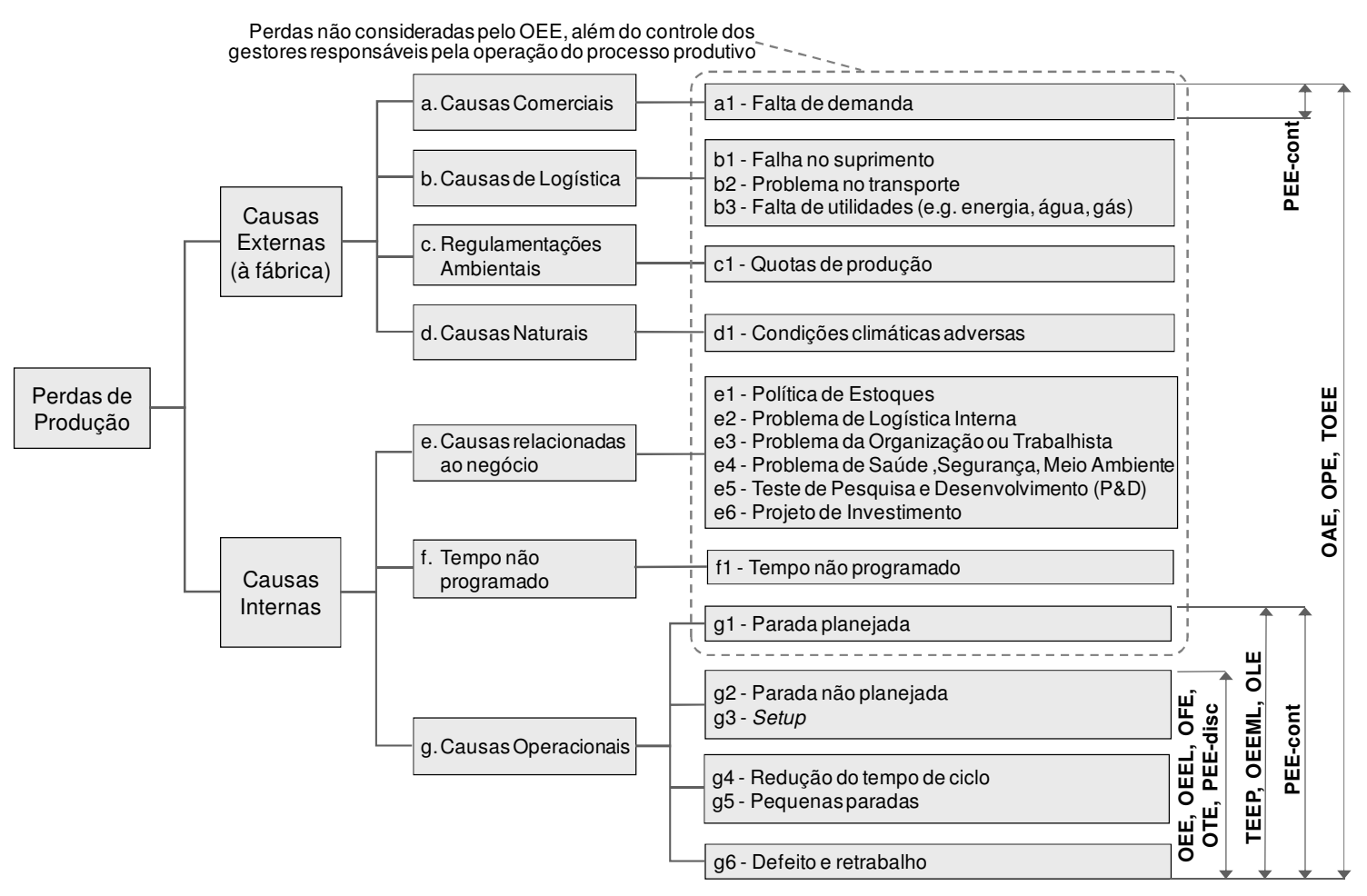

Figura 10 - Classificação das perdas de produção para avaliação do desempenho da manufatura. Adaptada de Muchiri e Pintelon (2008). 


\section{Análise dos indicadores derivados do OEE como instrumentos de medição do desempenho global da manufatura}

Neste capítulo, os indicadores identificados na revisão da literatura (OEE, TEEP, PEE-disc, PEE-cont, OPE, OAE, OFE, OTE, OEEML, OEEL, TOEE, OLE) são comparados e organizados de modo a facilitar a identificação de modelos mais apropriados para se avaliar e gerenciar o desempenho global da manufatura de forma mais integrada. Desta forma pretende-se contemplar a Questão 2 - Como se caracterizam os indicadores derivados do OEE enquanto possíveis instrumentos para balizar o sistema de medição do desempenho global da manufatura? Para isso, foi elaborado um quadro referencial que apresenta o contexto em que estes indicadores podem ser aplicados em função da abrangência do sistema produtivo que propõem avaliar e da amplitude da classificação dos tipos de perdas que consideram. O quadro referencial elaborado é apresentado na Figura 11.

Nesta figura é proposto um enquadramento dos indicadores derivados do OEE que foram identificados. O eixo horizontal representa a abrangência do sistema de operações considerado pelo indicador que pode ser limitado a somente uma máquina/equipamento ou ampliado para avaliar uma linha ou fábrica. No eixo vertical, tem-se a representação da abrangência da classificação de perdas considerada pelo indicador em 4 níveis, definidos conforme os grupos de perdas apresentadas na Figura 10, como seguem:

i. Nível 1: as causas operacionais que correspondem às perdas g2, g3, g4, g5 e g6.

ii. Nível 2: as paradas planejadas que correspondem à perda g1 além das causas operacionais consideradas no Nível 1.

iii. Nível 3: as causas comerciais que correspondem às perdas classificadas como a1 além de todos os tipos de perdas consideradas no Nível 2.

iv. Nível 4: abrange todos os tipos de perdas apresentados na Figura 10. 
As quadrículas com fundo mais escuro delimitam o contexto primário para a aplicação desses indicadores e suas possíveis extensões.
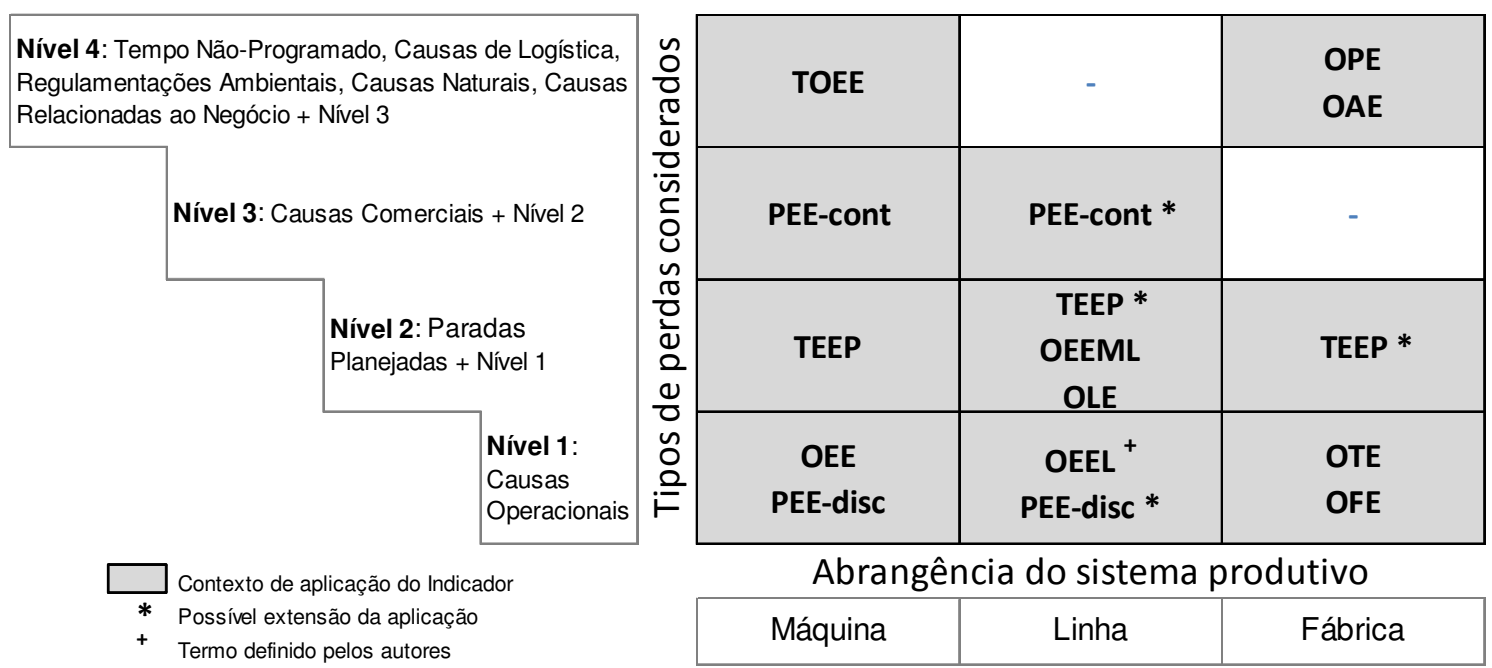

Figura 11 - Matriz das derivações do OEE conforme a classificação dos tipos de perdas e abrangência do sistema produtivo que considera. Fonte: Busso e Miyake (2012).

A seguir, as alternativas de indicadores derivados do OEE levantadas são analisadas quanto às suas propriedades. Para conduzir esta análise comparativa, foi utilizada a relação de dimensões e características proposta por Johsson e Lesshammar (2009), de forma análoga à análise estruturada do OEE apresentada na Tabela 5.

\section{a) Estratégia}

Esta dimensão permite identificar o quanto o indicador atende a um objetivo relacionado com a estratégia da função considerada, neste caso a manufatura. Sendo assim, se o indicador auxilia a empresa no alcance de algum(ns) objetivo(s) como qualidade, custo, lead time de entrega ou flexibilidade, em algum nível da organização, pode-se considerar que ele atende ao quesito de promover 0 direcionamento estratégico das ações tomadas no âmbito da manufatura.

Em relação ao alinhamento do indicador à estratégia de negócio, observa-se que, assim como o OEE, os indicadores OFE, OTE, OLE, OEEML, TEEP e PEE-disc 
podem traduzir as estratégias corporativas quando amparados por algum programa gerencial e/ou melhoria que os sustente.

Isto ocorre porque estes indicadores consideram as perdas somente na abrangência da manufatura (máquina, linha ou fábrica) não incluindo perdas relacionadas a outras áreas da organização que também podem impactar o negócio. Quando atrelados a um programa de melhoria estes indicadores tornam-se ferramentas para promover ações que gera impacto direto em objetivos estratégicos como: cumprimento das entregas, diluição de custo fixo através do aumento de volume e aumento da qualidade pela redução de perdas por defeitos. É possível que os indicadores PEE-cont, TOEE, OPE e OAE reflitam impactos causados por fatores externos à fábrica como comportamento do mercado e estratégias seguidas por outras partes da cadeia produtiva (e.g. plano de P\&D, políticas de Meio Ambiente, etc.).

\section{b) Orientação ao Fluxo}

Esta dimensão avalia o quanto 0 indicador reflete 0 desempenho das diferentes áreas que constituem a cadeia de valor. Assim, se 0 indicador possibilita medição de perdas em abrangência maior do que somente uma máquina ou contemplando outras áreas da empresa, pode-se considerar que a dimensão de orientação ao fluxo é atendida (ainda que parcialmente).

As derivações do OEE em termos de abrangência do sistema produtivo não permitem uma visão mais ampla do fluxo produtivo, pois se limitam a avaliar diferentes equipamentos somente do âmbito da manufatura. Com exceção do OEE, OEEL, OTE, OFE, TEEP, OEEML, OLE e PEE-disc, as demais derivações permitem contemplar o fluxo produtivo por outras atividades e funções ao longo da cadeia. Já as derivações que ampliam a classificação de perdas como o PEE-cont e, em especial, o TOEE, OPE e OAE permitem avaliar como decisões tomadas ou mesmo restrições pré-existentes em outras partes da cadeia, como a área Comercial e/ou a Logística, afetam na utilização da capacidade na área produtiva.

\section{c) Eficiência Interna}


Esta dimensão verifica se $o$ indicador possibilita comparar o desempenho de diferentes funções internas ao sistema avaliado. Assim, indicadores financeiros têm mais possibilidades de balizar uma comparação entre departamentos. Um indicador que mede a utilização da capacidade só permite sua comparação entre diferentes áreas, quando os impactos de cada área podem ser considerados separadamente $\mathrm{e}$ assim pode-se considerar que a dimensão de eficiência interna é atendida.

Todos os indicadores apresentados, assim como o OEE, auxiliam o controle da produção e podem ser úteis na comparação da eficiência de diferentes funções ou áreas da empresa. O PEE-cont, TOEE, OPE e OAE por considerar um maior número de tipos de perdas, são os indicadores que oferecem mais possibilidades de comparação dos impactos que diferentes áreas de suporte à fábrica causam na eficiência da manufatura. Estes indicadores, por exemplo, permitem detectar como paradas excessivas para realização de testes pela área de desenvolvimento de novos produtos podem comprometer a eficiência ao diminuir a disponibilidade para produção.

Já o OEEL, OTE, OFE, OEEML, OLE, TEEP e PEE-disc nem sempre permitem comparações de desempenho de diferentes áreas, pois as perdas que consideram envolvem basicamente as funções de Produção, Qualidade e Manutenção restringindo assim a comparação entre diversas funções internas da empresa, tais como Marketing, Comercial, entre outras áreas que não fazem parte da manufatura.

\section{d) Eficácia Externa}

Para atender a essa dimensão um indicador deve ser capaz de refletir o impacto do desempenho do sistema avaliado na satisfação do cliente, seja em termos de qualidade ou nível de atendimento. Esta dimensão está relacionada com a satisfação do cliente e a comparação de resultados externos de forma a garantir o cumprimento das prioridades competitivas. 
Nenhum dos indicadores enumerados envolve a abordagem de clientes para medir seu nível de satisfação ou permite uma comparação clara de resultados externos. O PEE-cont, TOEE, OPE e OAE ao medirem o tempo de parada por falta de demanda podem sugerir indiretamente um possível problema de aceitação do produto pelo mercado. Contudo, tal associação deve ser considerada com ressalvas já que uma demanda fraca pode-se dar por outros motivos tais como estratégias de venda, distribuição ou de marketing ineficazes.

\section{e) Direcionador de Melhoria}

Para atender a característica de direcionador de melhoria o indicador deve apoiar a dinâmica de melhoria contínua, ou seja, deve possibilitar a identificação de oportunidades que possam trazer futuras melhorias. Assim os indicadores que permitem uma estratificação de perdas, as quais possam ser eliminadas ou reduzidas, são considerados indicadores que podem ser utilizados como ferramentas em um processo de melhoria contínua. Contudo, é necessário que o indicador seja utilizado sistematicamente, de forma a evidenciar a melhoria.

Todos os indicadores enumerados podem contribuir com o processo de melhoria contínua, desde que não sejam utilizados somente como informação, mas como mais uma ferramenta para que grupos tais como os formados para melhoria contínua ou aqueles do tipo força tarefa (FT) possam atuar.

\section{f) Simples e Dinâmico}

Para atender essa característica, um indicador deve ser simples e fácil de ser entendido, calculado e aplicado no contexto do sistema avaliado. Um indicador pode ser considerado simples quando não necessitar de muitas adequações devido a configuração do layout do sistema de produção ou se a consolidação do resultado do indicador for simples de ser realizada, tornando-o assim uma ferramenta prática e confiável para a tomada de decisão. 
O cálculo de indicadores ampliando o escopo do sistema produtivo a ser avaliado requer a consideração de um maior número de equipamentos e do layout como os mesmos estão dispostos (se estão em série ou em paralelo) o que tende a dificultar o cálculo e requerer revisões sempre que houver alguma mudança no sistema. Faz parte do cálculo dos indicadores a etapa de coleta de dados. Jeong e Phillips (2001) colocam que uma das grandes dificuldades da medição do OEE bem como de outros indicadores, é a coleta de dados: qualquer erro pode invalidar a medição. Atualmente, existem sistemas computadorizados que já efetuam esta coleta de forma automática, reduzindo o risco de erros e simplificando o processo de medição.

Já a ampliação da classificação de perdas implica basicamente em manter a forma de cálculo dos tipos básicos de perdas e adicionar os valores das novas classes de perdas. Neste sentido, o OEE e o TOEE são simples de calcular, mas consideram poucas variáveis que impactam no sistema de produção, e precisam ser complementados. Já indicadores como TEEP, PEE-disc, PEE-cont, OPE e OAE são indicadores que possuem cálculo simplificado desde que se tenha uma boa consolidação de dados. Nestes dois casos, mudanças de configuração de layout ou mudanças significativas no sistema produtivo são mais simples de serem adequadas na forma de cálculo. Já para os indicadores OEEL, OFE, OTE, OEEML e OLE, nos quais o arranjo físico dos equipamentos e linhas impactam na identificação de gargalos e do fluxo que atravessa o sistema de produção, o cálculo pode requerer revisões e assim tornar a medição mais complexa.

Para avaliação dos indicadores derivados do OEE que foram identificados na pesquisa bibliográfica, foram consideradas as dimensões e características propostas por Johsson e Lesshammar, considerando os critérios descritos na Tabela 7 para facilitar a avaliação de cada indicador. Para cada critério foi considerado se 0 indicador atende completamente, atende parcialmente ou não atende aquele critério (ver avaliações no ANEXO 4A), em seguida, os indicadores afins foram agrupados (ver ANEXO 4B), e assim, finalmente foi obtida a Tabela 8. 
Tabela 7 - Critérios para avaliação dos indicadores derivados do OEE, conforme as dimensões e características propostas por Johsson e Lesshammar (1999).

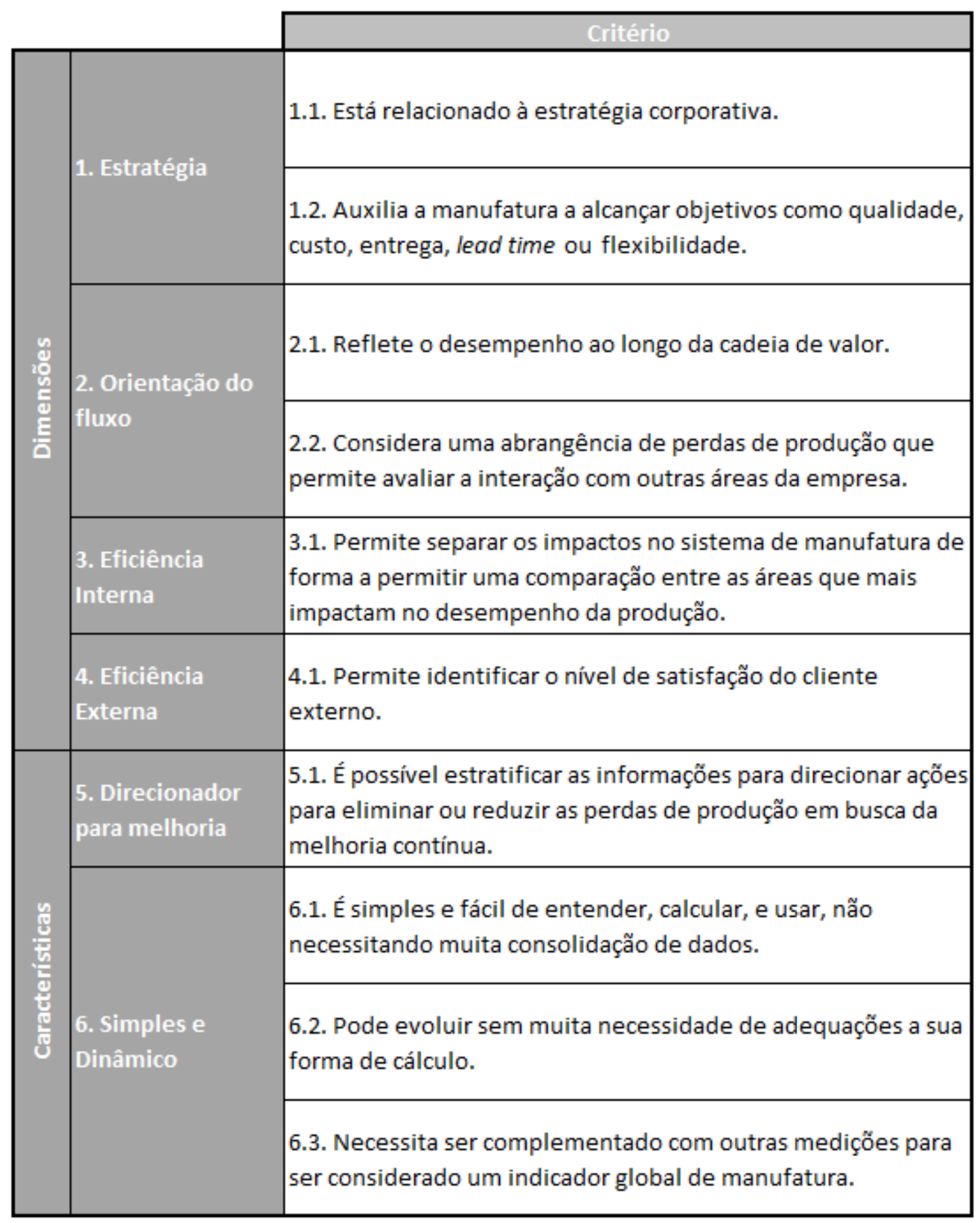

A Tabela 8 apresenta uma análise comparativa destes indicadores conforme os critérios de Johsson e Lesshammar, detalhados na Tabela 7. Esta tabela resume a análise comparativa dos indicadores enumerados e fornece uma visão de como o sistema de medição pode ser aprimorado adotando-se indicadores com escopo menos restrito que o OEE. 
Tabela 8 - Comparação de indicadores vis-à-vis dimensões e características de um sistema de medição do desempenho global. Fonte: Busso e Miyake (2012)

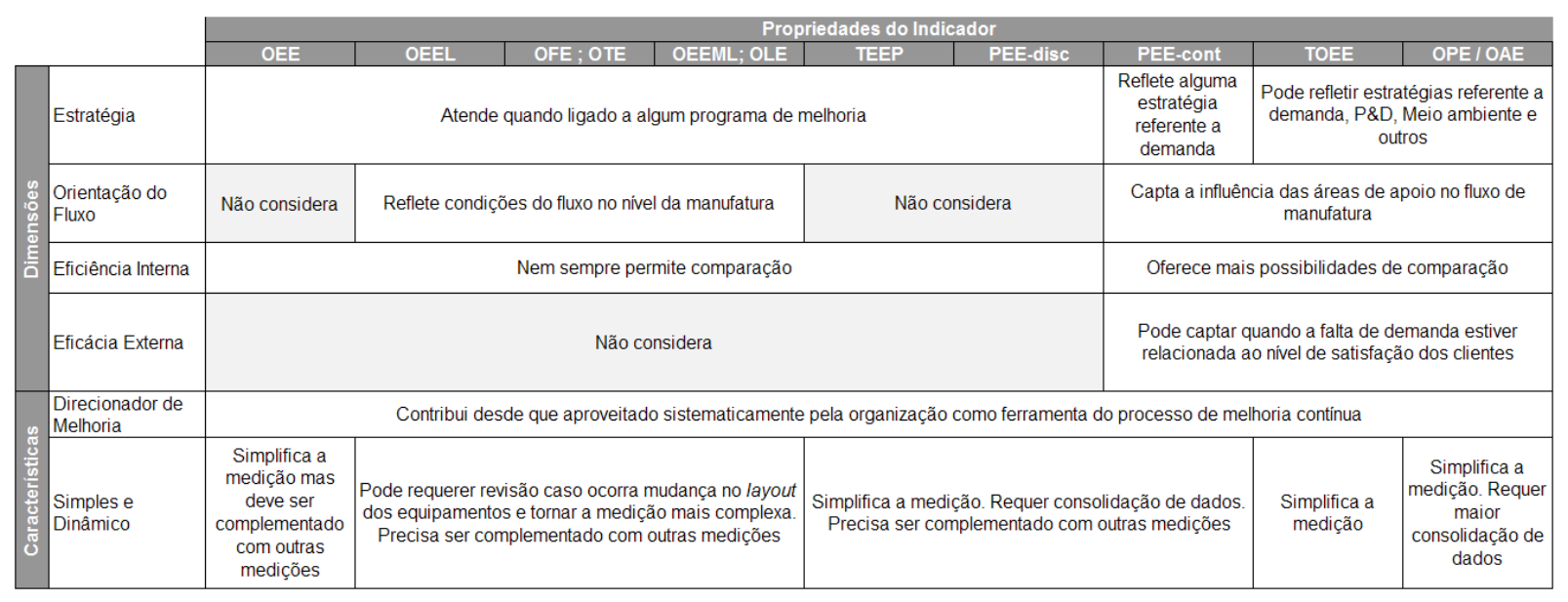

Este quadro orientativo fornece subsídios ao processo de seleção e implementação de indicadores para a medição do desempenho global da manufatura. A revisão da literatura permitiu avaliar as limitações do OEE como indicador de desempenho global e identificar alternativas de indicadores derivados do OEE que podem ser adotados como uma ferramenta mais adequada para cumprir esta função. Também possibilitou determinar a forma de cálculo destes indicadores o que auxilia os gestores a identificar os dados de entrada e as condições ou premissas para poder aplicá-lo no sistema de manufatura cujo desempenho global se deseja medir e avaliar. 


\section{Estudo de caso: implementação de indicadores de desempenho global da manufatura}

Este capítulo apresenta o Estudo de Caso em duas seções. A seção 5.1 descreve o caso. Inicialmente o sistema de manufatura, objeto de estudo é caracterizado. Em seguida são apresentadas as experiências de aprimoramento e ampliação do uso do indicador OEE e da subsequente evolução para adoção do indicador de OPE. A descrição do caso evidencia que o desenvolvimento de um sistema de medição do desempenho global evoluiu da busca de dados agregados por linha para a busca de dados agregados no nível da manufatura como um todo. Ainda nesta seção são descritos como os grupos de solução de problema tipo FT foram organizados e seus membros envolvidos para atuar sobre os indicadores considerados e obter o resultado esperado. A seção 5.2 apresenta uma análise do Estudo de Caso discutindo os principais conceitos aplicados e relacionando-os com a literatura, e avaliando como a atuação dos grupos de solução de problema contribuiu para a obtenção de melhores resultados para a empresa com base na aplicação de indicadores de desempenho global.

\subsection{Descrição do Caso}

\subsubsection{Caracterização da empresa}

A empresa do caso estudado é uma multinacional americana, presente no Brasil há mais de 100 anos, sendo uma das principais empresas de agronegócio e alimentos do país, atuando nos seguintes segmentos: originação de grãos e processamento de soja e trigo, produção de fertilizantes, fabricação de produtos alimentícios e em serviços portuários. É uma das maiores exportadoras do Brasil e desde 2006 atua também no segmento de açúcar e bioenergia.

Presente em 16 estados de todas as regiões do país, a empresa possui hoje mais de 20 mil colaboradores e cerca de 150 unidades, entre indústrias, centros de 
distribuição, silos e instalações portuárias. O faturamento bruto da companhia em 2010 atingiu a cifra de US $\$ 14,7$ bilhões.

A unidade a que o caso se refere é uma planta localizada no Sul do país, operada por cerca de 300 funcionários, que tem como produto principal os derivados à base de óleo hidrogenado do segmento de fabricação de produtos alimentícios.

Nesta unidade, o processo de produção é caracterizado por dois tipos de processo: a preparação é executada em bateladas e o envase/embalagem do produto ocorre num processo contínuo semi-automatizado, no qual a interferência humana se limita ao abastecimento de potes, tampas e embalagens secundárias. $O$ processo de envase é realizado por 4 linhas (L1, L2, L3, L4) que se diferenciam pelo tipo de produto e tamanho da embalagem. Como é um processo crítico neste ramo de negócio, sua operação precisa ser rigorosamente controlada para se buscar a plena utilização de sua capacidade e assegurar a competitividade do produto em custo. Por este motivo este processo constitui o foco dos esforços de melhoria contínua.

O desenvolvimento do sistema de avaliação do desempenho global na unidade de análise foi iniciado em 2008 e se insere no bojo de uma ação corporativa desdobrada a partir de um projeto denominado "Mais Produção" (MP) que teve como objetivo viabilizar um aumento de produção (volume em toneladas de margarina), através da maior utilização da capacidade nominal da linha de produção de margarina doméstica para acompanhar a tendência de crescimento do mercado.

Para avaliar os resultados da manufatura, a gerência optou por inicialmente focar as perdas contempladas na medição do OEE, ou seja, as perdas de disponibilidade, de desempenho e de qualidade. Esta decisão foi motivada pelo elevado número de horas paradas por causas operacionais que vinham sendo registradas pelo serviço de manutenção.

\subsubsection{A etapa da introdução do OEE à aplicação do OPEL}

Esta etapa é caracterizada por quatro fases distintas. Estas fases se diferenciam pela aplicação do OEEL e OPEL, o OPEL é um indicador de eficiência total de uma linha derivado do conceito do OPE para medição da eficiência total de 
uma planta apresentado na literatura. Trata-se de um indicador não identificado na revisão da literatura, que foi adaptado pela empresa, e assim foi denominado com o acréscimo do sufixo $L$ (de linha) na presente dissertação para distingui-lo do OPE (de planta). Estes indicadores são aplicados em diferentes momentos com o objetivo de aumentar a utilização da capacidade de produção de uma linha através da análise de perdas que cada um destes indicadores possibilita.

$\mathrm{Na}$ unidade de análise, cada linha de produção é composta de três equipamentos em série nos quais o OEE pode ser medido separadamente. Contudo, como o fluxo em cada linha é contínuo e unidirecional, sua vazão é limitada pela capacidade do equipamento gargalo. Portanto, a empresa optou por medir primariamente o OEEL em cada linha tomando como base as condições no gargalo das linhas, que é o equipamento de envase do produto. Para o cálculo do OEEL a empresa adotou a Equação 8, considerando dados da produção total da linha, 0 tempo de carregamento do equipamento gargalo e a capacidade de produção teórica do equipamento gargalo. Estes dados são extraídos de uma base alimentada por um sistema informatizado de apontamento de perdas que discrimina a duração e o motivo das mesmas, por linha.

\subsubsection{Organização do grupo multifuncional para solução de problemas}

No início das atividades para o acompanhamento e gestão do desempenho global da unidade com base na avaliação do OEEL, foi estabelecido um grupo multifuncional composto por responsáveis pela Produção, Qualidade e Manutenção. Este grupo optou por desenvolver uma prática geral de monitoramento do desempenho de fábrica e realização de melhorias visando o aumento do volume de produção buscado no projeto MP e focando seus esforços inicialmente numa linha piloto, para isso selecionou a L2.

Em uma primeira reunião definiu-se uma agenda para as interações entre as pessoas, os responsáveis por cada grupo de perdas e uma rotina diária, semanal e mensal de encontros para que o indicador acompanhado pudesse trazer os resultados esperados através do tratamento dos problemas. 
Para o aprofundamento da causa raiz, o grupo multifuncional selecionou as ferramentas de Gráfico de Pareto das principais perdas, o Diagrama de Causa-eEfeito (Ishikawa) e o método dos 5 Por quês. Desta forma procurou-se definir ações para a eliminação de perdas e melhoria dos resultados de utilização da capacidade.

Estas reuniões aconteciam diariamente em um espaço reservado para a análise do problema. A Figura 12 mostra o espaço reservado para estas reuniões e tratamento de perdas.

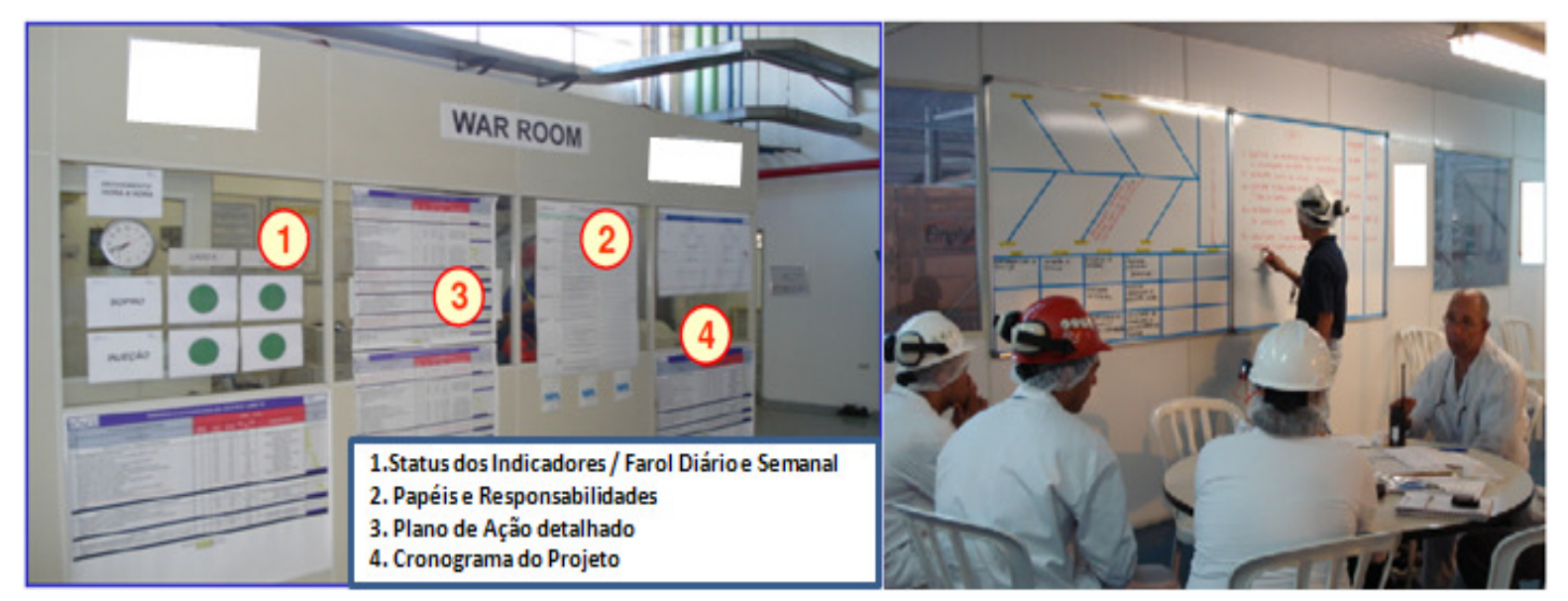

Figura 12 - Espaço para acompanhamento das reuniões e tratamento de perdas.

A evolução do OEEL da L2 durante o primeiro período pode ser vista na Figura 13. Os dados levantados para o cálculo destes valores de OEEL estão tabelados no ANEXO 5. 


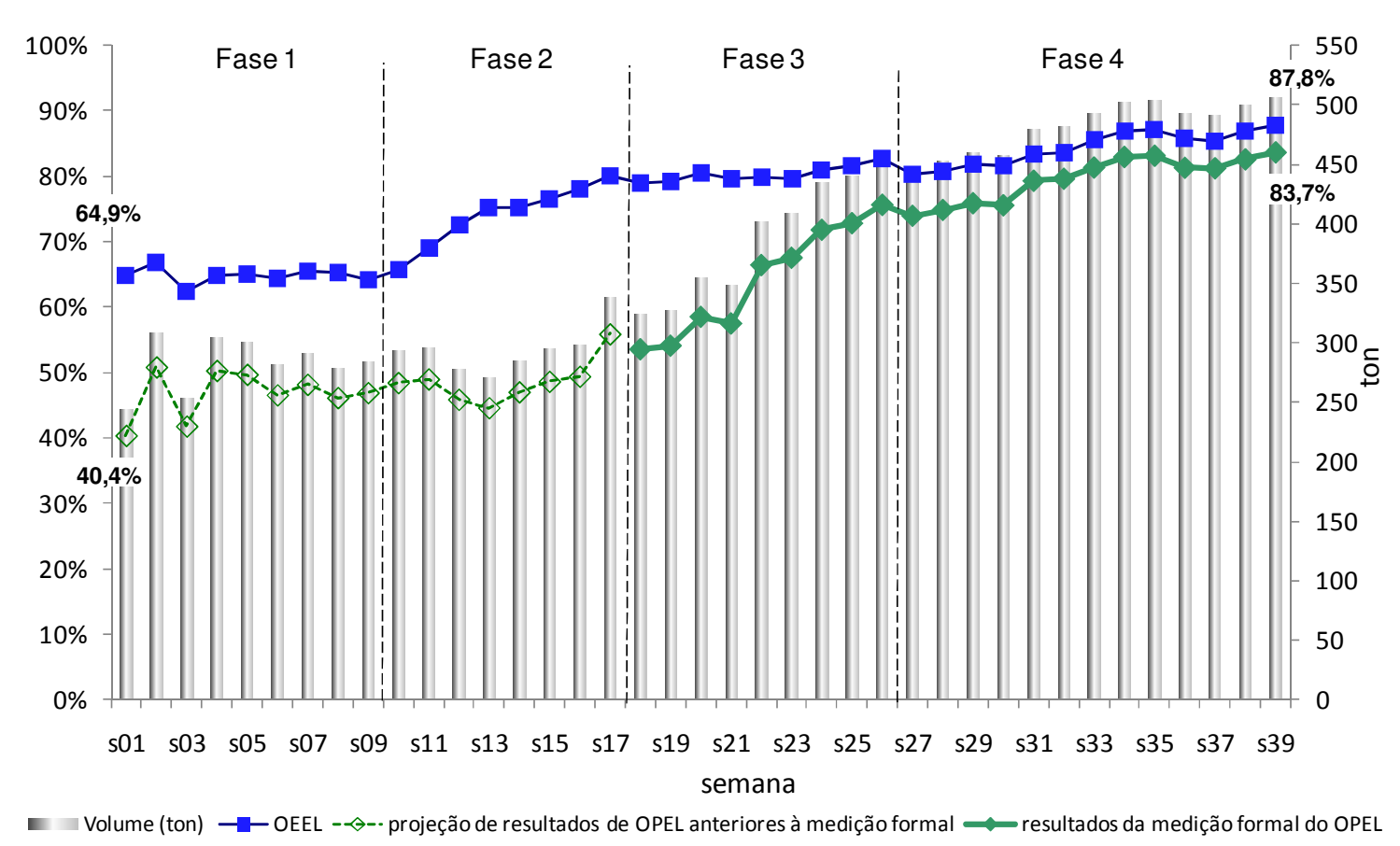

Figura 13 - Evolução do OEEL e OPEL na L2 durante o primeiro período em 2008.

A Figura 13 mostra as quatro fases distintas no primeiro período de implementação. Na Fase 1 foi introduzida a utilização do OEEL como indicador de desempenho global das linhas e deu-se início à geração de um histórico para se poder identificar as principais causas de perdas. A análise da natureza das perdas identificadas nesta fase revelou que algumas causas não consideradas no cálculo do OEEL eram responsáveis por parcela significativa das perdas, quais sejam:

- Perdas por paradas planejadas (g1) por causas como Manutenção Preventiva e Limpeza de Linha representavam cerca de 17,6\% do tempo total de paradas.

- Perdas por outras causas além do controle dos gestores responsáveis pela operação das linhas como as paradas por Falta de Demanda (a1) embora a unidade opere em regime de 7 dias por semana, 24 horas por dia, não havia demanda suficiente para ocupar todo o tempo de produção disponível - e por Testes de P\&D (e5), que representavam, as duas, cerca de $53,7 \%$ do tempo total de paradas. 
De maneira geral, foi evidenciado que as causas que afetavam o OEEL como aquelas que geram perdas de disponibilidade (g2, g3), desempenho e qualidade representavam $29 \%$ do tempo total de paradas e que as causas que provocavam paradas não consideradas pelo $\operatorname{OEEL~(a1,~b3,~e5,~g1)~representavam~}$ $71 \%$ do tempo total de paradas, conforme mostra a Figura 14.

$\mathrm{Na}$ Fase 2, o grupo multifuncional passou a se reunir semanalmente para avaliar os resultados do OEEL com base no Gráfico de Pareto das principais paradas e, a partir de sua análise disparar ações para eliminar as causas raízes dos problemas. Entre a semana 10 (em Junho de 2008) e a semana 17 (em Julho de 2008), houve uma sensível elevação do OEEL de $65,7 \%$ para $80,1 \%$ como mostra a Figura 13, sobretudo pela via da redução das perdas de disponibilidade. Para isso contribuíram bastante as ações que a equipe de melhoria da manufatura realizou junto aos principais dispositivos do equipamento de envase que causavam paradas não planejadas - colocador de tampas com aba mole e o termoselador - conforme indica a Figura 15 e o acompanhamento do grupo multifuncional para a sustentação do resultado.

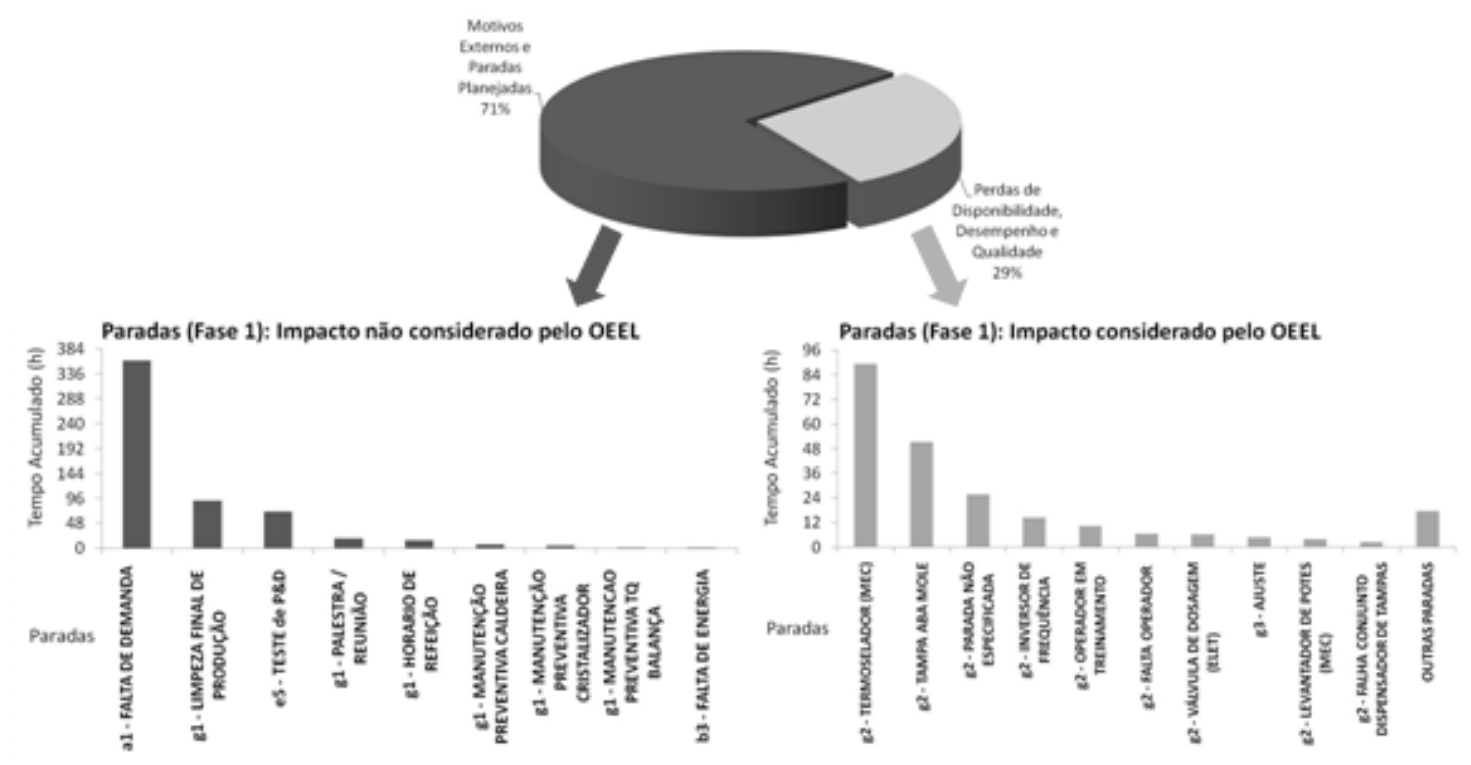

Figura 14 - Análise das perdas que impactam ou não impactam no OEEL - Análise da Fase 1. Fonte: Busso e Miyake (2012) 

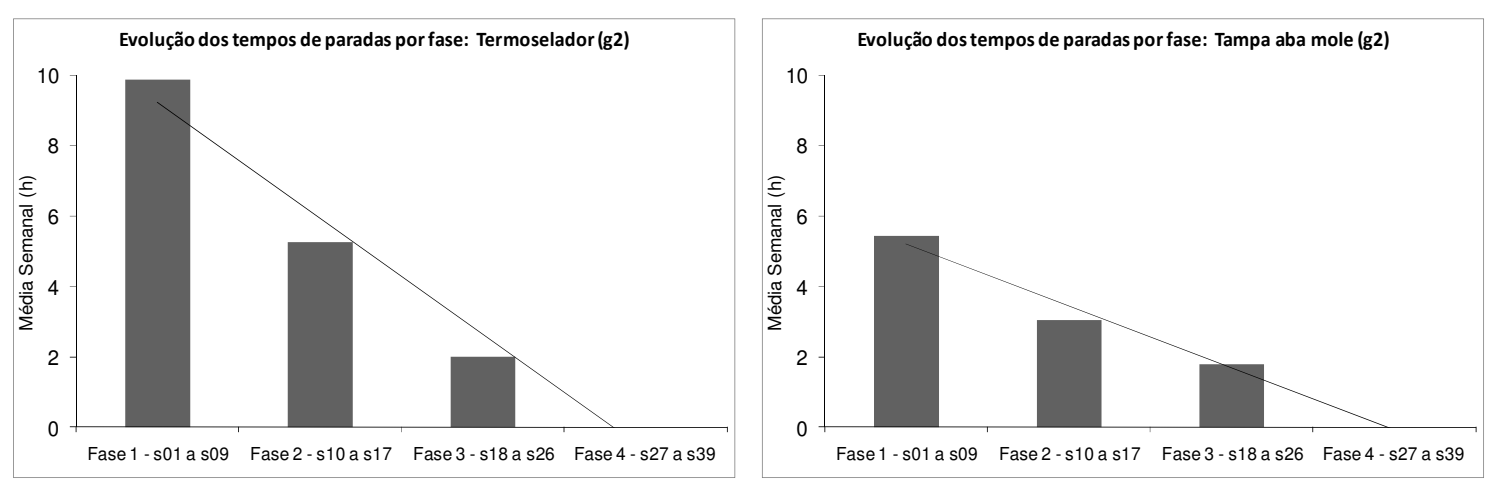

Figura 15 - Evolução das principais paradas que impactam no OEEL durante o primeiro período. Fonte: Busso e Miyake (2012)

Contudo, mesmo assim, a unidade não atingiu as metas de produção para acompanhar o crescimento do mercado. Ainda na Fase 2, o grupo multifuncional detectou que somente ações para elevação do OEEL poderiam não ser suficientes para alcançar incrementos adicionais significativos no volume de produção devido à magnitude das perdas causadas por fatores que estavam fora da alçada da área operacional. Uma análise de Pareto das paradas registradas na Fase 1 confirmou que somente os responsáveis pela operação das linhas não teriam como atuar para assegurar 0 incremento de produção necessário, pois as principais causas destas perdas que impediam a plena utilização da capacidade de produção eram as seguintes:

- Falta de Demanda (a1): $45 \%$ do tempo total em que a produção esteve parada foi devido à falta de vendas de forma nivelada durante todo o mês, que provocava falta de espaço para armazenagem dos produtos produzidos e então parada da produção.

- Limpeza de Linha (g1): embora obrigatória para atendimento às normas de segurança alimentar, como não estava otimizada, o tempo para sua realização representava $11,4 \%$ do tempo total de paradas causando uma redução de disponibilidade maior que a prevista.

- Teste de Novos Produtos (e5): 8,7\% do tempo total de paradas era causado por testes realizados pela área de P\&D que, embora fundamentais para o lançamento de novos produtos também subtraem disponibilidade de tempo para produção efetiva e, portanto, precisam ser 
bem programados.

Considerando a capacidade de produção da L2 (3,6 toneladas/hora) e analisando a evolução das perdas nesta linha (ver ANEXO 5), observa-se que 0 volume de produção perdido devido às perdas de disponibilidade, desempenho e qualidade baixou de uma média de 153 toneladas por semana (42,6 horas perdidas por semana) na Fase 1, para uma média de 104 toneladas por semana (28,8 horas perdidas por semana) na Fase 2. Já as perdas por paradas planejadas e outras causas fora da responsabilidade dos gestores da área operacional, somadas foram responsáveis por uma perda de volume de produção maior, que se manteve em torno de 187 toneladas por semana (51,9 horas perdidas por semana) nas Fases $1 \mathrm{e}$ 2.

Assim, os responsáveis das áreas relacionadas aos fatores causadores de perdas externos à operação (Comercial, Marketing, PCP e P\&D) foram agregados ao grupo multifuncional inicial (Produção, Manutenção e Qualidade). Esta ampliação das áreas funcionais representadas no grupo foi o marco que deu início à Fase 3.

\subsubsection{Ampliação do grupo multifuncional para solução de problemas}

Para alcançar maiores resultados, os participantes do grupo ampliado foram designados pela alta direção, pois após uma análise dos resultados das Fases 1 e 2 percebeu-se que além de ser necessário o envolvimento de outras áreas para a tratativa e eliminação de diversos problemas apontados no Gráfico de Pareto das causas de perdas, também era necessário que as pessoas envolvidas tivessem autoridade para definir e implementar ações de impacto estratégico nos resultados esperados.

Assim, pelo perfil de seus componentes e natureza de seus propósitos e responsabilidades, este grupo se caracterizou como um grupo do tipo FT que na Figura 7 (SHIBA et al., 1997) posiciona-se no nível tático-estratégico, incumbido de tratar de questões que demandavam gerenciamento inter-funcional. 
Inicialmente, os novos integrantes do grupo multifuncional ampliado foram inteirados sobre as perdas que estavam impedindo a linha de alcançar melhores resultados de produção e as responsabilidades por cada tipo de perda foram claramente evidenciadas, de forma que cada integrante do grupo pudesse contribuir eliminando ou controlando causas que tinham origem em atividades ou decisões de sua área funcional.

A Tabela 9 mostra uma matriz com os papéis e responsabilidades de cada área representada no grupo multifuncional mobilizado para solução dos problemas. Esta matriz foi construída a partir de uma primeira análise dos dados de perdas utilizando o Gráfico de Pareto, o Diagrama de Causa-e-Efeito e o método dos 5 Por quês. Essa análise permitiu evidenciar as causas de perdas que deveriam ser evitadas e em seguida o principal responsável para atuar sobre cada uma delas foi identificado entre os integrantes do grupo, conforme sua responsabilidade pelo problema e, também, considerando a autoridade para implementar as ações necessárias na área que causava a perda em questão.

Tabela 9 - Matriz de papéis e responsabilidades - grupo multifuncional ampliado.

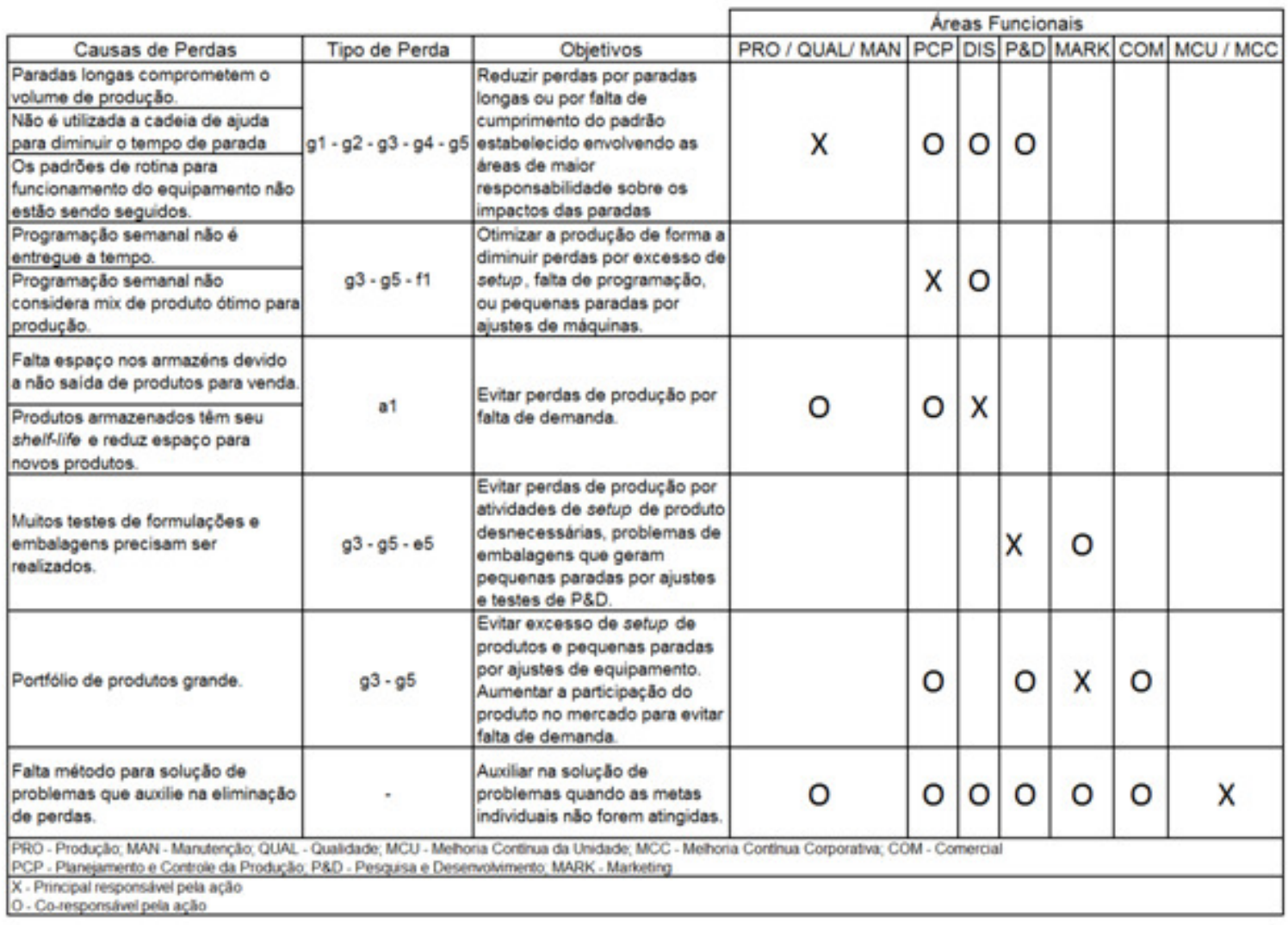


As reuniões do grupo multifuncional ampliado continuaram acontecendo no local estabelecido (Figura 12), contudo, definiu-se uma outra rotina para reuniões de tratamento e apresentação de resultados para a gerência e alta direção (diretores e vice-presidência) de forma que fosse possível acompanhar a evolução do projeto e melhorar as tomadas de decisão, não somente através de análise dos resultados dos indicadores de OEEL e OPEL e suas principais perdas, mas também pela consideração de dados complementares referentes às principais causas de perdas enumeradas na Tabela 9, tais como:

i. Aderência ao plano de produção.

ii. Uso racional do espaço para armazenagem.

iii. Controle do shelf-life em produtos estocados.

iv. Composição do atual portfólio de produtos.

Nestas reuniões, eram apresentados os resultados dos indicadores monitorados, as ações delineadas e seus status. Além disso, era realizada uma atividade denominada Lean Walk, que se trata de uma caminhada rápida pelo chão de fábrica com a participação da Alta Direção para verificar em campo as melhorias realizadas. A Figura 16 mostra a agenda estabelecida, os itens de controle avaliados e as atividades realizadas com os participantes envolvidos.

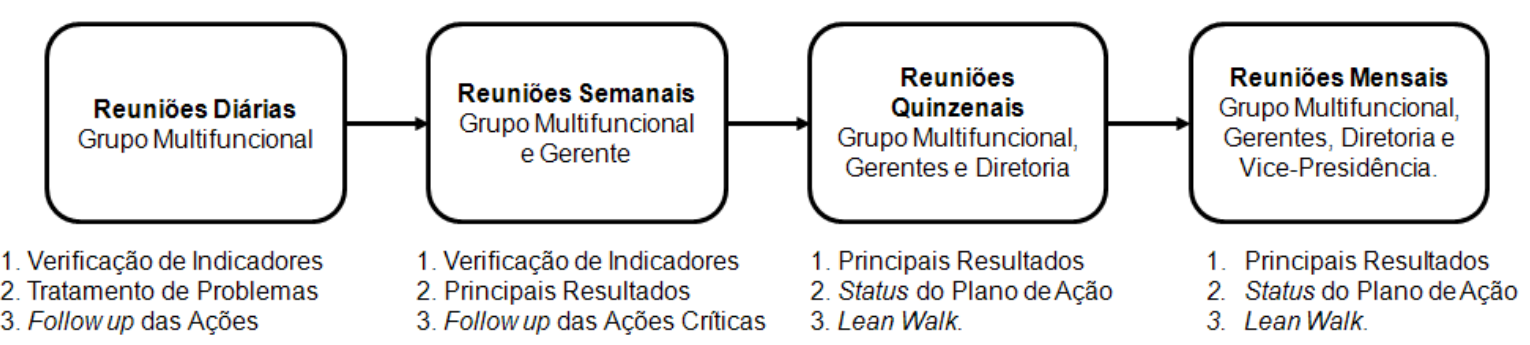

Figura 16 - Agenda de reuniões e itens de controle para acompanhamento dos resultados obtidos pela vice-presidência, diretoria e gerência.

O grupo ampliado avançou no entendimento do que seria necessário para atingir o objetivo final de obter um significativo aumento do volume de produção da 
fábrica, tendo sido esclarecido que isso não dependeria somente da redução das perdas de disponibilidade, desempenho e qualidade, mas também de ações direcionadas à melhoria do desempenho integrado de toda a manufatura pelo engajamento das áreas de apoio à produção em esforços de redução de paradas por falta de demanda, falha no suprimento e falha na programação de produção e teste, entre outras causas.

Isso motivou a empresa a passar a medir também as perdas não computadas pelo OEE e OEEL visando a atuar no controle das mesmas e assim poder buscar um volume de produção ainda maior. Decidiu-se então adotar a abordagem de medição mais ampla proposta pelo OPE. Embora este indicador tenha sido concebido para a avaliação do desempenho de toda a manufatura sob a perspectiva da estratégia de negócio (MUCHIRI; PITELON, 2008), na unidade em questão, a gerência optou por inicialmente considerá-lo no âmbito intermediário de uma linha de produção, introduzindo assim o indicador que no presente trabalho foi denominado de OPEL.

Na Fase 3, o grupo multifuncional ampliado se reuniu diariamente para avaliar os indicadores de OEEL, OPEL e volume de produção. Sempre que uma meta diária não era atingida, o grupo analisava os problemas ocorridos, identificava suas causas e estabelecia ações para reduzir as perdas relacionadas. $O$ desdobramento dessas ações foi acompanhado sistematicamente para garantir a sua realização. Os gerentes e diretores interessados na evolução dos esforços que buscavam melhores resultados para o negócio passaram a ser informados por meio de relatórios diários sobre os ganhos obtidos e ações que precisavam contar com maior apoio da liderança.

A medição conjunta do OEEL e do OPEL permitiu que análises e tomadas de decisão de nível mais estratégico envolvendo a cadeia de valor do produto pudessem ser realizadas. As ações tomadas para evitar paradas de produção por falta de capacidade de armazenagem ilustram bem isso. Este problema é causado pela sazonalidade da demanda no mês que resulta no acúmulo de cerca de $60 \%$ do faturamento mensal na última semana. Para atender este pico de vendas, o PCP procura antecipar a produção necessária distribuindo-a no decorrer das semanas anteriores de modo a racionalizar a ocupação da capacidade instalada. Contudo, frequentemente, os armazéns ficavam lotados no meio do mês obrigando as linhas 
afetadas a parar, e isso comprometia o cumprimento do plano de produção e o pleno atendimento da carteira de pedidos. A medição pelo OPEL trouxe uma percepção mais clara do impacto causado por tais paradas. Um estudo conduzido pelo grupo multifuncional demonstrou ser mais vantajoso à empresa investir no aumento e adequação de seus armazéns do que conviver com as perdas e despesas (e.g. uso de armazéns externos, transportes extras de produto, ineficiência de partida de produção) causadas por tais paradas de produção.

A intensificação dos esforços de Marketing que contribuíram para aumentar as vendas, a racionalização do procedimento de limpeza de linha sob a supervisão da Engenharia e validação da área de Qualidade, bem como a melhor programação dos testes de novos produtos e uma revisão das formulações do mix de produtos que reduziram o tempo das paradas de linha requeridas pelo $P \& D$, são também evidências de ações que puderam ser efetivadas com a implementação da avaliação balizada no OPEL. A análise do desempenho da manufatura sob uma visão mais sistêmica e a mobilização de um grupo multifuncional competente na sua gestão possibilitaram uma sensível melhora nos resultados de OPEL (ver Figura 13), notadamente, a partir da semana 18 (em Agosto de 2008).

$\mathrm{Na}$ Figura 17, os gráficos de pizza ilustram a evolução das perdas que não consideradas pelo OEEL. Na Fase 1, tais perdas representavam $28 \%$ do total e as perdas de disponibilidade, desempenho e qualidade representavam $25 \%$. Ao atuar sobre as perdas com impacto no OEEL o grupo multifuncional percebeu uma redução destas, na Fase 2, para 17\%, contudo observa-se que o tempo com valor agregado aumenta de $47 \%$ para apenas $49 \%$, evidenciando que o tempo de perdas que não impactam no OEEL era muito mais significativo.

Assim, observa-se, por estes gráficos, que ao realizar as ações para eliminação das causas que não são consideradas pelo OEEL, o grupo de FT conseguiu que a porcentagem do tempo total representada por estas perdas fosse reduzida de 14\% entre as Fases 2 e 3 e, sua continuidade possibilitou atingir uma redução adicional de 15\% entre as Fases 3 e 4, tornando-as responsáveis por grande parcela do salto registrado no OPEL. 


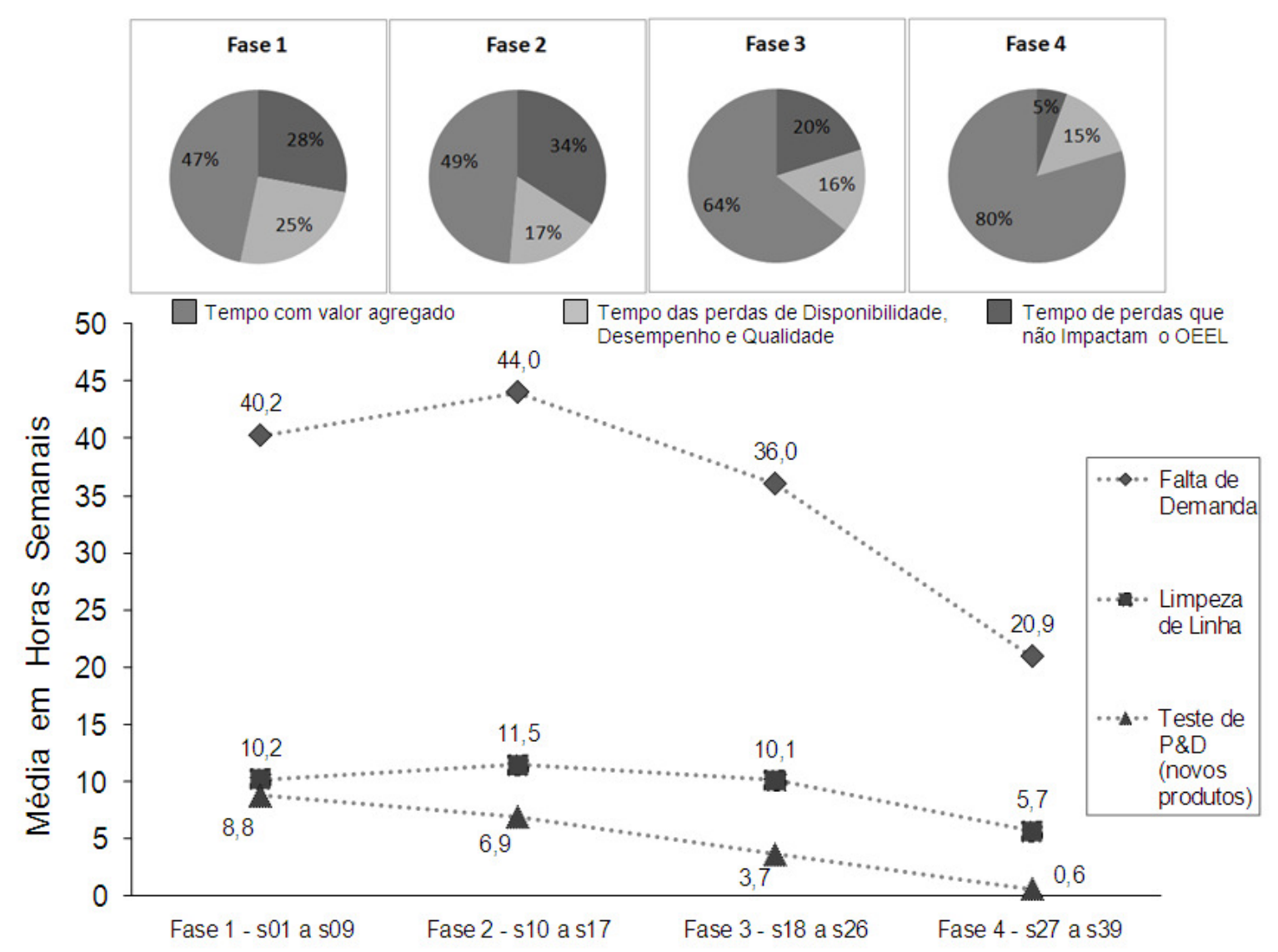

Figura 17 - Evolução das principais paradas que não afetam o OEEL, mas medidas pelo OPEL. Fonte: Busso e Miyake (2012)

Essas perdas foram reduzidas focando as principais paradas identificadas pelo OPEL: Falta de Demanda, Limpeza de Linha e Testes de P\&D (novos produtos). Para cada uma dessas perdas foi identificada a sua causa e buscou-se soluções para eliminar o problema conforme é descrito a seguir:

- Falta de Demanda: a sazonalidade da demanda do negócio com concentração de vendas no fim de cada mês impactava na ocupação dos armazéns que ficavam cheios e isso motivava paradas de produção em tais períodos por falta de espaço para armazenagem. Isso foi reduzido através de uma ação da área comercial que atuou junto ao mercado na busca por clientes menores que pudessem absorver a produção durante as primeiras semanas do mês, melhorando assim o nivelamento das vendas e consequentemente da produção, sem precisar investir em aumento da capacidade de armazenagem. Ainda assim, houve utilização de estoques de 
terceiros para complementar a capacidade de armazenagem durante alguns dias do mês até que a ação da área comercial se tornasse efetiva.

- Limpeza de Linha: trata-se de uma perda sob a responsabilidade da Produção e da área de Qualidade que não pode ser totalmente eliminada, devido aos requisitos de segurança alimentar, mas que pode ser reduzida através de uma análise do processo de limpeza e otimização de suas atividades de forma a reduzir as perdas em espera por materiais e recursos para limpeza.

- Testes de P\&D: esta perda foi reduzida com a revisão do processo de desenvolvimento de novos produtos, no qual as etapas preliminares foram refinadas para ao necessitar parar a produção para testes, a parada fosse realizada em menor tempo e com maior eficácia.

Vale salientar que durante a Fase 3, o grupo multifuncional concentrou-se na melhoria dos resultados de OPEL sem, contudo descuidar-se de manter os resultados de OEEL no patamar relativamente elevado (cerca de $80 \%$ ) que havia alcançado no final da Fase 2 valendo-se da melhor integração da Produção com as áreas de Manutenção e Qualidade.

$\mathrm{Na}$ Fase 4, conseguiu-se atingir um nível de OPEL superior a $80 \%$ na $\mathrm{L} 2$, indicando que seus maiores problemas haviam sido superados e, assim, as necessidades de intervenção do grupo multifuncional tornaram-se menos frequentes.

Esta abordagem de gestão mais integrada baseada no monitoramento do OEEL e OPEL foi reconhecida pela alta direção como meio-chave para racionalizar a utilização da capacidade de produção das linhas, e assim ela decidiu estender sua aplicação à gestão das demais três linhas. Nestas linhas, a adoção do controle de perdas pela medição destes indicadores motivou também o desdobramento de ações efetivas visando a um uso mais eficiente da capacidade de produção das mesmas. 
Uma vez implantada a avaliação pelo OEEL e OPEL em todas as linhas, o desenvolvimento do sistema de avaliação de desempenho avançou para o estabelecimento da medição do desempenho global da fábrica e da manufatura, adotando-se para isso o OTE, como uma derivação do OEE para a medição da utilização da capacidade de toda a fábrica, mas ainda considerando somente as perdas por causas operacionais. Analogamente, para medir as perdas cuja responsabilidade recai sobre as áreas funcionais além da fábrica, optou-se por medir o OPE, como uma derivação do OPEL. Tanto o OTE como o OPE são indicadores que, conforme sugerem Muchiri e Pintelon (2008) são alternativas para a avaliação do desempenho num nível mais global.

Para o cálculo do OTE e do OPE na unidade objeto de estudo foram definidas, respectivamente, a Equação 23 - obtida da expansão da Equação 8 - e a Equação 24, conforme seguem, observando a existência de 4 linhas em paralelo (n $=4)$ :

$$
\begin{aligned}
& \text { OTE }=\frac{\sum_{i}^{n} V_{i}}{\sum_{i}^{n}\left(\mathrm{TC}_{\mathrm{i}} \times \mathrm{Cp}_{\mathrm{i}}\right)} \\
& \mathrm{OPE}=\frac{\sum_{\mathrm{i}}^{\mathrm{n}} \mathrm{V}_{\mathrm{i}}}{\sum_{\mathrm{i}}^{\mathrm{n}}\left(\mathrm{TT}_{\mathrm{i}} \times \mathrm{Cp}_{\mathrm{i}}\right)}
\end{aligned}
$$

na qual:

$V_{i}=$ Volume produzido pela linha i no período

$\mathrm{TC}_{\mathrm{i}}=$ Tempo de carregamento da linha i no período (em horas)

$\mathrm{TT}_{\mathrm{i}}=$ Tempo total da linha i no período (em horas)

$C p_{i}=$ Capacidade de produção por hora da linha i no período

$\mathrm{n}=$ número de linhas na fábrica 
$\mathrm{Na}$ segunda etapa de coleta de dados do presente trabalho, foram obtidos valores para estes indicadores medidos no período de Julho de 2010 a Dezembro de 2010. Na Figura 18 são apresentados os resultados de OTE da fábrica juntamente com os dados de OEEL de cada uma das quatro linhas neste segundo período.

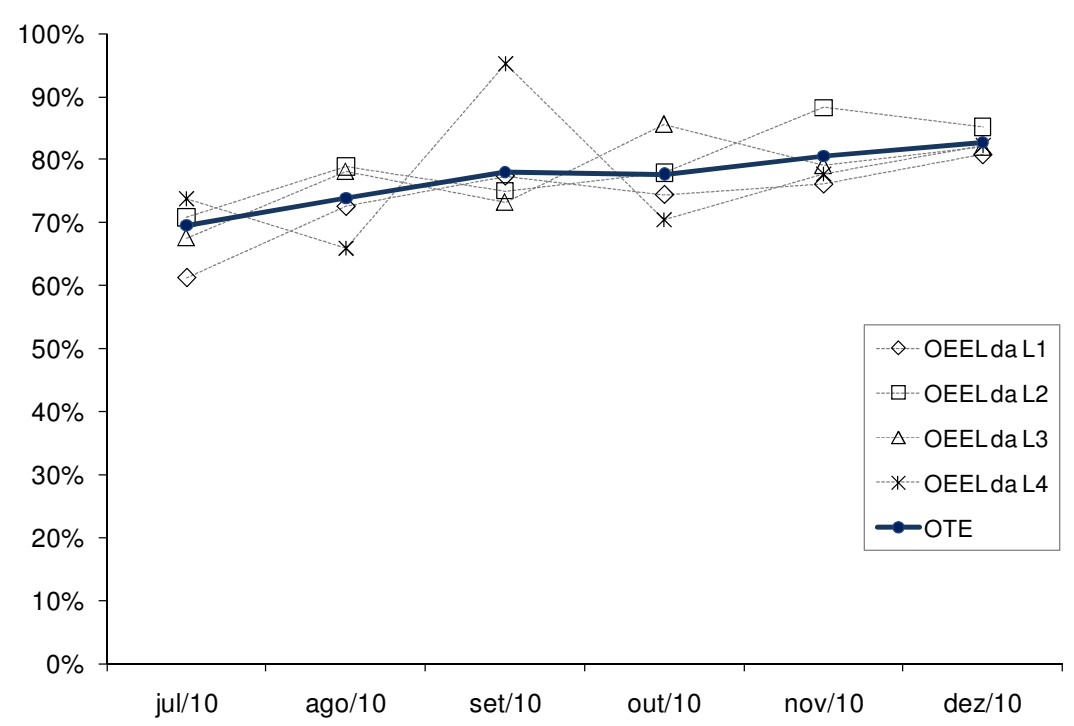

Figura 18 - Evolução do OTE da fábrica e do OEEL das 4 linhas de produção no período de Julho a Dezembro de 2010. Fonte: Busso e Miyake (2012)

Analogamente, na Figura 19 são apresentados os resultados de OPE de toda a manufatura juntamente com os dados de OPEL das linhas L1 a L4. 


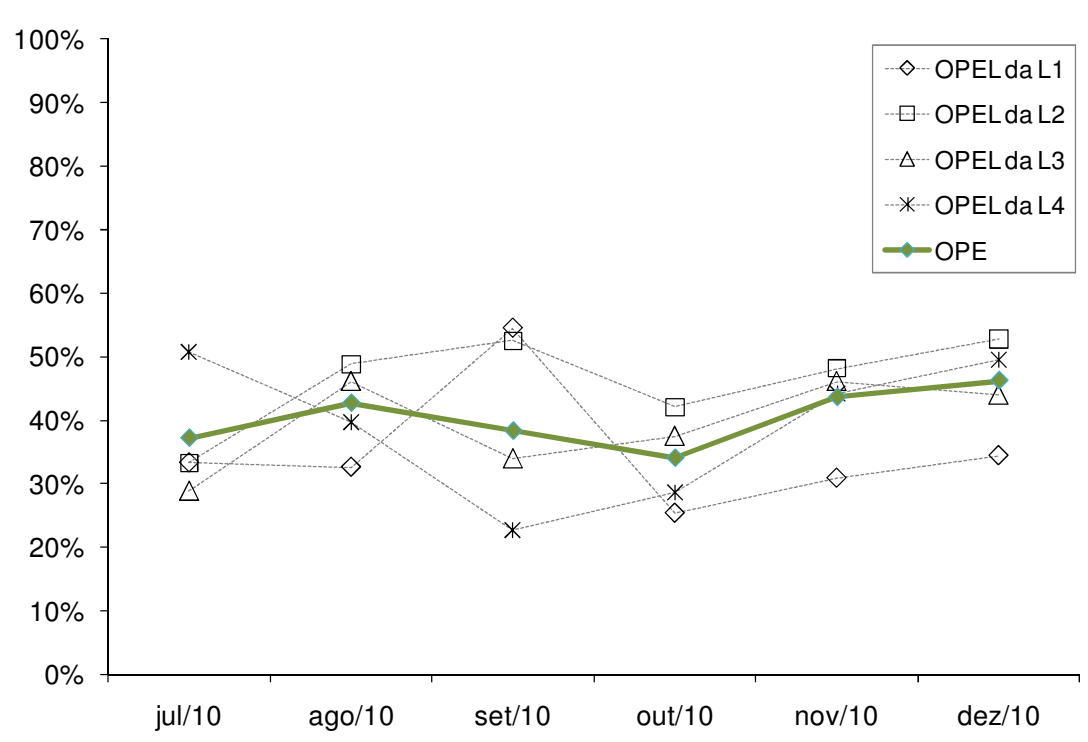

Figura 19 - Evolução do OPE da fábrica e do OPEL das 4 linhas de produção no período de Julho a Dezembro de 2010. Fonte: Busso e Miyake (2012)

No segundo período, observou-se que a manufatura como um todo operou com valores de OPE inferiores ao OPEL de cerca de $80 \%$ que a $\mathrm{L} 2$ havia atingido na Fase 4 do primeiro período. Isso se deveu, sobretudo a um aumento das paradas de linha por falta de demanda causado por estratégias comerciais que se mostraram infrutíferas. Já os resultados de OTE da fábrica variaram entre 70 e $80 \%$, tendo ficado acima do OEEL de cerca de $65 \%$ observado na $L 2$ na fase inicial do primeiro período.

Vale notar que para a L2, onde se iniciou a implementação do sistema de avaliação do desempenho global e que se encontra num estágio mais avançado de controle das perdas de produção, no segundo período, a média de seus resultados de OEEL medidos mensalmente $(79,4 \%)$ foi superior à média dos resultados de OTE da fábrica (77,1\%). Além disso, como se pode observar na Figura 19, a L2 foi mais bem sucedida no controle dos impactos causados por perdas não consideradas pelo OEE tendo alcançado um valor médio de OPEL (46,3\%) maior que o valor médio de OPE $(40,3 \%)$ de toda a manufatura. 


\subsection{Análise do Caso}

\subsubsection{Análise do processo de implementação}

Somente a análise do OEEL de uma linha ou do OTE pode não possibilitar a identificação da principal causa de variação do volume produzido, respectivamente, pela linha ou pela fábrica a que se referem. No caso estudado, o total das perdas não consideradas pelo OEE como paradas planejadas e por outras causas além da alçada dos gestores responsáveis pela operação das linhas de produção era significativo e a magnitude de seu impacto só pode ser medida pela adoção de indicadores que têm uma perspectiva mais ampla das possíveis perdas como o OPEL e OPE.

O caso revela que o entendimento coletivo do que consiste o desempenho global em uma organização é algo complexo e demanda substancial esforço de aprendizagem. Na Figura 20, é apresentada a trajetória percorrida no caso para o desenvolvimento do sistema de medição buscado pela empresa. No primeiro período, a abordagem de medição do OEE foi inicialmente ampliada horizontalmente para passar a avaliar o desempenho de subsistemas como linhas e não de recursos elementares como máquinas. Em seguida, ela foi expandida verticalmente para abarcar perdas não consideradas pelo OEE. Uma vez estabelecida a medição do OEEL e OPEL no âmbito de cada linha, no segundo período, a abrangência do sistema a ser avaliado foi então ampliada para passar a avaliar o desempenho no âmbito da fábrica e no âmbito global da manufatura pela adoção, respectivamente, do OTE e OPE. 

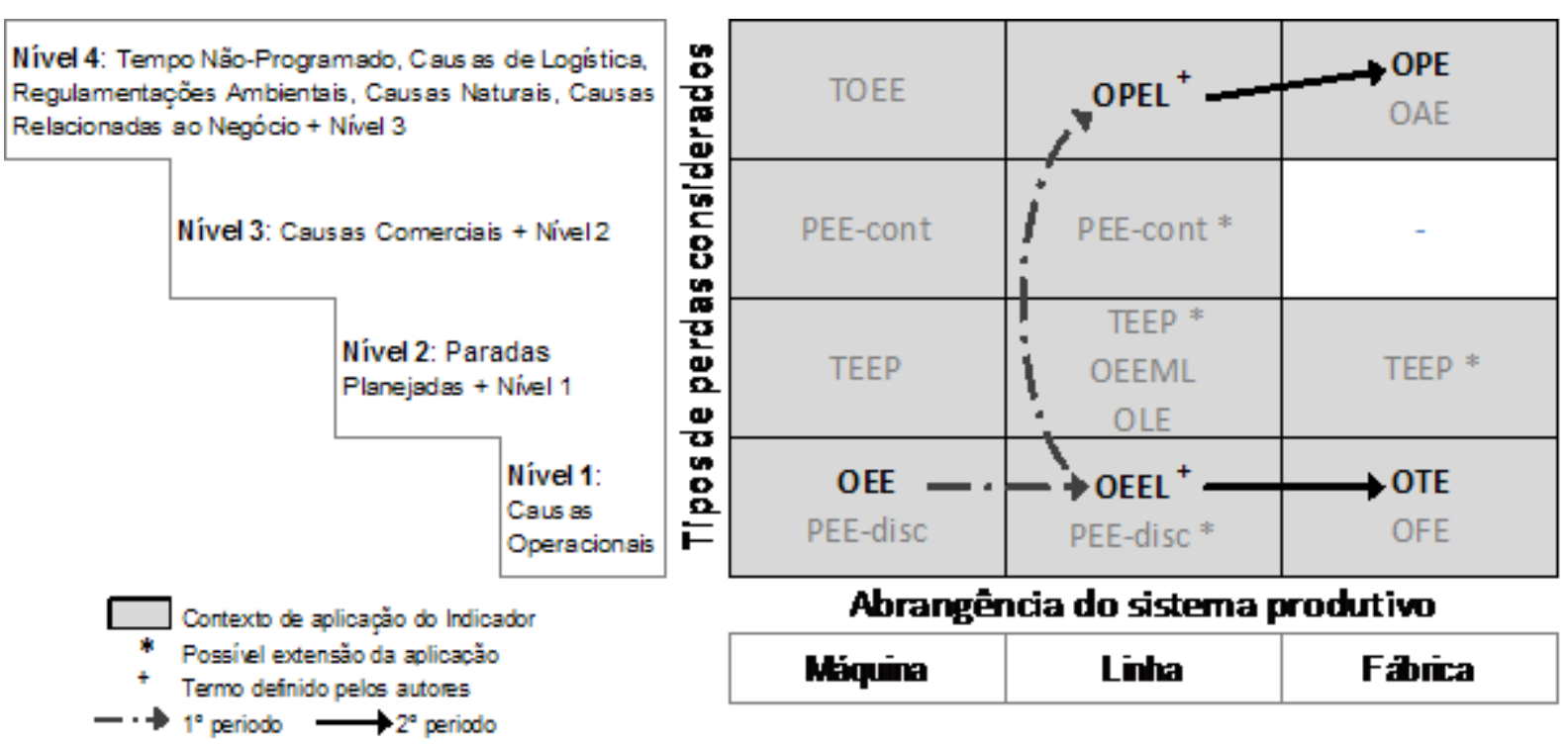

Figura 20 - Indicadores aplicados pela unidade objeto de estudo. Fonte: Busso e Miyake (2012)

O caso estudado permitiu a identificar algumas etapas fundamentais para orientar a articulação do processo de implementação de um indicador de avaliação global da utilização da capacidade de produção, conforme seguem:

$1^{\underline{a}}$ etapa - Alinhamento com o objetivo estratégico: conforme sugere Kaydos (1999 apud Mathur et al. 2011), as medições podem ser um bom meio de comunicação da estratégia da companhia para toda organização. No caso estudado, observou-se que para atender ao objetivo estratégico de aumento de vendas, foi desdobrado um projeto para a área de manufatura para buscar uma melhor utilização da capacidade nominal, além de reduzir a diferença entre a capacidade disponível e a capacidade real. Por meio de ações como esta, direcionadas ao objetivo da empresa, foi possível mobilizar toda a organização em direção à estratégia determinada pela empresa.

$2^{2}$ etapa - Seleção e adaptação de indicador(es) a partir da definição dos objetivos da empresa e seus desdobramentos para a manufatura e condução de um processo que possibilite implementá-los efetivamente como ferramenta de gestão. 
$3^{\mathrm{a}}$ etapa - Estabelecimento de uma dinâmica de identificação/resolução de problemas que envolva a formação de um grupo multifuncional para gestão, monitoramento e tomada de decisões com base nos resultados do(s) indicador(es) focado(s).

4aㅡ etapa - Estruturação do processo de análise e tratamento das causas de perdas.

As medidas que foram tomadas nas etapas 3 e 4 são exemplos práticos de que a estruturação de grupos multifuncionais para análise de indicadores possibilita à gerência delegar aos mesmos maior responsabilidade e autoridade para identificar as causas dos problemas que comprometem o desempenho global e propor e implementar melhorias, conforme sugerem Bamber et al. (2003).

5 etapa - Ampliação da abrangência do indicador: no Estudo de Caso, dada a constatação de que apesar do sensível incremento de OEEL observado na L2 nas Fases 1 e 2 as metas de aumento de produção não seriam alcançadas pela fábrica, a gerência decidiu passar a analisar as paradas não programáveis ou não planejadas. Tais paradas constituíam perdas que estavam ocultas, mas ficaram evidentes nas Fases 3 e 4 . Além da ampliação da abrangência das perdas a serem controladas, o caso mostrou também a aplicação de indicadores com abrangência para medir o desempenho de toda a fábrica.

Vale salientar que a iniciativa de ampliação da abrangência dos indicadores de utilização da capacidade de produção que foi observada na quinta etapa do processo de implementação do sistema de medição e avaliação do desempenho global da manufatura no caso estudado representa uma contribuição da pesquisa realizada, dado que se trata de um tópico que ainda não havia sido tratado em profundidade por nenhum dos trabalhos identificados na revisão bibliográfica discutida na seção 3.4 .

\subsubsection{Análise dos indicadores implementados}

O OEE é um indicador relativamente restrito que considera somente a eficácia na utilização da capacidade de produção correspondente ao tempo de 
carregamento, na nomenclatura de Elmaghraby (1991). O OEE se limita a mostrar a diferença entre a capacidade planejada e a capacidade real, para um único equipamento ou linha, mas isso não desmerece a sua aplicabilidade. No próprio caso estudado, as medições baseadas na conceituação do OEE foram suficientes para que, na Fase 1 do primeiro período, a gerência pudesse estabelecer uma referência inicial para a eficácia produtiva de uma linha de produção em que foi instituída a medição pelo OEEL e, na Fase 2, conseguisse direcionar esforços de redução das perdas operacionais incrementando os resultados deste indicador em cerca de $14 \%$ na linha piloto. Destarte, quando é preciso se concentrar na redução das perdas de Disponibilidade, Desempenho e Qualidade no âmbito de uma dada máquina ou linha, a conceituação do OEE ou OEEL pode ser efetivamente aplicada para balizar o planejamento e direcionamento de melhorias.

Já para se buscar uma utilização ainda maior da capacidade nominal, é preciso adotar ferramentas de medição que possam relacionar as influências de outras áreas da organização sobre a operação das linhas e da fábrica e em última instância da manufatura como um todo. Isso possibilita vislumbrar meios para reduzir as paradas planejadas e outras paradas causadas por fatores externos à competência da área operacional. No caso estudado, o OPEL (referente à linha) e o OPE (referente à fábrica) foram bem aplicados com esta função e isso propiciou que partes diferentes da cadeia de valor passassem a atuar de forma mais integrada e melhor alinhada aos objetivos estratégicos da empresa. Conforme enfatizado por Tangen (2002 apud Mathur et al., 2011) esta é uma das características importantes que um indicador de desempenho global deve possuir.

Vale salientar que estes dois indicadores são bastante afetados por tendências de mercado e das vendas contribuindo para evidenciar o impacto das estratégias Comercial e de Marketing sobre o desempenho da Produção.

Em relação à aplicação de indicadores agregados como OTE e OPE, como no segundo período do caso estudado, observa-se que os mesmos servem basicamente para informar a alta direção qual foi o nível de utilização geral da capacidade nominal no âmbito de uma unidade de manufatura. Ao final do segundo período, a alta direção da empresa já dispunha de dados de OTE e OPE não apenas da unidade focada no estudo de caso, como também de outras fábricas controladas por ela. Isso tornou possível avaliar comparativamente o desempenho das diversas 
unidades ajudando a obter uma visão estratégica da situação da manufatura no âmbito de toda a empresa.

Contudo, em fábricas constituídas por um conjunto de linhas como a analisada no caso, resultados de OTE e OPE não necessariamente refletem bem a situação de cada linha. Assim sendo, para subsidiar tomadas de decisão e direcionar a atuação dos gestores responsáveis por racionalizar a utilização da capacidade, é indispensável manter a medição do OEEL e OPEL estratificada por linhas como sugerem as Figuras 18 e 19. Tal visão possibilita enxergar em cada momento a natureza da contramedida a ser priorizada, e.g. aumento do OEEL ou do OPEL, e para qual linha os esforços e recursos para melhoria devem ser direcionados dada a variação da magnitude das perdas que afetam estes indicadores nas linhas consideradas. 


\section{Conclusões}

\subsection{Conclusões relacionadas com o objetivo do trabalho}

Esta pesquisa baseou-se na premissa evidenciada na revisão bibliográfica de que, conforme sugerem diversos autores, o OEE revela limitações quando aplicado sob circunstâncias e propósitos bem distintos daqueles considerados na sua conceituação inicial. Por exemplo, a aplicação do OEE estendido em um sistema de produção mais amplo não é suficiente para verificar possíveis causas de ineficiências no aproveitamento da capacidade produtiva global por não reconhecer outras perdas, além das que estão definidas em seu conceito. Estas e outras limitações identificadas na pesquisa bibliográfica estão resumidas na Tabela 6.

Ao utilizar os critérios de Johsson e Lesshammar (1999) para examinar a adequação do OEE enquanto um indicador de desempenho global da manufatura, observa-se que ele não atende aos critérios de orientação do fluxo e eficácia externa, e que satisfaz os outros critérios de forma superficial, como mostra a Tabela 5.

O objetivo da pesquisa realizada foi verificar a existência de indicadores derivados do OEE que possibilitassem as empresas aprimorar a medição do desempenho sistêmico e identificar suas principais características. Deste objetivo foram elaboradas duas questões de pesquisa.

A primeira questão, Q1, visou à elucidação da seguinte indagação: "Quais são os indicadores derivados do OEE para possibilitar uma medição mais abrangente do desempenho da manufatura?". O levantamento realizado na revisão da literatura permitiu detectar diversos indicadores derivados do OEE, que apresentam derivações no nível de abrangência do sistema produtivo considerado máquina, linha, fábrica - e/ou derivações em relação à abrangência da classificação de perdas que considera. Estas derivações implicam em formas de cálculo diferentes, porém todos os indicadores identificados foram propostos com a mesma motivação de serem utilizados na melhoria da utilização da capacidade nominal e redução da diferença entre a capacidade planejada e a capacidade real (ver os conceitos de capacidade definidos por Elmaghraby (1991)). 
Esses indicadores foram organizados nas Figuras 9 e 10 a partir das quais foi originada a Figura 11, que auxilia a escolha de um indicador conforme as características do sistema de produção que se deseja avaliar e o que se deseja evidenciar no desempenho da manufatura.

Para responder a segunda questão, Q2, "Como se caracterizam os indicadores derivados do OEE enquanto possíveis instrumentos para balizar 0 sistema de medição do desempenho global da manufatura?" tomou-se como base o modelo de análise de Johsson e Lesshammar (1999). Esta análise revelou que os indicadores que podem ser melhor aplicados como indicador de desempenho global da manufatura são o OPE e o OAE, pois adotam uma classificação de perdas que considera a influência de outras áreas funcionais da organização e, além disso, é um indicador bastante representativo da fábrica.

Esta pesquisa procurou destacar a importância dos seguintes pontos:

1. definição da abrangência ("fronteira") do sistema produtivo objeto de análise,

2. definição do escopo da classificação de perdas que melhor se adéqua à natureza das perdas que afetam as operações da empresa,

3. estabelecimento de uma dinâmica de identificação/resolução de problemas que envolva representantes-chave das áreas relacionadas. $A$ matriz apresentada na Tabela 8 foi estruturada neste trabalho para subsidiar a busca de um indicador adequado em função dos pontos 1 e 2 acima.

Com o objetivo de ilustrar como indicadores de desempenho global da manufatura podem auxiliar os gestores nas tomadas de decisão para a melhor utilização da capacidade produtiva de seus recursos de forma a garantir uma vantagem competitiva, foi realizado um Estudo de Caso que mostra como uma abordagem de gerenciamento mais sistêmico do sistema produtivo, balizada em indicadores globais como o OPEL e OPE, favorece a concatenação de ações entre a manufatura, suas áreas de apoio e outras áreas da cadeia de valor para se obter uma utilização mais efetiva de seus recursos e contribuir na busca de resultados melhores ao negócio. Isso corrobora a proposta da utilização de indicadores mais abrangentes que o OEE, ou como no caso, o OTE quando a utilização da capacidade torna-se crítica ao desempenho global de uma unidade de manufatura. 
O estudo de caso possibilitou identificar de diversos cuidados gerenciais que devem ser tomados para selecionar e implementar indicadores. Independentemente do indicador medido, o resultado numérico por si só não passa de mera informação. O histórico de cerca de nove meses de uso sistemático do OEEL e OPEL como indicadores no primeiro período do caso estudado ilustra bem o grande envolvimento que a gerência deve demonstrar para que, a partir das informações assim obtidas, ações de melhoria e controle sejam realmente desdobradas e deste modo conseguir que uma nova prática como esta seja consolidada.

A decisão de qual linha focar numa iniciativa de melhoria do desempenho da manufatura depende da estratégia da empresa naquele momento, já que cada linha pode produzir um produto ou uma família de produtos específica.

Assim, para medir o desempenho global da manufatura os indicadores de maior abrangência nos níveis de classificação de perdas, são os que mais auxiliam no alcance do objetivo do negócio, pois captam a influência de áreas funcionais da empresa. Foi possível observar no caso estudado que, nas Fases 1 e 2, a criação de um grupo multifuncional, composto pela Produção, Qualidade e Manutenção, permitiu ações nas perdas que impactam o OEEL, porém não resultou no aumento de produção esperado.

Assim, a partir da Fase 3, com a estruturação de um grupo de solução de problemas, do tipo $\mathrm{FT}$, foi possível atuar em causas que mais impactavam na utilização da capacidade de manufatura, permitindo assim aumentar o volume de produção. A ampliação da abrangência do indicador aplicado na medição do desempenho pela adoção do OPEL, se fez necessária, pois isso veio a permitir melhor visualização das perdas internas às áreas da manufatura e das perdas provocadas por áreas funcionais que podem exercer influência sobre o desempenho da manufatura como P\&D, Marketing, entre outras.

A forma de definição dos membros do grupo de trabalho do tipo $\mathrm{FT}$, durante a Fase 3 , suas responsabilidades e papéis para a implementação das ações decorrentes de decisões tomadas por este grupo, as ferramentas aplicadas no tratamento de perdas e o acompanhamento dos resultados assumido pela alta direção foram cruciais para o alcance das melhorias identificadas no caso estudado, 
conforme sugerido por Shiba et al. (1997) e foram críticas para a efetiva implementação do sistema de medição do desempenho global da manufatura.

A literatura que se baseia na conceituação do OEE para propor um indicador de desempenho mais abrangente, em geral, concentra-se na concepção de um determinado modelo de cálculo. Esta pesquisa mostra que o projeto de um sistema de avaliação do desempenho global da manufatura não pode ficar limitado à seleção da melhor fórmula de cálculo a ser adotada na medição, já que a visão analítica requerida pode mudar com o tempo e as circunstâncias. O desafio reside, portanto no estabelecimento de um processo que permita à organização identificar e selecionar um modelo de indicador com uma estrutura que reflita a realidade e as necessidades de seu sistema de produção e torná-lo operacional.

Outro ponto relevante que deve ser observado é a questão de que ainda que o indicador de desempenho global da manufatura, como o OPE seja utilizado para gestão no nível estratégico da empresa, a gestão de indicadores desdobrados ao nível de linha (ex. OPEL) ou equipamento (ex. OEE), auxiliam no refinamento do foco do que controlar ou do que melhorar, principalmente em casos em que há restrição de orçamento para investimento na área de manufatura e as melhorias são a alternativa para melhoria do desempenho global de uma linha ou da fábrica.

\subsection{Limitações do trabalho}

Uma limitação deste trabalho reside no fato de que na unidade focada no estudo de caso, a variedade de produtos é pequena e as linhas são independentes operando em fluxo contínuo unidirecional. A abordagem de medição do desempenho global apresentada precisa, portanto, ser considerada com ressalvas e/ou adaptações no projeto do sistema de medição em sistemas produtivos mais complexos.

Além disto, nem todas as alternativas de indicadores derivados do OEE identificados e comparados na Tabela 8 puderam ser avaliadas neste estudo de caso. 


\subsection{Propostas de continuidade da pesquisa}

Uma possível extensão do presente estudo parte da limitação do estudo de caso ter tratado da utilização da capacidade em linhas de produção de fluxo contínuo unidirecional. Assim vale destacar a necessidade de considerar aspectos como a variação de roteiros de produção, organização do layout de equipamentos por processo (e não por produto) e a existência de estoques intermediários, que podem influenciar a forma de ponderação e consolidação de dados para medição de indicadores globais.

$\mathrm{Na}$ revisão da literatura sobre aplicações do OEE foi constatada uma carência de trabalhos que discutem o que é um bom resultado de OEE ou quando esforços de melhoria precisam ser realizados devido ao resultado de OEE estar muito aquém do nível que poderia ser atingido por um dado tipo de sistema de manufatura. Assim, outra proposta de continuidade da pesquisa seria desenvolver critérios para a definição de valores esperados de OEE conforme o tipo de manufatura, auxiliando assim os responsáveis pelo resultado medido por este indicador no balizamento da meta a ser buscada pela organização. 


\section{REFERÊNCIAS}

ANDERSSON, P.; ARONSSON, H.; STORHAGEN, N.G. Measuring logistics performance. Engineering Costs and Production Economics, v.17, pp. 253-62, 1989.

ANDERSSON, T.D. Traditional key ratio analysis versus data envelopment analysis: a comparison of various measurements of productivity and efficiency in restaurants. Productivity Management in Hospitality and Tourism, London: Cassell,, pp. 209-26, 1996.

BALEY, D.E. Manufacturing Improvement Team Programs in the Semiconductor Industry. IEEE Transactions on Semiconductor Manufacturing, v.10, n.1, pp. 1-10, 1997.

BAMBER, C.J.; CASTKA, P.; SHARP, J.M.; MOTARA, Y. Cross-functional team working for overall equipment effectiveness (OEE). Journal of Quality in Maintenance Engineering, v.9, n.3, pp. 223-238, 2003.

BARNEY, J. Firm resources and Sustained Competitive Advantage. Journal of Management, v.17, n.1, pp 99-120, 1991.

BOHORIS, G.A.; VAMVALIS, C.; TRACEY, W.; IGNATIADOU, K. TPM implementation in Land-Rover with the assistance of a CMMS. Journal of Quality in Maintenance Engineering, v.1, n.4, pp. 3-16, 1995.

BRAGLIA, M.; FROSOLINI, M.; ZAMMORI, F. Overall Equipment effectiveness of a manufacturing line (OEEML) - an integrated approach to assess systems performance. Journal of Manufacturing Technology Management, v.20, n.1, pp. 8-29, 2009.

BUSSO, C.M.; MIYAKE, D.I.; Integração entre o Lean e o Six Sigma pela análise de Mapas Estratégicos. XXIX Encontro Nacional de Engenharia de Produção. Salvador, BA, 2009.

BUSSO, C.M.; MIYAKE, D.I.; Análise da aplicação de indicadores alternativos ao Overall Equipment Effectiveness (OEE) na gestão do desempenho global de uma fábrica. Revista Produção, São Paulo, 2012. No prelo. 
CHAND, G.; SHIRVANI, B. Implementation of TPM in cellular manufacture. Journal of Material Processing Technology, v.103, pp. 149-154, 2000.

CORREAA, H.L. The links between uncertainty, variability of outputs and flexibility in manufacturing systems. Warwick, 317p.,1992.

DANGAYACH, G.S.;DESHMUKH, S.G. Evidence of manufacturing strategies in Indian Industry: a survey. International Journal of Production Economics, v. 83, pp. 279-298, 2003.

ELMAGHRABY, S.E. Manufacturing Capacity and its measurement: a critical evaluation. Computers Operation Research, v.18, n.7, pp 615-627, 1991.

FLEISCHER, J.; WEISMANN, U.; NIGGESCHMIDT, S. Calculation and Optimization model for costs and effects of availability relevant service elements. Proceedings of LCE2006, 2006.

GAGNON, S. Resource-based competition and the new operations strategy. International Journal of Operations \& Production Management, v.19, n.2, pp. 125138, 1999.

GHALAYINI, A.M.; NOBLE, J.S.; The changing basis of performance measurement. International Journal of Operations \& Production Management, v.16, n.8, pp. 63-80, 1996.

GHALAYINI, A.M.; NOBLE, J.S.; CROWE, T.J. An integrated dynamic performance measurement system for improving manufacturing competitiveness. International Journal of Production Economics, v.48, pp. 207-225, 1997.

GIBBONS, P.M.; BURGESS, S.C. Introducing OEE as a measure of lean six sigma capability. International Journal of Lean Six Sigma, v.1, n.2, pp.134-156, 2010.

GOLD.B. Technology, Productivity, and Economic Analysis. The International Journal of Management Science, v.1, n.1, pp.5-24, 1973.

GOUVEIA DA COSTA, S.E; PINHEIRO DE LIMA, E. Uses and misuses of the 'overall equipment effectiveness' for production management. Engineering Management Conference, v. 2, pp. 816-820, 2002. 
GUZZO, R.A; DICKSON, M.W. Teams Organizations: Recent Research on Performance and Effectiveness. Annu.Rev, Psychol., 47, pp 307-338, 1996.

HAFEEZ, K., ZHANG, Y; MALAK, N. Core competence for sustainable competitive advantage: a structured methodology for identifying core competence. IEEE Transactions on Engineering Management, v. 49 No. 1, pp. 28-35, 2002.

HÖGFELDT, D. Plant efficiency: a value stream mapping and overall equipment effectiveness study. 93 p. Master Thesis (Master of Science Programme Mechanical Engineering) - Department of Applied Physics and Mechanical Engineering Luleå University of Technology, Luleå, 2005.

JAVIDAN, M. Core Competence: What Does it Mean in Practice? Long Range Planning, v.31, n.1, pp.60-70, 1998.

JONSSON, P.; LESSHAMMAR, M. Evaluation and improvement of manufacturing performance measurement systems - the role of OEE. International Journal of Operations and Production Management, v.19, n.1, pp. 55-78, 1999.

JURIE, J.D. Building capacity - Organizational competence and critical theory. Journal of Organization Change Management, v.13, n.3, pp 264-274, 2000.

KWON, O.; LEE, H. Calculation methodology for contributive managerial effect by OEE as a result of TPM activities. Journal of Quality in Maintenance Engineering, v.10, n.4, pp. 263-272, 2004.

LIKER, J.K. O Modelo Toyota: 14 príncipios de gestão do maior fabricante do mundo. Porto Alegre: Bookman, pp. 46-47, 2005.

LIKER, J.K.; MEIER, D. Modelo Toyota: Manual de Aplicação. Porto Alegre: Bookman, pp. 285-290, 2007

LJUNGBERG, O. Measurement of overall equipment effectiveness as a basis for TPM activities, International Journal of Operations \& Production Management, v.18, n.5, pp. 495-507, 1998.

LJUNGQUIST, U. Specification of core competence and associated components - a proposed model and a case illustration. European Business Review, v.20, n.1, pp 7390, 2008. 
LOPES, M.L.M; MOLLO, M.L.R. Regime de Metas de Inflação, Regra de Taylor e Neutralidade da Molda - Uma crítica Pós Keynesiana. Recuperado em 29 de setembro de 2011, de http://www.sep.org.br.

MARTINS, R.A. Sistemas de Medição de Desempenho: um modelo para a estruturação do uso. 1998. 248p. Tese (Doutorado) - Escola Politécnica, Universidade de São Paulo, São Paulo, 1998.

MATHUR, A.; DANGAYACH, M.L.; SHARMA, M; SHARMA, M.K. Performance measurement in automated manufacturing. Measuring Business Excellence., v.15, n.1, pp 77-91, 2011.

MEREDITH, J. Building Operations Management Theory through case and field research. Journal of Operations Management, n.16, pp. 441-454, 1998.

MIGUEL, P.A.C; Metodologia de Pesquisa em Engenharia de Produção e Gestão de Operações. 1 ed. Rio de Janeiro: Elsevier, 2010.

MILLS, J.; NEELY, A,.:PLATTS, K.; GREGORY, M. Manufacturing strategy: a pictorial representation, International Journal of Operation and Production Management, v.18, n.11, pp. 1067-1085, 1998.

MUCHIRI, P.; PINTELON, L. Performance measurement using overall equipment effectiveness (OEE): literature review and practical application discussion. International Journal of Production Research, v.46, n.13, pp. 3517-3535, 2008.

MUSCAT, A.R.N. Produtividade e Gestão da Produção. Curso de Administração da Produtividade, Fundação Alberto Vanzolini, pp.1 -33, sem data (sd).

MUTHIAH, K.M.H.; HUANG, S.H. Overall Throughput Effectiveness (OTE) metric for factory-level performance monitoring and bottleneck detection. International Journal of Production Research, v.45, n.20, pp. 4753-4769, 2007.

MUTHIAH, K.M.N.; HUANG, S.H.; MAHADEVAN, S. Automating factory performance diagnostics using overall throughput effectiveness (OTE) metric. International Journal of Advanced Manufacturing Technology, v.36, n.7-8, pp. 811-824, 2008. 
NACHIAPPAN, R.M.; ANANTHARAMAN, N. Evaluation of Overall Line Effectiveness (OLE) in a continuous product line manufacturing system, Journal of Manufacturing Technology, v.17, n.7, pp. 987-1008, 2006

Inflação e Utilização da Capacidade Instalada - Outubro 2007. Recuperado em 27 de setembro de 2011, de http://www.fiesp.com.br/economia/pdf/nuci_inflacaoversao-final.pdf

NAKAJIMA, S. Introduction to Total Productive Maintenance (TPM) Cambridge: Productivity Press, 1989.

NEELY, A.; MILLS, J.; PLATTS, K., GREGORY, M.; RICHARDS, H. Realizing Strategy through Measurement. International Journal of Operations \& Production Management, v.14, n.3, pp. 140-152, 1994.

JEONG, K.Y.; PHILLIPS, D.T. Operational Efficiency and Effectiveness Measurement. International Journal of Operations \& Production Management, v.21, n.11, pp. 1404-1416, 2001.

OECHSNER, R.; PFEFFER, M.; PFITZNER, L.; BINDER, H.; MULLER, E.; VONDERSTRASS, T. From Overall Equipment Effectiveness to Overall Fab Effectiveness (OFE). Materials Science in Semiconductor Processing, v.5, pp. 333339, 2003.

RAOUF, A. Improving capital productivity through maintenance. International Journal of Operations \& Production Management, v.14, n.7, pp. 44-52, 1994.

RAPOSO, C.F.C. Overall Equipment Effectiveness: Aplicação em uma empresa do setor de bebidas do pólo industrial de Manaus. Revista Produção Online, v.11, n.3, pp. 648-667, 2011.

RON, A.J.; ROODA, J.E. Equipment Effectiveness: OEE Revisited. IEEE Transactions on Semiconductor Manufacturing, v.18, n.1, pp. 190-196, 2005.

SAKAKIBARA, S.; FLYNN, B.B.; SCHROEDER, R.G.; BATES, K.A.; FLYNN, J. Empirical Research Methods in Operations Management. Journal of Operations Management, v.9, n.2, pp.205-228, 1990. 
SANCHEZ, R. Understanding competence-based management: identifying and managing five modes of competence. Journal of Business Research, v.57 n. 5, pp. 518-32, 2004.

SCHROEDER, R.G. Operations Management: Decision Making in the Operations Function. New York: McGraw-Hill, 1985.

SHAHIN, A; MAHBOD, M.A. Prioritization of key performance indicators - An integration of analytical hierarchy process and goal setting. International Journal of Productivity and Performance Management, v.56, n.3, pp. 226-240, 2007.

SHIBA, S.; GRAHAM, A.; WALDEN, D. TQM: quatro revoluções da gestão da qualidade. 5. ed. Bookman, pp. 191-196, 1997.

SINK, D. S.; TUTTLE, T. C. Planning and measurement in your organization. Norcross, Industrial Engineering and Management Press, 1989.

SLACK, N.; CHAMBER, S.; HARDLAND, C.; HARRISON, A.; JOHNSTON, R. Administração da Produção. 2 ed. São Paulo: Atlas, 2002.

SLACK, N.; CHAMBERS, S.; JOHNSTON, R. Operations Management, 3rd ed., Pearson Education, Harlow, 2001.

STAUDT, F.H.; COELHO, A.S.; GONÇALVEZ, M.B. Determinação da capacidade real necessária de um processo produtivo utilizando a cadeia de Markov. Produção, v. 21, n.4, pp. 634-644, 2011.

SUMANTH, D.J. Productivity Measurement and Evaluation Models for Manufacturing Companies. 1979, 665p. Tese. Illinois Institute of Technology.

SUMANTH, D.J. Productivity Engineering and Management. New York: McGraw-Hill, 1985.

SUZUKI, T. TPM in process industries. New York: Productivity Press, 1994.

TANGEN, S. Analysing the requirements of performance measurement systems. Measuring Business Excellence, v. 9, n.4, pp. 46-54, 2005a.

TANGEN, S. Desmystifying productivity and performance. International Journal of Productivity and Performance Management, v 54, n.1, pp 34 - 46, 2005b. 
TAYLOR, B.W; DAVIS, R.K. Corporate productivity - getting it all together. Industrial Engineering, v. 9 No. 3, pp. 32-6, 1977.

TSAROUHAS, P. Implementation of total productive maintenance in food industry: a case study. Journal of Quality in Maintenance Engineering, v.13, n.1, pp.5-18, 2007.

VOSS, C; TSIKRIKTSIS, N.; FROHLICH, M. Case Research in operations management. International Journal of Operations \& Production Management, v.22, n.2, pp 195-219, 2002.

YIN, R. K., Estudo de Caso - Planejamento e Métodos, 3 ed. Bookman, 2005.

ZHANG, Q; VONDEREMBSE, M.A.; LIM, J. Manufacturing flexibility: defining and analyzing relationships among competence, capability, and customer satisfaction. Journal of Operations Management. v.21, pp. 173-191, 2003. 


\section{ANEXOS}

\section{ANEXO 1 - Mapa estratégico do segmento de fabricação de produtos alimentícios}

\section{Conceito de Mapa Estratégico e suas características}

Mills et al. (1998) observam que um meio para visualizar o desenvolvimento da estratégia numa organização seria a representação gráfica. $O$ benefício oferecido por esta ferramenta é que através da representação gráfica é possível registrar formalmente as informações consideradas para consultá-las no momento da definição de uma nova estratégia ou do alinhamento da estratégia existente.

Por este motivo, estes autores sugerem a utilização do Mapa Estratégico que além de dar maior consistência à avaliação do processo da formulação estratégica, pode ser útil na revisão da estratégia de manufatura ou, simplesmente, para o aprendizado do processo de planejamento estratégico através da experiência.

O Mapa Estratégico é formado por registro dos eventos estratégicos que consideram as decisões operacionais para apoiar as estratégias de manufatura e/ou de negócios que estejam relacionadas com objetivos da empresa como, por exemplo, redução de custos, melhoria da qualidade e flexibilidade. No Mapa Estratégico estas decisões operacionais são representadas por caixas coloridas, cuja cor identifica a área de decisão relacionada. A identificação de potenciais interações entre as principais áreas de decisão em uma organização empresarial identificadas com base em critérios como os propostos por Hayes et al. (1998 apud Mills et al., 1998) (i.e. tecnologia de processo, recursos humanos, integração vertical, controle de produção, organização, medição de desempenho, qualidade, utilização da capacidade e instalações) pode resultar no registro de eventos multicoloridos. Nem todos os eventos podem estar relacionados a alguma área de decisão. 
Esses eventos podem também estar conectados entre si, indicando que alguns eventos impactam em outros, ou seja, o sentido das setas nos ajuda a entender a dinâmica da relação de causa-e-efeito dos eventos.

O registro dos eventos, segundo Mills et al. (1998), permite que o Mapa Estratégico:

- contenha os objetivos do negócio e da manufatura,

- contenha ações e decisões nas diferentes áreas de decisão da estratégia de manufatura,

- indique interações e relações entre as áreas de decisão,

- mostre relações de causa-e-efeito entre os eventos, e

- contenha qualquer evento que possa ser percebido como de importância estratégica.

Outras noções são informadas pelo Mapa Estratégico por meio de seus eixos. $O$ eixo horizontal permite a análise dos eventos que antecederam os eventos planejados no tempo. O eixo vertical mostra uma perspectiva top-down do desdobramento de objetivos estratégicos em objetivos funcionais e destes em decisões e ações gerenciais.

\section{Estudo de Caso: Análise do Mapa Estratégico em uma Indústria de Fabricação de Alimentos}

A condução da aplicação do Mapa Estratégico que descreve como a estratégia de manufatura foi planejada e desdobrada em duas unidades de negócio pertencentes à empresa em que o estudo de caso foi desenvolvido no período de 2000 a 2009, quais sejam: a divisão de Alimentos e Ingredientes (ANEXO 1A) e a divisão de Esmagamento de Soja (ANEXO 1B). Para avaliação da foram aplicados os 4 aspectos sugeridos por, Mills et al. (1998)

a) Grupo para a construção do Mapa Estratégico: construiu-se o mapa estratégico com o grupo que participou da última definição estratégica de 
forma a promover o consenso, facilitar a recordação de eventos que podiam ficar esquecidos e, assim, procurar reduzir os erros no desenho do mapa.

b) Validação: pelo menos duas evidências que comprovavam um evento foram levantadas para que o mesmo pudesse ser considerado válido para inclusão no desenho do Mapa Estratégico.

c) Abrangência a verificação dos eventos foi realizada nas áreas de decisão relacionadas e um detalhamento ou observação em campo foi realizado quando necessário para validação.

d) Facilitador: a autora conduziu o processo e conforme Mills et al. (1998) só pode intervir em dois momentos: para explicar a base do mapa e sua construção e para confirmar cada evento que fosse colocado no mapa. Foi também responsável por assegurar que o texto descritivo de cada evento expressasse fielmente o que foi levantado, debatido e acordado durante a discussão com o grupo envolvido na formulação da estratégia investigada. 
ANEXO 1A - Mapa estratégico da divisão de ingredientes e alimentos.

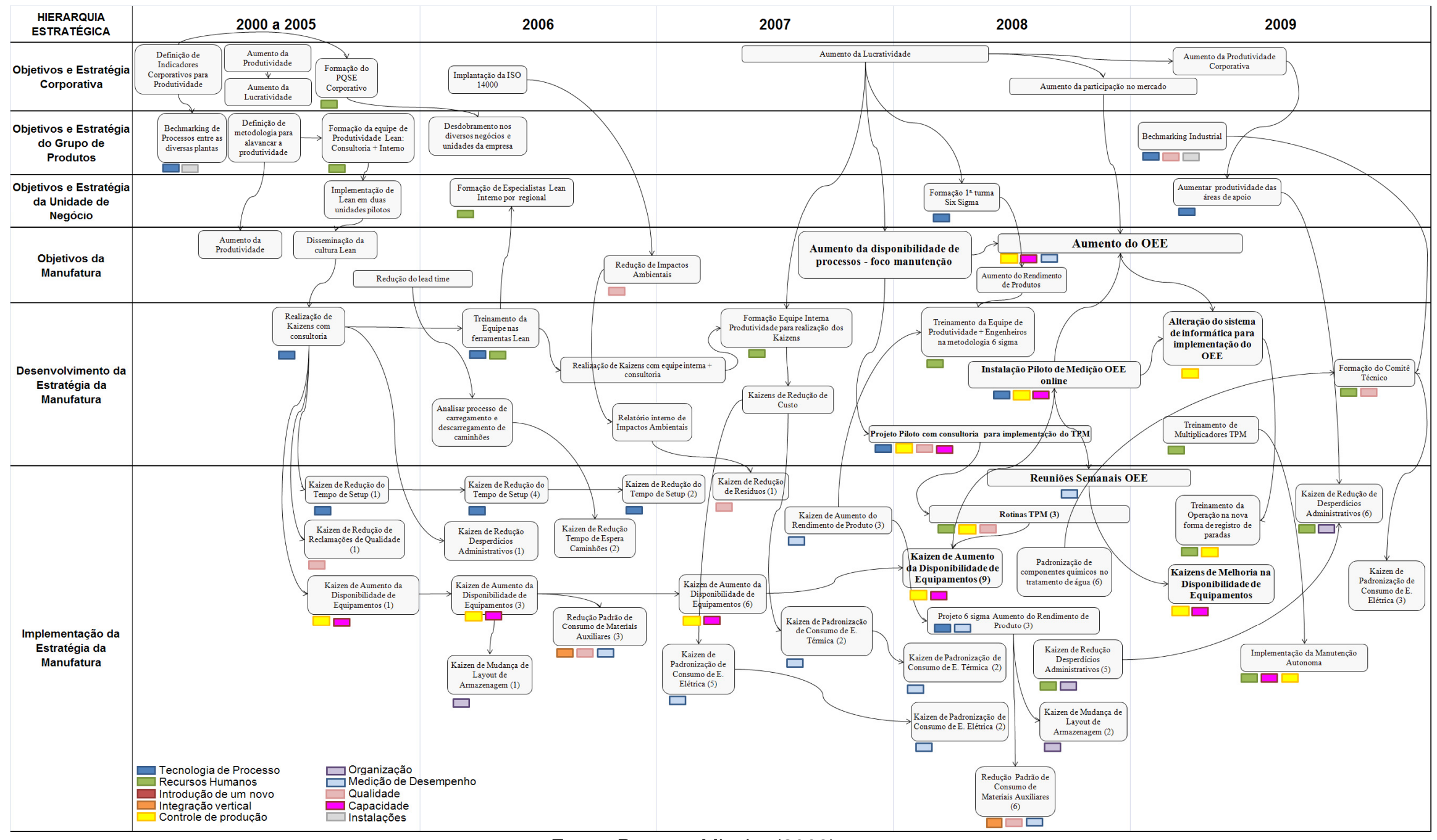

Fonte: Busso e Miyake (2009) 
ANEXO 1B - Mapa estratégico da divisão de esmagamento de soja.

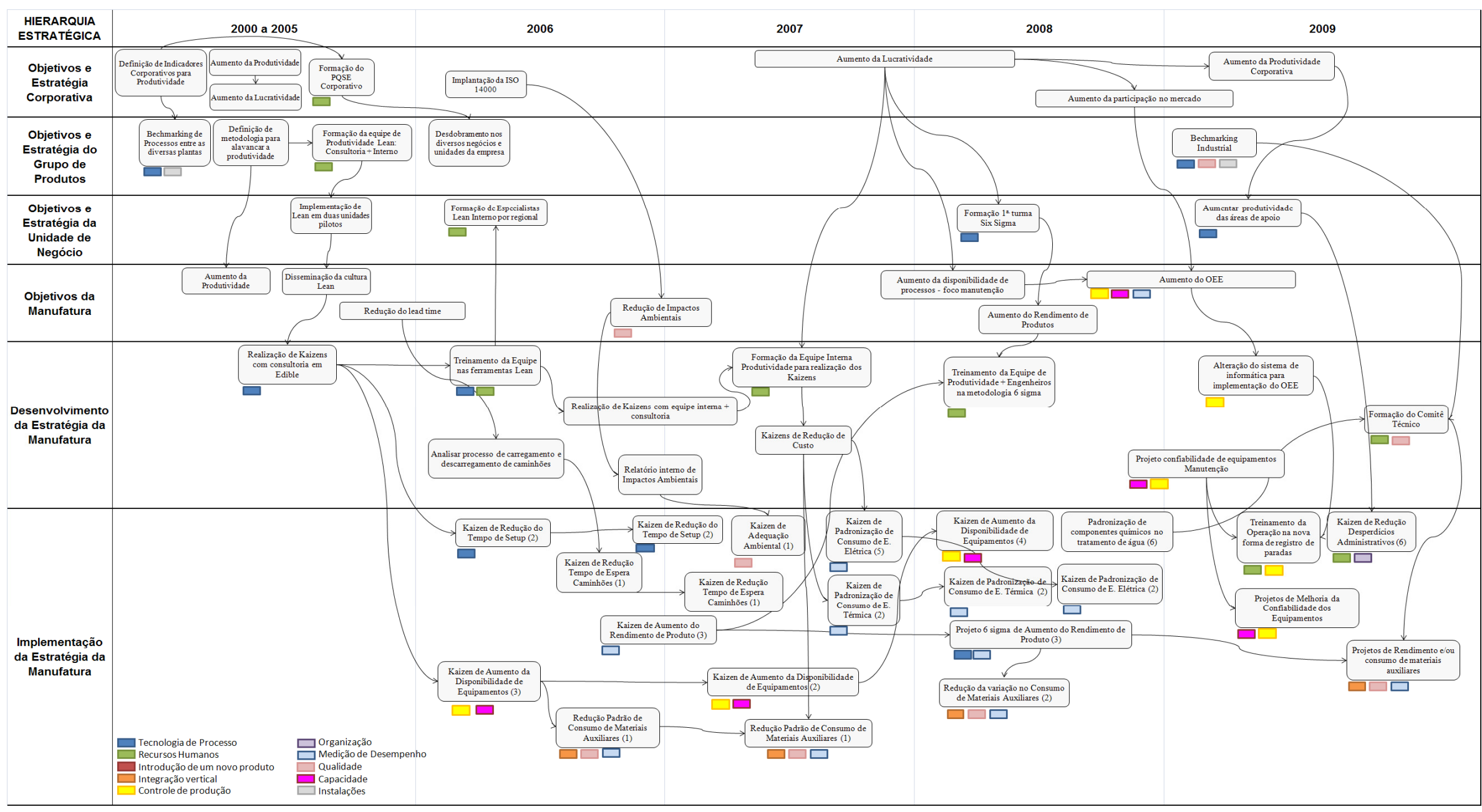




\section{ANEXO 2 - Protocolos das etapas 1 e 2 do estudo de caso}

\begin{tabular}{|c|c|c|}
\hline & Etapa 1 & Etapa 2 \\
\hline $\begin{array}{l}\text { Contexto } \\
\text { a se ter } \\
\text { em mente }\end{array}$ & $\begin{array}{l}\text { Introdução de um sistema de avaliação do } \\
\text { desempenho global da fábrica com base na } \\
\text { conceituação do OEE }\end{array}$ & $\begin{array}{l}\text { Aprimoramento e expansão do sistema de } \\
\text { avaliação do desempenho global da fábrica com } \\
\text { base na conceituação do OEE }\end{array}$ \\
\hline Objetivo & $\begin{array}{l}\text { Conhecer o sistema de medição do desempenho } \\
\text { global da fábrica em implementação, a dinâmica } \\
\text { de análise dos resultados gerados pelo mesmo e } \\
\text { a forma como as ações de controle e melhoria } \\
\text { são desdobradas }\end{array}$ & $\begin{array}{l}\text { Verificar a evolução do sistema de medição, } \\
\text { avaliação e melhoria do desempenho global da } \\
\text { fábrica em desenvolvimento e seus principais } \\
\text { efeitos na organização desde a visita anterior }\end{array}$ \\
\hline 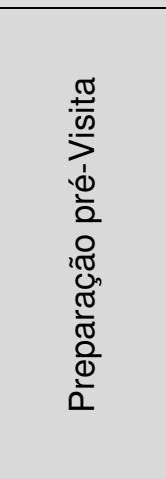 & $\begin{array}{l}\text { 1. Obtenção do apoio do coordenador de MCC } \\
\text { para realização do estudo e definição da fábrica } \\
\text { a ser abordada (unidade de análise) } \\
\text { 2. Por consulta prévia ao coordenador de MCC: } \\
\text { a. Obter informações gerais sobre esta fábrica } \\
\text { (organograma, produtos, posição na cadeia, } \\
\text { negócio, tamanho) } \\
\text { b. Identificar as áreas funcionais envolvidas no } \\
\text { sistema de medição do desempenho na unidade } \\
\text { de análise } \\
\text { c.Solicitar agendamento de entrevistas com } \\
\text { representantes destas áreas } \\
\text { d. Agendar visita à fábrica }\end{array}$ & $\begin{array}{l}\text { 13. Obtenção do apoio do coordenador de MCC } \\
\text { para realização de uma visita de retorno à } \\
\text { unidade de análise } \\
\text { 14. Por consulta prévia ao coordenador de MCC: } \\
\text { a. Obter informações gerais sobre a evolução do } \\
\text { sistema de medição de desempenho da fábrica } \\
\text { b. Identificar as áreas funcionais envolvidas na } \\
\text { expansão do sistema de medição do } \\
\text { desempenho global } \\
\text { c. Solicitar agendamento de entrevistas com } \\
\text { representantes destas áreas } \\
\text { d. Agendar visita à fábrica }\end{array}$ \\
\hline \multirow{4}{*}{ 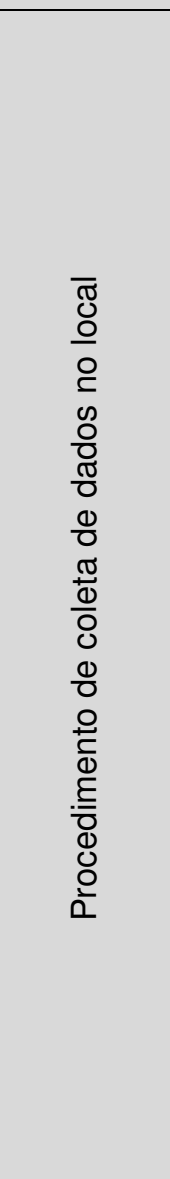 } & \multicolumn{2}{|c|}{$\begin{array}{c}\text { Na reunião de entrevista com os representantes das áreas envolvidas e o coordenador de MCC, } \\
\text { seguir o roteiro semi-estruturado abaixo: }\end{array}$} \\
\hline & $\begin{array}{l}\text { 3. Registrar dados sobre cada entrevistado } \\
\text { 4. Levantar dados para caracterização geral da } \\
\text { fábrica (processos, recursos, etc.) e da } \\
\text { conjuntura em que ela está inserida } \\
\text { 5. Inquirir sobre o sistema de medição e } \\
\text { avaliação de desempenho introduzido: } \\
\text { a. Finalidade do sistema } \\
\text { b. Definição formal (fórmula) do(s) indicador(es) } \\
\text { de desempenho aplicados } \\
\text { c. Classificação das perdas consideradas } \\
\text { d. Sistemática de coleta de dados e cálculo do(s) } \\
\text { indicador(es) } \\
\text { e. Método de análise dos resultados } \\
\text { f. Organização mobilizada na gestão do } \\
\text { desempenho global da fábrica } \\
\text { 6. Obter exemplos de cálculo do(s) indicador(es) } \\
\text { global(is) focado(s) } \\
\text { 7. Verificar a evolução do(s) indicador(es) e o } \\
\text { histórico das principais ações desdobradas num } \\
\text { período recente } \\
\text { 8. Inquirir sobre as principais ações desdobradas } \\
\text { no período considerado no item 7: propósito, } \\
\text { área(s) envolvida(s), resolução tomada }\end{array}$ & $\begin{array}{l}\text { 15. Registrar dados sobre cada entrevistado } \\
\text { 16. Verificar se houve mudanças significativas na } \\
\text { caracterização geral da fábrica desde a visita } \\
\text { anterior } \\
\text { 17. Verificar se houve mudanças significativas na } \\
\text { conjuntura de mercado/negócio/corporativa em } \\
\text { que a fábrica está inserida desde a visita anterior } \\
\text { 18. Inquirir sobre a expansão do sistema de } \\
\text { medição e avaliação do desempenho global em } \\
\text { desenvolvimento, procurando verificar mudanças } \\
\text { em relação às dimensões } 5 a, 5 b, 5 c, 5 d, 5 e \text { e } 5 f \\
\text { desde a visita anterior } \\
\text { 19. Obter exemplos de cálculo do(s) } \\
\text { indicador(es) global(is) incorporado(s) no } \\
\text { sistema expandido } \\
20 \text {. Verificar a evolução dos indicadores } \\
\text { monitorados pelo sistema expandido e o } \\
\text { histórico das principais ações desdobradas num } \\
\text { período recente } \\
21 . \text { Inquirir sobre as principais ações } \\
\text { desdobradas no período considerado no item } 20 \text { : } \\
\text { propósito, área(s) envolvida(s), resolução } \\
\text { tomada }\end{array}$ \\
\hline & \multicolumn{2}{|c|}{ Além da coleta de dados por meio da reunião de entrevista: } \\
\hline & $\begin{array}{l}\text { 9. Realizar observação in loco das instalações da } \\
\text { fábrica } \\
\text { 10. Obter dados históricos de produção e } \\
\text { perdas no período considerado no item } 7 \text { e } \\
\text { documentos complementares. }\end{array}$ & $\begin{array}{l}\text { 22. Realizar observação in loco focada nas } \\
\text { quatro linhas de produção } \\
\text { 23. Obter dados históricos de produção e perdas } \\
\text { das quatro linhas no período considerado no } \\
\text { item } 20 \text { e documentos complementares }\end{array}$ \\
\hline $\begin{array}{l}\text { Estágio } \\
\text { pós-visita }\end{array}$ & \multicolumn{2}{|c|}{$\begin{array}{l}11 \text { (Etapa 1), } 24 \text { (Etapa 2). Elaborar relatório com dados descritivos levantados na visita e enviar ao } \\
\text { coordenador de MCC para validação } \\
12 \text { (Etapa 1), } 25 \text { (Etapa 2). Consultar o coordenador de MCC para esclarecimento de dúvidas que } \\
\text { surgirem da reflexão pós-visita sobre dados e documentos coletados para a pesquisa }\end{array}$} \\
\hline
\end{tabular}


ANEXO 3 - Participação dos entrevistados nas atividades enumeradas nos protocolos do estudo de caso

\begin{tabular}{|c|c|c|c|c|c|c|c|c|c|c|c|c|c|c|c|c|c|c|}
\hline \multirow[b]{2}{*}{ Entrevistado } & \multicolumn{9}{|c|}{ Etapa 1} & \multicolumn{9}{|c|}{ Etapa 2} \\
\hline & U & 음 & 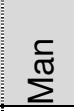 & 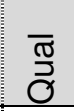 & $\stackrel{?}{\Sigma}$ & $\begin{array}{l}0 \\
0 \\
\Omega\end{array}$ & ळ & $\stackrel{\substack{\underline{N} \\
\Sigma}}{\Sigma}$ & है & U & 음 & $\sum_{\Sigma}^{\frac{\Gamma}{\pi}}$ & $\frac{\bar{\sigma}}{\widetilde{O}}$ & $\stackrel{?}{\Sigma}$ & $\begin{array}{l}0 \\
0\end{array}$ & ळે & 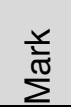 & है \\
\hline $\begin{array}{l}\text { Preparação } \\
\text { pré-visita }\end{array}$ & 1,2 & - & - & - & - & - & - & - & - & $\begin{array}{l}13, \\
14\end{array}$ & - & - & - & - & - & - & - & - \\
\hline $\begin{array}{c}\text { Procedimento } \\
\text { de coleta de } \\
\text { dados no local }\end{array}$ & $\begin{array}{c}3,5 \mathrm{a} \\
8\end{array}$ & 3 a 9 & 3 a 9 & $\begin{array}{l}3,4, \\
7,8\end{array}$ & $\begin{array}{l}3 \mathrm{a} \\
10\end{array}$ & 3,7 & 3,7 & 8,7, & 3,7 & $\begin{array}{c}15, \\
17 \mathrm{a} \\
21\end{array}$ & $\begin{array}{c}15 \mathrm{a} \\
22\end{array}$ & $\begin{array}{c}15 \mathrm{a} \\
22\end{array}$ & $\begin{array}{l}15 \\
16 \\
20 \\
21\end{array}$ & $\begin{array}{c}15 \mathrm{a} \\
23\end{array}$ & $\begin{array}{l}15, \\
20, \\
21\end{array}$ & $\begin{array}{l}15, \\
20, \\
21\end{array}$ & $\begin{array}{l}15, \\
20, \\
21\end{array}$ & $\begin{array}{l}15, \\
20, \\
21\end{array}$ \\
\hline $\begin{array}{c}\text { Estágio pós- } \\
\text { visita }\end{array}$ & 11,12 & & & & $\begin{array}{l}11, \\
12\end{array}$ & - & - & - & - & $\begin{array}{l}24, \\
25\end{array}$ & - & - & - & $\begin{array}{l}24, \\
25\end{array}$ & - & - & - & - \\
\hline
\end{tabular}

Abreviaturas: MCC: Melhoria Contínua Corporativo, Prod: Produção, Man: Manutenção, Qual: Qualidade, MCU: Melhoria Contínua da Unidade, PCP: Programação e Controle da Produção, P\&D: Pesquisa e Desenvolvimento, Mark: Marketing, Com: Comercial 
ANEXO 4 -Avaliação dos indicadores derivados do OEE

\section{ANEXO 4A - Avaliação dos indicadores derivados do OEE conforme critérios definidos na Tabela 7}

\begin{tabular}{|c|c|c|c|c|c|c|c|c|c|c|c|c|}
\hline & & & & & \\
\hline & ofE & ofiz & OFE/ OIE & OEFML OOIE & TEEP & PEE dise & PEE cont & rofe & OPEOOAE \\
\hline \multirow{6}{*}{ 1. Estratatgia } & \multirow{3}{*}{ 1.1. Está relacionado à estatatégia corporativa. } & & 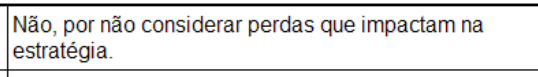 & \multirow{3}{*}{$\mathbf{0}$} & \multirow{3}{*}{$\mathbf{0}$} & \multirow{3}{*}{$\mathbf{0}$} & \multirow{3}{*}{ o } & \multirow{3}{*}{$\mathbf{0}$} & \multirow{3}{*}{$\mathbf{0}$} & \multirow{3}{*}{$\mathbf{0}$} & \multirow{3}{*}{ - } & \multirow{3}{*}{ - } \\
\hline & & 0 & Considera perdas somente no âmbito da manutatura. & & & & & & & & & \\
\hline & & - & $\begin{array}{l}\text { Considera uma maior abrangênncia de perdas maior } \\
\text { que se relacionam com os resultados do negocio. }\end{array}$ & & & & & & & & & \\
\hline & \multirow{3}{*}{ 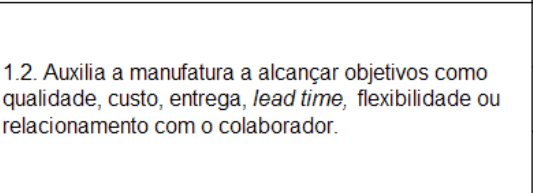 } & 0 & 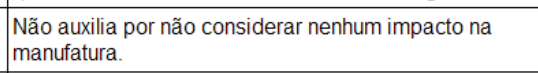 & \multirow{3}{*}{ o } & \multirow{3}{*}{$\mathbf{0}$} & \multirow{3}{*}{$\mathbf{0}$} & \multirow{3}{*}{ o } & \multirow{3}{*}{$\mathbf{0}$} & \multirow{3}{*}{$\mathbf{0}$} & \multirow{3}{*}{ - } & \multirow{3}{*}{ - } & \multirow{3}{*}{ - } \\
\hline & & 0 & \begin{tabular}{|l} 
Considera somente impactos que refletem fatores \\
internos a manufatura.
\end{tabular} & & & & & & & & & \\
\hline & & - & $\begin{array}{l}\text { Considera aimpactos que refletem fatorese externos à } \\
\text { manufatura }\end{array}$ & & & & & & & & & \\
\hline \multirow{6}{*}{$\begin{array}{l}\text { 2. rientaçăo } \\
\text { do fluxo }\end{array}$} & \multirow{3}{*}{$\begin{array}{l}\text { 21.1. Reflete o desempenho a o longo da cadeia de } \\
\text { valor. }\end{array}$} & 0 & Limita-se à avaliaçăo do equipamento. & \multirow{3}{*}{0} & \multirow{3}{*}{$\mathbf{0}$} & \multirow{3}{*}{ o } & \multirow{3}{*}{ o } & \multirow{3}{*}{0} & \multirow{3}{*}{0} & \multirow{3}{*}{ - } & & \\
\hline & & o & 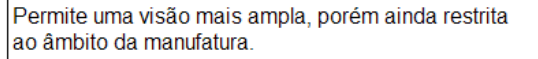 & & & & & & & & - & - \\
\hline & & - & 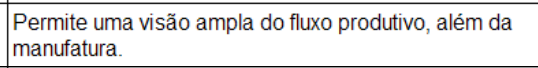 & & & & & & & & & \\
\hline & & 0 & Năo considera perdas além do âmbito da manufuatura. & & & & & & & & & \\
\hline & 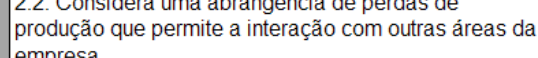 & $\mathbf{0}$ & 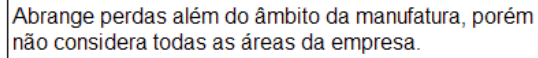 & 0 & 0 & 0 & 0 & 0 & 0 & - & - & - \\
\hline & & - & 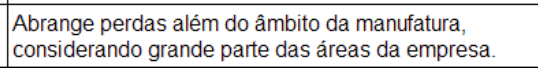 & & & & & & & & & \\
\hline & 31 Permite senarar os impactos no sistema de & 0 & Não permite comparaçăo entre as âreas. & & & & & & & & & \\
\hline $\begin{array}{l}\text { 3. EEciciencolia } \\
\text { Interna }\end{array}$ & 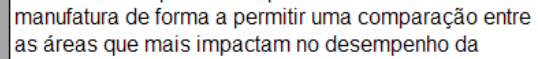 & 0 & Permite pequena comparaçăo entre as áreas. & 0 & 0 & 0 & 0 & 0 & 0 & $\mathbf{0}$ & - & - \\
\hline & & - & Permite comparaçăo entrea a maior parte das áreas. & & & & & & & & & \\
\hline & & 0 & 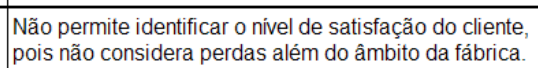 & & & & & & & & & \\
\hline $\begin{array}{l}\text { 4.ECicienclia } \\
\text { Externa }\end{array}$ & $\begin{array}{l}\text { 4.1. Permite identificar o o nivel de saisfsaçăo do cliente } \\
\text { extermo. }\end{array}$ & $\mathbf{0}$ & 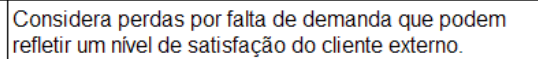 & 0 & 0 & 0 & 0 & 0 & 0 & o & o & $\mathbf{0}$ \\
\hline & & - & $\begin{array}{l}\text { Mede o onvel de satisfaçăo do c ciente externo de forma } \\
\text { clara. }\end{array}$ & & & & & & & & & \\
\hline & & & & - & Atendec & etamente & $\mathbf{0}$ & & almente & 0 & & \\
\hline
\end{tabular}


ANEXO 4A - Avaliação dos indicadores derivados do OEE conforme critérios definidos na Tabela 7 (continuação)

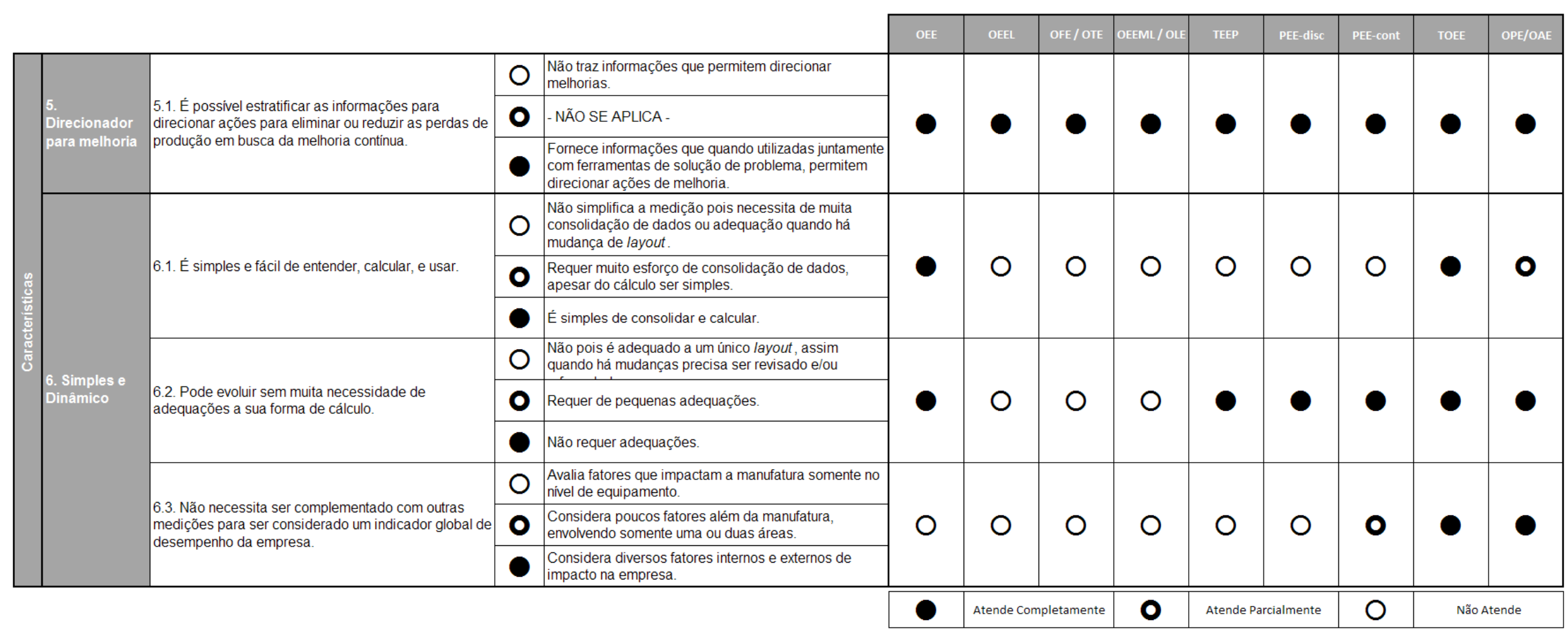


ANEXO 4B - Agrupamento de indicadores afins com base nos critérios definidos na Tabela 7

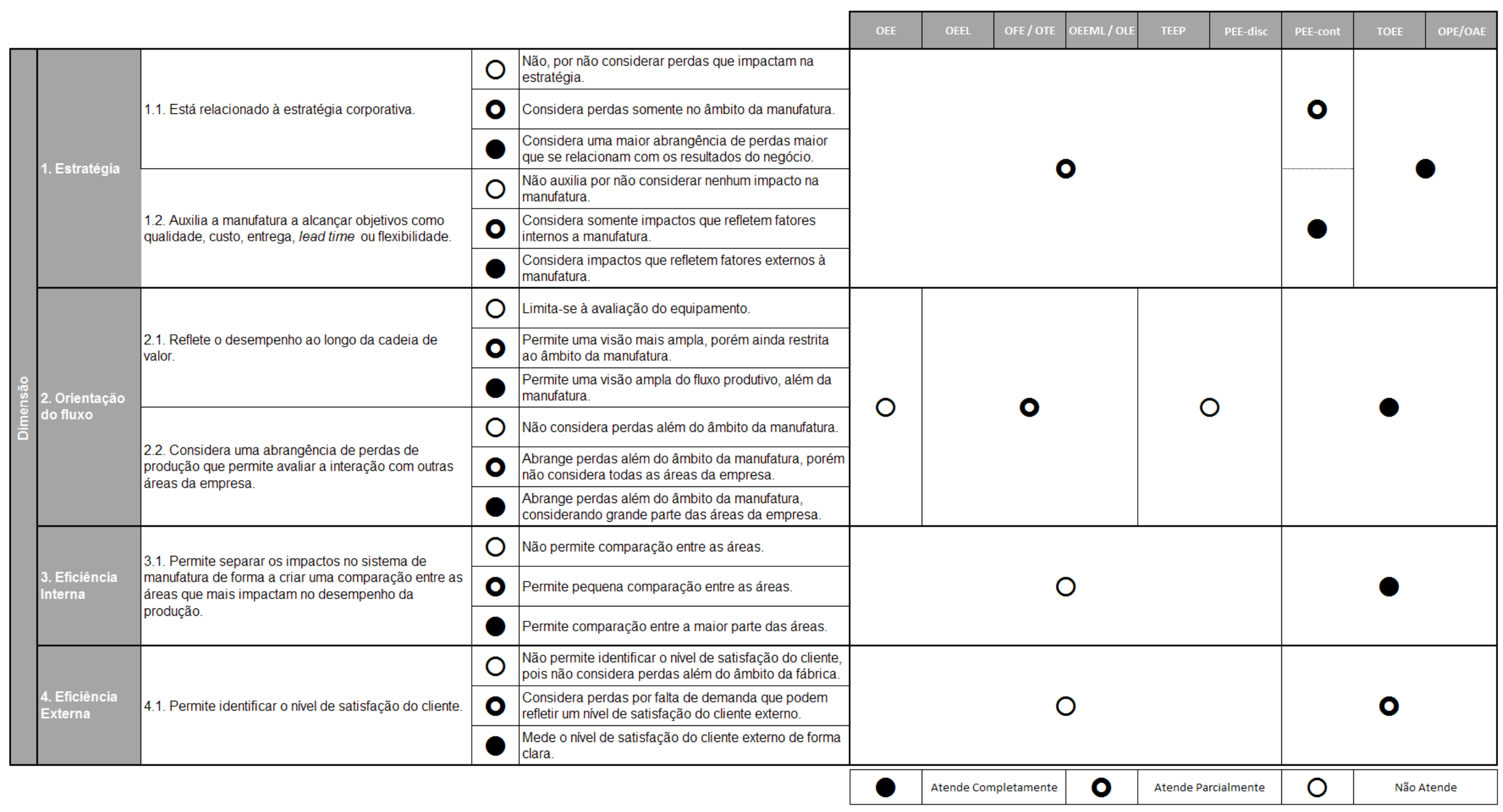


ANEXO 4B - Agrupamento de indicadores afins com base nos critérios definidos na Tabela 7 (continuação)

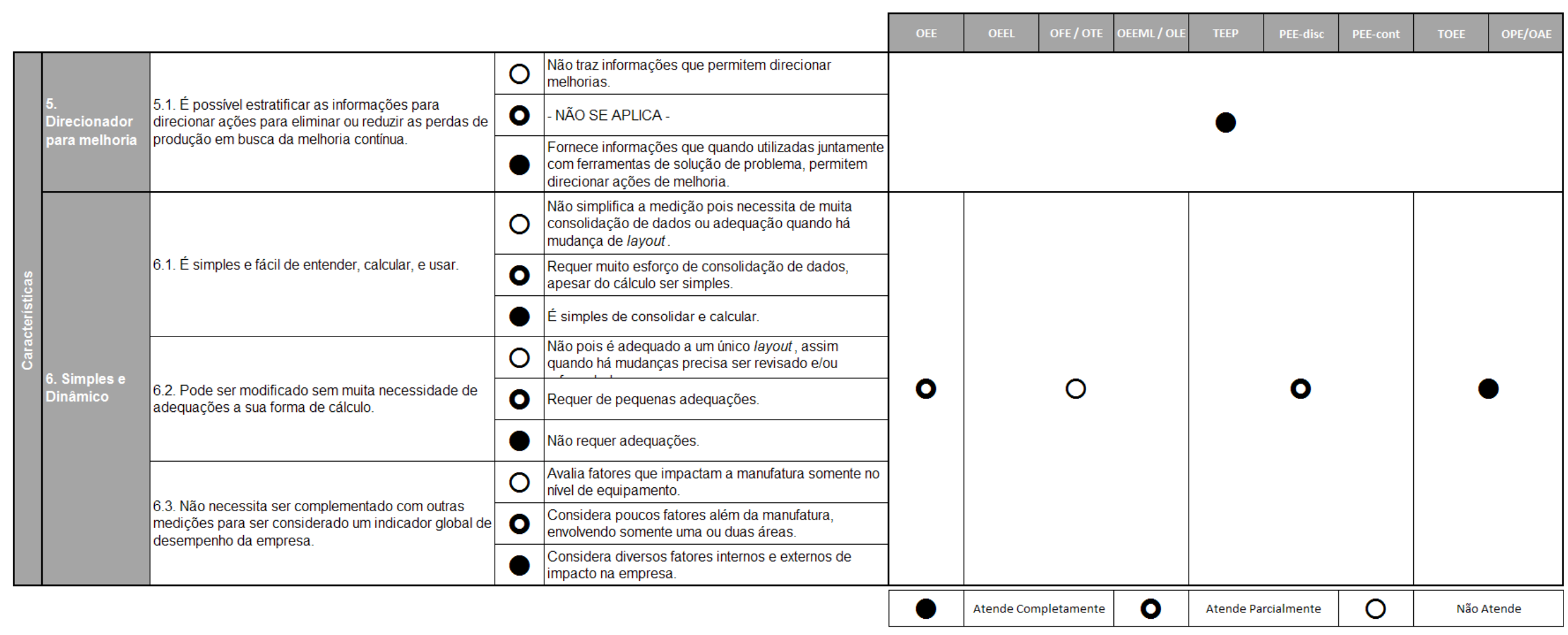




\section{ANEXO 5 - Dados utilizados no cálculo do OEEL e OPEL para a linha analisada} (L2)

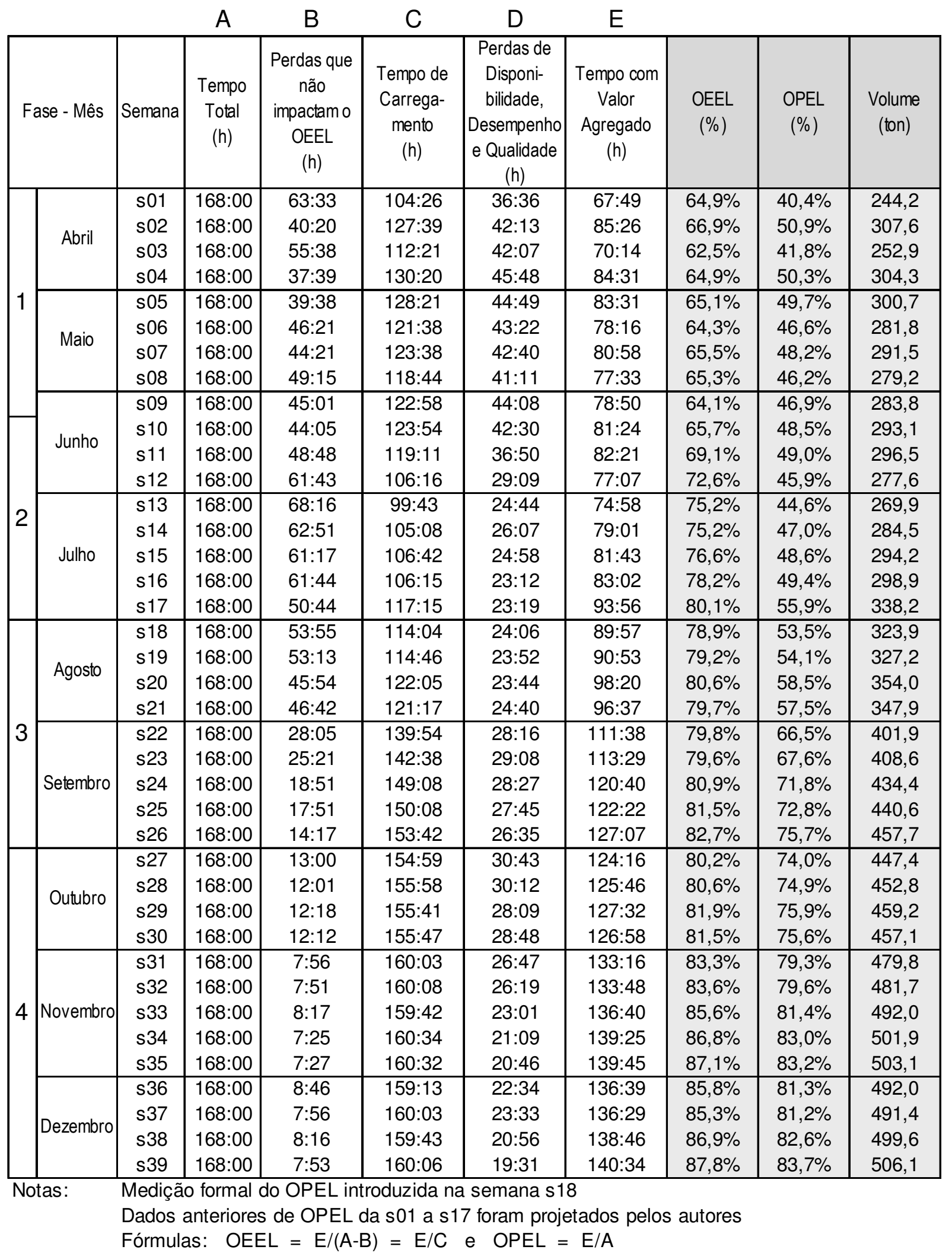

